\title{
LEANDRO EJNISMAN
}

Estudo em cadáveres sobre a associação entre os ângulos tomográficos do impacto fêmoro-acetabular e a histologia da lesão do lábio acetabular

Tese apresentada à Faculdade de Medicina da Universidade de São Paulo para obtenção do título de Doutor em Ciências

Programa de Ortopedia e Traumatologia Orientador: Prof. Dr. Alberto Tesconi Croci

São Paulo

2015 
Dados Internacionais de Catalogação na Publicação (CIP)

Preparada pela Biblioteca da

Faculdade de Medicina da Universidade de São Paulo

Oreprodução autorizada pelo autor

Ejnisman, Leandro

Estudo em cadáveres sobre a associação entre os ângulos tomográficos do impacto fêmoro-acetabular e a histologia da lesão do lábio acetabular / Leandro Ejnisman. -- São Paulo, 2015.

Tese(doutorado)--Faculdade de Medicina da Universidade de São Paulo.

Programa de Ortopedia e Traumatologia.

Orientador: Alberto Tesconi Croci.

Descritores: 1.Quadril 2.Cartilagem articular 3.Osteoartrite do quadril 4.Tomografia 5.Histologia 6.Acetábulo 7.Cadáver 8.Ortopedia

USP/FM/DBD-497/15 
Aos meus pais Abel e Paulina, por todo o amor, dedicação, empenho incansável, e incentivo ao meu desenvolvimento e educação.

Ao meu amor Juliana, por fazer parte da minha vida de maneira tão especial, e ter me transformado numa pessoa melhor. 


\section{AGRADECIMENTOS}

Aos Profs. Drs. Gilberto Luis Camanho, Olavo Pires de Camargo e Tarcísio E. P. de Barros Filho, pela oportunidade de realizar este trabalho no Instituto de Ortopedia e Traumatologia do Hospital das Clínicas da Faculdade de Medicina da Universidade de São Paulo (IOT-HCFMUSP).

Ao Prof. Dr. Alberto Tesconi Croci, pela confiança, exemplo, e orientação na tese.

Ao Dr. José Ricardo Negreiros Vicente, pela amizade e apoio constante neste trabalho e em minha vida acadêmica.

Ao Dr. André Pedrinelli, pelos ensinamentos e incentivo ao meu desenvolvimento na área da traumatologia esportiva.

Ao Dr. Rafael Trevisan Ortiz, pelo apoio na minha formação profissional e frequentes conversas engrandecedoras.

Aos Drs. Jorge dos Santos Silva e Kodi Edson Kojima, pelo auxílio no meu aprimoramento no grupo de Trauma.

Aos meus colegas do Grupo de Quadril, Drs. Carlos Antonio Soares Ulhôa, Itiro Suzuki, Antonio Carlos Bernabé, Antonio Faga, Evaristo Batista de Campos Melo, Wlastemir Grigoletto Jr., Henrique Antonio Berwanger de Amorim Cabrita, Henrique Melo de Campos Gurgel, Carlos Augusto M. Luzo, e Helder de Souza Miyahara, por me acompanharem desde o início do meu aprendizado na cirurgia do quadril.

Aos residentes e ex-residentes que passaram pelo Grupo de Quadril, pelo auxílio nas dissecções, fundamental para o êxito deste projeto. 
À Profa. Dra. Consuelo Junqueira e a Maria do Carmo Nunes e Simone Kneipp Cavalheiro, pelo auxílio no preparo das lâminas, avaliação histológica e, principalmente, pela paciência em responder minhas constantes dúvidas.

Aos membros do projeto PISA Prof. Dr. Luiz Fernando Ferraz da Silva, Khallil Taverna Chaim, Glaucia Bento dos Santos e Milena C. Modolo Picka, por acreditarem no meu projeto e viabilizarem sua execução.

Ao Dr. Felipe Souza, pela amizade e dedicação no estudo dos ângulos tomográficos deste trabalho.

Aos Drs. Marcelo Rosa de Rezende, Raphael Martus Marcon e Edgard de Novaes França Bisneto, pela fundamental contribuição no exame de qualificação e análise crítica essencial ao estudo.

Ao Fernando Weno, pela edição das figuras e desenho das ilustrações desta tese.

A Tania Borges e Rosana Costa, secretárias da Pós-Graduação do IOT-HCFMUSP, por todo o suporte e grande eficiência durante todo o programa de pós-graduação.

Aos queridos amigos Cassio Trevizani, Marcelo Loquette, Rafael Leal, Rafael Tutihashi, Ricardo Perez, Tiago Fruges e a todos os Bermas por estarem sempre ao meu lado e serem minha segunda família.

Ao amigo Andre Wajnsztejn pelo companheirismo constante na minha vida pessoal e profissional.

As minhas queridas cunhadas Alessandra Celani Ejnisman e Marcela Waksman Ejnisman, meus sobrinhos e meu irmão de criação Beny Fiterman, pelo carinho e agradável convivência em família. 
Ao meu irmão Renato Ejnisman, pelo incentivo na carreira acadêmica, amizade e por estar sempre presente em minha vida.

Ao meu irmão Benno Ejnisman, pelo exemplo na ortopedia, aconselhamento frequente, carinho diário, e em especial pela ajuda na revisão desta tese. 


\section{EPÍGRAFE}

"Crê nos que buscam a verdade. Duvida dos que a encontram".

("Believe those who are seeking the truth. Doubt those who find it.")

Andre Gide 


\section{Normalizações}

Esta tese de doutoramento está de acordo com as seguintes normas, em vigor no momento desta publicação:

Referências: adaptado de International Committee of Medical Journals Editors (Vancouver).

Estrutura e apresentação: Guia de apresentação de dissertações, teses e monografias. Universidade de São Paulo. Elaborado por Anneliese Carneiro da Cunha, Maria Julia de A. L. Freddi, Maria Fazanelli Crestana, Marinalva de Souza Aragão, Suely Campos Cardoso, Valéria Vilhena. 3a ed. São Paulo: Serviço de Biblioteca e Documentação/Faculdade de Medicina da USP; 2011.

Abreviaturas dos títulos dos periódicos de acordo com List of Journals Indexed in Index Medicus.

Nomes das estruturas anatômicas baseados na Terminologia Anatômica, aprovada em 1998 e traduzida pela Comissão de Terminologia Anatômica da Sociedade Brasileira de Anatomia - CTA-SBA. 1a ed. (Brasileira) São Paulo, Editora Manole 2001. 248p

Vocabulário ortográfico da língua portuguesa, 5a edição, 2009, elaborado pela Academia Brasileira de Letras, em consonância com o Acordo Ortográfico da Língua Portuguesa, promulgado pelo decreto no 6583/2008. 


\section{SUMÁRIO}

Lista de abreviaturas, símbolos e siglas

Lista de Figuras

Lista de Tabelas

Resumo

Summary

1. INTRODUÇÃO

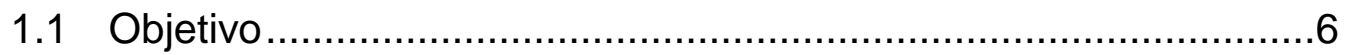

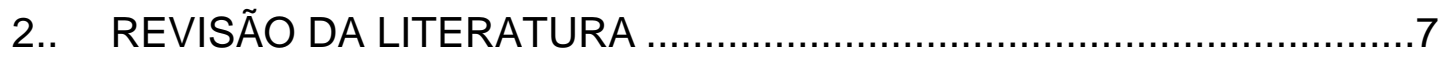

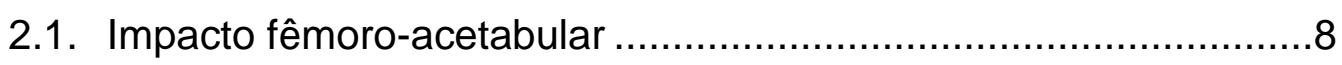

2.2. Lábio acetabular ..................................................... 13

2.3. Análise radiológica do impacto fêmoro-acetabular ................... 20

2.4. Relação entre aspectos radiológicos e lesões labiais no IFA ..... 23

2.5. Tratamento do impacto fêmoro-acetabular ............................. 26

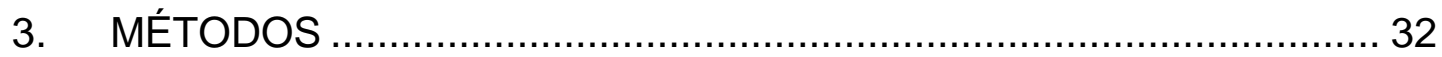

3.1. Desenho do estudo .................................................... 33

3.2. Aprovação na comissão de ética ....................................... 33

3.3. Características e locação do estudo ................................... 34

3.4. Participantes .......................................................... 34

3.5. Critérios de seleção .................................................... 35

3.5.1. Critérios de inclusão ................................................ 35

3.5.2. Critérios de exclusão ....................................... 35

3.6. Técnica tomográfica.................................................... 36

3.7. Técnica de dissecção.................................................... 38

3.8. Preparação das lâminas ................................................. 41

3.9. Avaliação histológica.................................................. 45

3.10. Avaliação das imagens tomográficas...................................... 47

3.11. Análise estatística .............................................................. 54

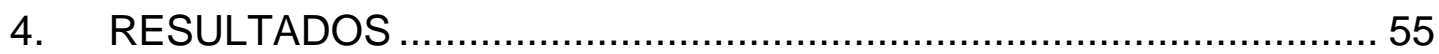

4.1. Caracterização da amostra ............................................ 56

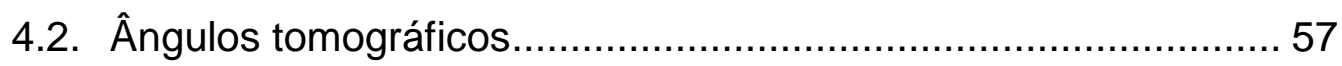




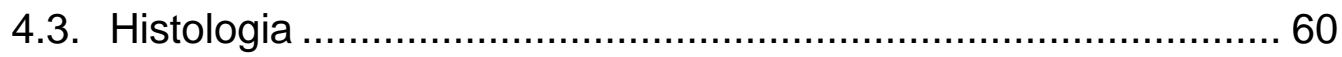

4.4. Relação entre achados tomográficos e histológicos .................6 67

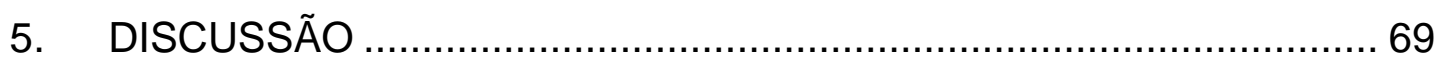

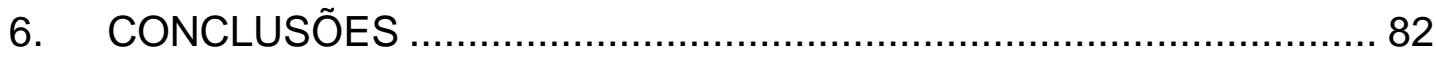

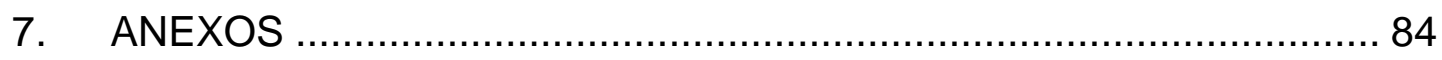

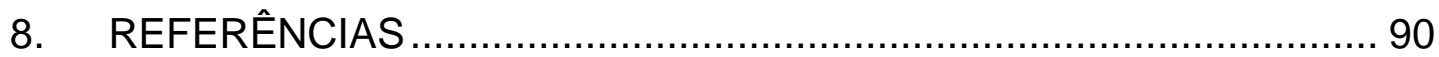




\section{LISTA DE ABREVIATURAS, SÍMBOLOS E SIGLAS}

\section{ABREVIATURAS}

$\begin{array}{ll}\text { D } & \text { Direito } \\ \text { E } & \text { Esquerdo } \\ \text { et al. } & \text { E outros } \\ \text { F } & \text { Feminino } \\ \text { M } & \text { Masculino }\end{array}$

\section{SímBOLOS}

$\begin{array}{ll}\mathrm{cm} & \begin{array}{l}\text { centímetro } \\ \mathrm{kg}\end{array} \\ \mathrm{m} & \text { milograma } \\ \mu \mathrm{m} & \text { micrômetro } \\ \mathrm{mm} & \text { milímetro } \\ \mathrm{N} & \text { Newtons } \\ \circ & \text { grau } \\ \% & \text { por cento }\end{array}$


SIGLAS

$\begin{array}{ll}\text { dGEMRIC } & \text { Delayed gadolinium-enhanced MRI of cartilage } \\
\text { DICOM } & \text { Digital Imaging and Communications in Medicine } \\
\text { FMUSP } & \text { Faculdade de Medicina da Universidade de São } \\
& \text { Paulo } \\
\text { HCFMUSP } & \begin{array}{l}\text { Hospital das Clínicas da Faculdade de Medicina } \\
\text { da Universidade de São Paulo }\end{array} \\
\text { HE } & \text { Hematoxilina e eosina } \\
\text { HOS } & \text { Hip Outcome Score } \\
\text { IFA } & \text { Impacto fêmoro-acetabular } \\
\text { IMC } & \text { Índice de massa corpórea } \\
\text { IOT-HCFMUSP } & \text { Instituto de Ortopedia e Traumatologia do Hospital } \\
& \text { da Clínicas da Faculdade de Medicina da } \\
\text { UIM } & \text { Universidade de São Paulo } \\
\text { NAHS } & \text { Laboratório de Investigação Médica } \\
\text { PISA } & \text { Non-Arthritic Hip Score } \\
\text { RM } & \text { Plataforma de Imagem na Sala de Autópsia } \\
\text { SVOC-USP } & \text { Ressonância magnética } \\
& \text { Serviço de Verificação de Óbitos da Capital da } \\
\text { SF-12 } & \text { Universidade de São Paulo } \\
\text { TC } & \text { Short Form 12 } \\
& \text { Tomografia computadorizada }\end{array}$




\section{LISTA DE FIGURAS}

Figura 1. Posicionamento do cadáver durante o exame de tomografia computadorizada: decúbito dorsal horizontal, pés presos próximos ao aparelho e membros superiores elevados 37

Figura 2. Incisão suturada com nylon 2,0 na região anterior do quadril (caso 8, lado esquerdo) 39

Figura 3. Dissecção acetabular (caso 8, lado esquerdo). Asterisco: osteótomo no púbis; seta cheia: cavidade acetabular; seta vazia: osteotomia ilíaca 40

Figura 4. Peça acetabular (caso 7, lado direito). Triângulo preto: lábio ântero-superior; seta branca: ligamento transverso; triângulo vazio: cápsula articular; triângulo branco: pulvinar; asterisco preto: cartilagem acetabular

Figura 5. Ilustração demonstrando a orientação dos cortes acetabulares segundo as horas do relógio. Os círculos pontilhados demonstram o local de retirada dos fragmentos, equivalente as posições de 10, 12 e 2 horas 42

Figura 6. Peça acetabular (caso 8, lado esquerdo) após realização do primeiro corte. Seta preta: corte entre 6 e 12 horas; triângulo preto: lábio póstero-superior; triângulo vazio: cápsula articular; triângulo branco: pulvinar; asterisco preto: cartilagem acetabular 43 
Figura 7. Fragmento acetabular superior (caso 1, lado esquerdo) previamente à rotina histológica. Triângulo preto: lábio acetabular; triângulo vazio: cápsula articular; asterisco preto: cartilagem acetabular; asterisco branco: osso acetabular; seta: transição condro-labial íntegra. 44

Figura 8. Classificação de Seldes modificada. $O$ tipo 1 apresenta destacamento do lábio da cartilagem acetabular, o tipo 2 apresenta um ou mais planos de clivagem na substância labial, e o tipo 3 apresenta um padrão misto que apresenta destacamento do lábio e lesões intrasubstanciais 46

Figura 9. Medida do ângulo alfa femoral (caso 1, lado esquerdo). A: Determinação do plano axial oblíquo por meio da linha "a", que passa pelo centro do colo e cabeça femoral. B: Medida do ângulo alfa compreendido pelas linha "b" que passa pelo centro do colo e cabeça femoral, e "c" que passa pelo centro da cabeça femoral e o ponto onde a cabeça perde a esfericidade, determinada pelo círculo "d" 48

Figura 10. Medida do ângulo de versão femoral (caso 3, lado direito) por meio da sobreposição de duas imagens: centro do colo femoral e ponto mais posterior dos côndilos femorais. A versão femoral é medida entre as linhas "a", formada pelos pontos mais posteriores dos côndilos femorais, e a linha "b" formada pelo centro do colo femoral. 49

Figura 11. Alinhamento da bacia no plano pélvico anterior previamente a medida dos ângulos acetabulares (caso 3) 50 
Figura 12. Medida do ângulo centro-borda acetabular (caso 3, lado direito). A linha "a" passa entre o centro das duas cabeças femorais e determina o plano horizontal, o círculo "d" determina o centro da cabeça femoral, a linha "b" é perpendicular à linha "a" e passa pelo centro da cabeça femoral, e a linha "c" passa pelo centro da cabeça femoral e o ponto mais lateral da borda acetabular. $\mathrm{O}$ ângulo centro-borda é determinado pelas linhas "b" e "c". 51

Figura 13. Medida da versão acetabular (caso 3, lado direito). A linha "a" passa pelos pontos mais posteriores dos dois acetábulos, a linha "c" passa pela parede anterior e posterior do acetábulo, e a linha "b" é perpendicular à linha "a" no ponto onde as linhas "a" e "c" cruzam-se. A versão acetabular é determinada pelas linhas "b" e "c". 52

Figura 14. Medida do ângulo de Tönnis (caso 3, lado direito). A linha "a" determina o plano horizontal (paralela à linha que liga as duas cabeças femorais) passando pelo ponto mais medial da zona de carga acetabular, e a linha "b" liga os pontos mais medial e mais lateral da zona de carga acetabular. O ângulo de Tönnis é determinado pelas linhas "a" e "b" 53

Figura 15. Ângulo centro-borda estratificado por gênero 58

Figura 16. Lesão labial macroscópica (caso 3, lado direito). Triângulo preto: lábio acetabular; triângulo vazio: cápsula articular; asterisco preto: cartilagem acetabular; seta: probe colocado na lesão labial associada a lesão em carpete da cartilagem 60 
Figura 17. Sulco sublabial posterior (caso 9, lado direito). Triângulo preto: lábio póstero-superior, triângulo vazio: cápsula articular; círculo: pinça cirúrgica entre o lábio e cápsula articular; asterisco: cartilagem acetabular; triângulo branco: pulvinar; seta preta: sulco sublabial posterior; seta branca: ligamento transverso

Figura 18. Lesão condral macroscópica (caso 17, lado direito). Triângulo preto: lábio acetabular anterior; triângulo vazio: cápsula articular; triângulo branco: pulvinar; asterisco preto: cartilagem acetabular; asterisco branco: osso acetabular exposto por lesão condral; seta preta: lesão labial 62

Figura 19. Lábio acetabular sem lesão (caso 1, lábio superior), coloração por tricrômico de Masson. A: objetiva com aumento original de uma vez demonstra transição entre lábio e cartilagem íntegra. B: objetiva com aumento original de quatro vezes demonstra zona de transição entre cartilagem e lábio acetabular, com características mistas de cartilagem hialina e tecido conjuntivo fibro-elástico. Triângulo preto: lábio acetabular; triângulo vazio: cápsula articular, asterisco preto: cartilagem acetabular; asterisco branco: osso acetabular; seta: indica zona de transição entre cartilagem e lábio 63

Figura 20. Lábio acetabular com lesão Seldes tipo 1 (caso 4, lábio anterior), coloração por tricrômico de Masson. A: objetiva com aumento original de uma vez, B: objetiva com aumento original de quatro vezes. Triângulo preto: lábio acetabular; triângulo vazio: cápsula articular; asterisco preto: cartilagem acetabular destacada do osso subcondral; asterisco branco: osso acetabular; seta preta: separação entre o lábio e a cartilagem acetabular 63 
Figura 21. Lábio acetabular com lesão Seldes tipo 1 (caso 13, lábio posterior) associado a formação de cisto ósseo, coloração por hematoxilina e eosina. A: objetiva com aumento original de uma vez; B: objetiva com aumento original de quatro vezes. Triângulo preto: lábio acetabular; triângulo vazio: cápsula articular; asterisco preto: cartilagem acetabular; asterisco branco: osso acetabular; seta preta: separação entre o lábio e a cartilagem acetabular; seta vazia: cisto ósseo 64

Figura 22. Lábio acetabular com lesão Seldes tipo 2 (caso 11, lábio superior), coloração por hematoxilina e eosina. A: objetiva com aumento original de uma vez, B: objetiva com aumento original de quatro vezes. Triângulo preto: lábio acetabular; triângulo vazio: cápsula articular; asterisco preto: cartilagem acetabular; asterisco branco: osso acetabular; seta preta: transição íntegra entre o lábio e a cartilagem acetabular; setas vazias: planos de clivagem na substância do lábio 64

Figura 23. Lábio acetabular com lesão Seldes tipo 3 (caso 6, lábio anterior), coloração por hematoxilina e eosina. A: objetiva com aumento original de uma vez, B: objetiva com aumento original de quatro vezes. Triângulo preto: lábio acetabular; triângulo vazio: cápsula articular; asterisco preto: cartilagem acetabular; asterisco branco: osso acetabular; seta preta: separação entre - lábio e a cartilagem acetabular; setas vazias: planos de clivagem na substância do lábio 65 
Figura 24. Sulco sublabial posterior (caso 10, lábio posterior), coloração por hematoxilina e eosina. A: objetiva com aumento original de uma vez, B: objetiva com aumento original de quatro vezes. Triângulo preto: lábio acetabular; triângulo vazio: cápsula articular; asterisco preto: cartilagem acetabular; asterisco branco: osso acetabular; seta preta: sulco entre a cartilagem e lábio acetabular 66

Figura 25. Ângulo alfa e sua relação com a presença de lesão labial ..... 68 


\section{LISTA DE TABELAS}

Tabela 1. Dados demográficos dos cadáveres incluídos. 56

Tabela 2. Ângulos tomográficos 57

Tabela 3. Diferença entre gêneros em relação aos ângulos tomográficos 58

Tabela 4. Lesão labial segundo classificação de Seldes 66 


\section{Resumo}

Ejnisman L. Estudo em cadáveres sobre a associação entre os ângulos tomográficos do impacto fêmoro-acetabular e a histologia da lesão do lábio acetabular [tese]. São Paulo: Faculdade de Medicina, Universidade de São Paulo; 2015.

INTRODUÇÃO: O impacto fêmoro-acetabular (IFA) é considerado importante causa de dor do quadril no jovem, podendo evoluir para osteoartrite do quadril. $O$ objetivo deste estudo foi investigar se há associação entre achados da tomografia computadorizada (TC) em cadáveres e lesões do lábio acetabular avaliadas histologicamente. MÉTODOS: Foram realizadas TCs de bacia de 20 cadáveres não formolizados. Os ângulos habituais relacionados ao IFA foram mensurados por um radiologista (ângulo alfa, versão femoral, versão acetabular, ângulo centro-borda e ângulo de Tönnis). O cadáver foi considerado portador de IFA tipo came quando apresentou um ângulo alfa maior que $50^{\circ}$. O cadáver foi considerado portador de IFA tipo pincer quando apresentou versão acetabular menor que $0^{\circ}$, ângulo centro-borda maior que $40^{\circ}$, ou ângulo de Tönnis menor que 0 . Os cadáveres foram então dissecados, o acetábulo foi ressecado, e três fragmentos foram obtidos da peça correspondendo às porções anterior, superior e posterior do rebordo acetabular. Após preparo histológico habitual, as lesões labiais foram avaliadas por um patologista. Quando presente, a lesão foi classificada segundo Seldes. RESULTADOS: A média de idade dos cadáveres foi de 50,2 anos $\pm 7,4$. Foram estudados 13 homens e 7 mulheres. Dezesseis (80\%) dos cadáveres foram considerados portadores de impacto tipo came. Oito (40\%) cadáveres foram considerados portadores de impacto tipo pincer. Mulheres apresentaram maior proporção de IFA tipo pincer $(21,4 \%$ dos homens apresentaram IFA tipo pincer e $83,3 \%$ das mulheres, $p=0,01)$. Histologicamente, $16(80 \%)$ dos espécimes apresentaram lesão microscópica em pelos menos um fragmento. Ao dividirmos as regiões, os fragmentos anteriores apresentaram lesão labial em $65 \%$ dos casos, os fragmentos superiores $50 \%$ e os fragmentos posteriores em $25 \%$. Segundo a classificação de Seldes, $60,7 \%$ das lesões foram do tipo $1,28,6 \%$ foram do tipo 2, e 10,7\% foram mistas. Indivíduos com lesão labial apresentaram um ângulo alfa maior (53,3ำ nos casos com lesão e 49,3ำ nos casos sem lesão, $p=0,01$ ). Alterações tipo pincer não apresentaram associação com presença de lesões labiais ( $p>0,05)$. Não foi encontrada associação entre pincer ou came e a classificação da lesão labial segundo Seldes $(p>0,05)$. CONCLUSÕES: Cadáveres com maior ângulo alfa apresentaram maior prevalência de lesão labial. Os demais ângulos analisados não apresentaram associação com a lesão labial. Nenhuma associação foi encontrada entre tipo de IFA e tipo de lesão labial segundo Seldes.

Descritores: 1. Quadril. 2. Cartilagem articular. 3. Osteoartrite do quadril. 4. Tomografia. 5. Histologia. 6. Acetábulo. 7. Cadáver. 8. Ortopedia. 


\section{Summary}

Ejnisman L. Cadaveric study on the association between femoroacetabular impingement tomographic angles and the histology of labral tears [thesis]. São Paulo: "Faculdade de Medicina, Universidade de São Paulo"; 2015.

INTRODUCTION: Femoroacetabular impingement (FAl) is an important cause of hip pain in the young patient, which may progress to hip arthritis. The purpose of this study was to investigate the relationship between computed tomographic findings in cadavers and histological labral findings. METHODS: Twenty fresh cadavers were submitted to a computed tomography (CT) scan. Standard FAl angles were measured, including alpha angle, femoral version, acetabular version, center-edge, and Tönnis angle. A cam lesion was defined as an alpha angle greater than $50^{\circ}$. A pincer lesion was defined as acetabular version less than $0^{\circ}$, or center-edge angle greater than $40^{\circ}$, or Tönnis angle less than 0 . Cadavers were dissected, the acetabulum was resected, and three fragments of each acetabuli were obtained corresponding to the anterior, superior and posterior acetabular rim. Following routine histological preparation, the histological slides were evaluated for possible labral tears. Tears were classified by Seldes type. RESULTS: The cadavers' mean age was 50.2 years (SD: 7.4), 13 were males, 7 females. Sixteen (80\%) specimens had a cam lesion. Eight $(40 \%)$ specimens had a pincer lesion. Females were more likely to present a pincer lesion $(21.4 \%$ males versus $83.3 \%$ females, $p=0.01)$. Histologically, 16 $(80 \%)$ specimens had a labral tear in at least one region. When divided by region; anterior labra had lesions in $65 \%$ of cases; superior labra in $50 \%$ and posterior labra in $25 \%$. According to Seldes classification, $60.7 \%$ of labral tears were type $1,28.6 \%$ were type 2 , and $10.7 \%$ were mixed. Patients who had a labral tear had significantly higher alpha angles (53.3ำ versus $49.3^{\circ}, \mathrm{p}$ $=0.01)$. Pincer lesions were not associated with labral tears $(p>0.05)$. We found no association between pincer or cam lesions and Seldes classification $(p>0.05)$. CONCLUSIONS: Cadavers presenting with higher alpha angles had higher prevalence of labral tears. Other FAl angles had no association with labral tears. No association was found between FAI type and Seldes classification.

Descriptors: 1. Hip. 2. Cartilage, Articular. 3. Osteoarthritis, Hip. 4. Tomography. 5. Histology. 6. Acetabulum. 7. Cadaver. 8. Orthopedics. 
1. INTRODUÇÃO 
As doenças do quadril jovem são cada vez mais frequentes nos consultórios ortopédicos e de medicina esportiva. O número de estudos e pesquisas relacionadas a essa área também vem aumentando. Dentre as afecções mais frequentes, está o impacto fêmoro-acetabular (IFA).

O IFA é uma doença do quadril caracterizada por alterações anatômicas. Estas podem causar lesão do lábio acetabular, que é uma causa frequente de dor, e progressão para osteoartrite do quadril. ${ }^{1-3} \mathrm{~A}$ fisiopatologia do IFA é melhor compreendida após o conhecimento dos tipos da doença.

O IFA pode ser classificado em três tipos: came, pincer e misto. ${ }^{1,2,4} \mathrm{~A}$ deformidade no IFA tipo came está no fêmur, na transição entre o colo e a cabeça femoral. Esta deformidade causa uma perda da esfericidade da cabeça femoral, aumentando seu raio de curvatura. O termo came é proveniente da engenharia mecânica: came é uma peça utilizada numa ligação mecânica utilizada para transformar movimento linear em movimento rotatório ou vice versa. ${ }^{5}$ No paciente com deformidade tipo came, o fêmur causa uma força de cisalhamento na cartilagem acetabular durante a flexão do quadril. Este cisalhamento é causado pela diferença de raio entre o fêmur e o acetábulo. O lábio acetabular é lesado na transição condro-labial, permanecendo com o tecido sadio nos estágios iniciais da doença.

Já no IFA tipo pincer, a deformidade encontra-se no acetábulo. O pincer ocorre devido a um excesso de cobertura acetabular, que pode ser global ou focal. A sobrecobertura global ocorre quando o acetábulo é fundo, como na protrusão acetabular e nos casos de ângulo centro-borda aumentado. Nos casos focais, ocorre uma retroversão relativa do acetábulo; aumentando a 
cobertura acetabular na sua porção ântero-superior. O lábio acetabular no IFA tipo pincer pode se encontrar degenerado e com cistos intra-substanciais.

O terceiro tipo de IFA, o impacto misto, apresenta características de IFA tipo came e pincer, com alterações tanto do lado femoral quanto acetabular. O IFA misto é o tipo mais comum de IFA, sendo responsável por aproximadamente $75 \%$ dos casos. ${ }^{6}$

A determinação do tipo de IFA é feita por métodos de imagem como a radiografia simples, a tomografia computadorizada (TC) e a ressonância magnética (RM). ${ }^{7,8}$ Com relação ao IFA tipo came, o principal ângulo utilizado para a determinação da deformidade é o ângulo alfa descrito por Nötzli et al. ${ }^{9}$ O ângulo alfa pode ser avaliado na radiografia, na TC e na $R M .^{10,11} \mathrm{Na}$ descrição original, o ângulo alfa é medido na RM no corte axial oblíquo.

A determinação do IFA tipo pincer é realizada por meio de três características no exame de imagem. Na radiografia de incidência ânteroposterior da bacia, avalia-se o fundo acetabular. Casos de acetábulos protrusos, nos quais a cabeça femoral ultrapassa o fundo do acetábulo, caracterizam o IFA tipo pincer. O segundo aspecto a ser avaliado é a cobertura acetabular. O principal ângulo aferido é o ângulo centro-borda. ${ }^{12}$ Inicialmente descrito na radiografia, ele também pode ser avaliado na TC e na RM. Valores acima de $40^{\circ}$ caracterizam IFA tipo pincer. Por fim, avalia-se a versão acetabular. O principal sinal de retroversão acetabular na radiografia é o sinal do cruzamento (também conhecido como cross-over). ${ }^{13}$ No acetábulo normal, as paredes anterior e posterior não se cruzam antes da borda lateral do acetábulo. No acetábulo retrovertido, as paredes se 
cruzam medialmente à borda lateral, definindo uma retroversão acetabular e IFA tipo pincer. A retroversão acetabular também pode ser avaliada na TC, onde, nos cortes axiais, o valor da versão acetabular pode ser mensurado quantitativamente em graus.

Alterações radiológicas do IFA são encontradas em populações assintomáticas. Kim et al., ${ }^{14}$ em um estudo com 430 pacientes adultos submetidos a TC, demonstram que $40 \%$ dos quadris apresentavam pelo menos uma alteração relacionada ao IFA. Nessa avaliação, pacientes do gênero masculino apresentaram mais alterações do que pacientes do gênero feminino $(43,2 \%$ e $35,4 \%$, respectivamente).

O processo de degeneração articular causado pelo IFA inicia-se pela lesão labial. O lábio acetabular é uma estrutura triangular, que se fixa à borda do acetábulo em quase toda sua circunferência, continuando inferiormente com o ligamento transverso do acetábulo. ${ }^{15,16}$ Trata-se de uma estrutura fibro-cartilaginosa, em continuidade com a cartilagem acetabular. $\mathrm{O}$ lábio acetabular atua como um selante da articulação do quadril, mantendo uma pressão negativa hidrostática dentro da articulação que auxilia na estabilidade. $^{17}$ Estudos biomecânicos demonstram a diminuição da estabilidade articular após a lesão labial. ${ }^{17-20}$

Wenger et al. ${ }^{21}$ demonstram que lesões do lábio acetabular raramente acontecem nos pacientes sem deformidades ósseas, e concluem que o IFA seria o principal responsável da lesão labial. Kohl et. al. ${ }^{22}$ avaliam diferenças histológicas nas lesões condro-labiais encontradas em pacientes com diferentes tipos de IFA, demonstrando que o tipo de IFA influencia na 
característica histológica da lesão acetabular. No mesmo artigo, os autores sugerem que seria interessante examinar as alterações histológicas num grupo controle assintomático com alterações radiográficas.

Frente a esse panorama, acreditamos que a relação entre as alterações ósseas do IFA e a lesão do lábio acetabular merecem estudos mais aprofundados e de melhor qualidade metodológica, visando um maior conhecimento da fisiopatologia para um tratamento mais adequado aos pacientes. 


\subsection{Objetivo}

O objetivo primário deste estudo foi analisar a associação entre o ângulo alfa femoral em cadáveres, mensurado na TC, e a presença de lesão do lábio acetabular, avaliada histologicamente.

Os objetivos secundários deste estudo foram avaliar:

- Associação da lesão labial com anteversão femoral, ângulo centroborda, versão acetabular e ângulo de Tönnis;

- Associação da lesão labial com tipo de IFA;

- Associação entre tipo de IFA e tipo de lesão labial histológica classificada segundo Seldes. 
2. REVISÃO DA LITERATURA 


\subsection{Impacto fêmoro-acetabular}

Smith-Petersen, ${ }^{23}$ em 1936, pioneiramente publica sobre uma osteotomia femoral e acetabular no tratamento de pacientes com dor no quadril. Nesse artigo, o autor questiona: "qual a origem da dor do paciente?", e responde: "o impacto entre o colo do fêmur e a parede anterior do acetábulo". Os resultados do tratamento de 11 pacientes (oito com diagnóstico de "malum coxae senilis", dois com diagnóstico de sequela de epifisiolistese da cabeça femoral e um com diagnóstico de protrusão acetabular) são relatados. A técnica cirúrgica consiste na exposição da articulação do quadril através de uma via tipo Smith-Petersen. Uma porção da parede anterior do acetábulo é ressecada, assim como uma porção da junção colo-cabeça do fêmur. Essa técnica é semelhante à descrita décadas depois para o tratamento cirúrgico do IFA.

Carlioz et al., ${ }^{24}$ em 1968, utilizam pela primeira vez o termo came para descrever a deformidade femoral associada ao IFA. Nesse artigo, eles descrevem a deformidade tipo came secundária a sequela da epifisiolistese femoral, que forma uma protuberância na junção colo-cabeça femoral responsável por uma carga excêntrica na articulação do quadril.

Murray e Duncan, ${ }^{25}$ em 1971, descrevem a associação entre atividade esportiva na adolescência e osteoartrite do quadril na vida adulta. Os autores questionam se a osteoartrite do quadril idiopática teria mesmo etiologia indefinida, ou seria causada por alterações menores na articulação do quadril. Eles investigam dois grupos de pacientes: um grupo de jovens 
envolvidos em atividades esportivas e um grupo de jovens sedentários não envolvidos em atividades esportivas. Uma radiografia ântero-posterior da pelve é obtida de todos os voluntários por meio da qual é mensurado o ângulo de inclinação da cabeça femoral. O grupo de pacientes envolvido em atividades esportivas apresenta prevalência significativamente maior de índices alterados, sugerindo uma possível relação entre atividades esportivas na adolescência e osteoartrite do quadril adulto.

Stulberg et al., ${ }^{26}$ em 1975, descrevem a deformidade denominada em cabo de pistola do fêmur proximal, que estaria presente em $40 \%$ dos pacientes que desenvolvem osteoartrite do quadril. O fêmur em cabo de pistola é mais tarde reconhecido como um tipo de deformidade came relacionada ao IFA.

Ganz et al., ${ }^{27}$ em 1988, descrevem uma nova técnica para o tratamento da displasia do desenvolvimento do quadril no adulto, conhecida como osteotomia peri-acetabular bernese (nome proveniente da cidade de Berna na Suiça, cidade desse grupo de pesquisadores). A osteotomia é realizada por meio de cinco cortes acetabulares realizados através de via única anterior. Possui como vantagem em relação às osteotomias acetabulares prévias a manutenção de uma porção íntegra da coluna posterior, o que aumenta a estabilidade da osteotomia e diminui a chance de necrose do fragmento osteotomizado. O desenvolvimento da osteotomia bernese possui relação com a história da descrição do IFA, pois mais tarde esses mesmos autores avançariam nos conceitos relacionados ao IFA por meio da observação de complicações ocorridas em pacientes tratados com a osteotomia bernese. 
Klaue et al., ${ }^{28}$ em 1991, descrevem a síndrome do rebordo acetabular, na qual a displasia do quadril causa lesão do lábio acetabular (nesse artigo, chamado de limbus), que seria uma lesão precursora da osteoartrite. Os autores também descrevem um sinal característico da lesão do lábio acetabular, realizado por meio da flexão, adução e rotação medial do quadril, e que é positivo quando o paciente apresenta dor na região do quadril. Este sinal é conhecido como sinal do impacto anterior do quadril.

Reynolds et al., ${ }^{29}$ em 1999, publicam um artigo demonstrando a associação entre a retroversão acetabular e a presença de dor no quadril. Os autores estudam 310 indivíduos (620 quadris) por meio de radiografias e TC. Desses quadris, 174 não apresentam sintomas, 383 apresentam displasia do quadril, 20 quadris sintomáticos não apresentam alteração nos exames de imagem, e 43 pacientes apresentam retroversão acetabular. Os autores relatam que, em casos leves de retroversão acetabular, a amplitude do movimento do quadril pode estar normal. Porém, em pacientes com quadros mais graves, a amplitude de movimento pode estar diminuída, limitando a flexão até $90^{\circ}$. A rotação medial apresenta-se bastante diminuída a $90^{\circ}$ devido ao impacto da porção anterior do colo femoral com a borda proeminente da parede anterior do acetábulo. Esses pacientes também apresentam tipicamente o sinal do impacto anterior positivo. Nesse artigo, os autores descrevem o sinal do cruzamento (cross-over na língua ínglesa) típico da retroversão acetabular. Outro sinal descrito no artigo, que pode ser encontrado em acetábulos retrovertidos, é a parede posterior deficiente. Normalmente, a parede posterior cruza o centro da cabeça femoral ou desce 
lateral ao centro; já em casos de retroversão, a parede posterior desce medialmente ao centro da cabeça femoral.

Myers et al., ${ }^{30}$ em 1999, reportam cinco pacientes apresentando dor inguinal após a realização de osteotomia periacetabular. Nesses pacientes, após a realização de uma luxação controlada do quadril, foi observado um impacto da porção anterior do colo femoral com a borda anterior do acetábulo. Essa alteração foi corrigida por meio de uma osteoplastia femoral, que possibilitou amplitude de movimento adequada, sem conflito entre o fêmur e o acetábulo. Nesse artigo, os autores também relatam uma mudança na técnica da osteotomia periacetabular bernese, na qual rotineiramente a cápsula articular é aberta com intuito de avaliar a presença de um possível conflito entre o colo do fêmur e o acetábulo pós-osteotomia. Nos casos em que esse impacto é observado, é realizada osteoplastia da porção anterior do fêmur. A constatação deste possível desarranjo entre o colo e a borda anterior do acetábulo levou o grupo suíço ao desenvolvimento do conceito do IFA tipo pincer.

Gautier et al., ${ }^{31}$ em 2000, descrevem a anatomia da artéria femoral circunflexa medial, principal responsável pela irrigação da cabeça femoral. Utilizam a injeção de látex na artéria para estudo do trajeto do vaso. Nesse estudo anatômico, os autores demonstram que o músculo obturador externo protege o ramo profundo da artéria circunflexa medial de uma possível lesão durante a luxação cirúrgica controlada do quadril. O estudo é a base para a técnica de luxação cirúrgica controlada do quadril, desenvolvida pelo mesmo grupo, sendo uma importante técnica no tratamento cirúrgico do IFA. 
Ganz et al., ${ }^{1}$ em 2003, compilam um artigo clássico de acordo com os achados prévios do grupo de Berna. Nesse trabalho, os fundamentos do IFA são estabelecidos. Os autores sugerem que deformidades discretas femorais e acetabulares são responsáveis pelo desenvolvimento da osteoartrite do quadril. O IFA é classificado em três tipos: came, pincer e misto. Os autores descrevem os achados clínicos característicos do IFA, os achados radiográficos característicos da síndrome e estabelecem o tratamento cirúrgico por meio da luxação cirúrgica do quadril, como o método padrão para tratamento.

Clohisy et al. ${ }^{32}$ em 2013, publicam sobre os pacientes tratados por IFA na América do Norte. O estudo inclui 1.076 pacientes consecutivos (1.130 quadris). A idade média é de 28,4 anos, o índice de massa corporal (IMC) médio é $25,1 \mathrm{~kg} / \mathrm{m}^{2}$, e $55 \%$ são mulheres. A distribuição entre os tipos de IFA é: came $(47,6 \%)$, pincer $(7,9 \%)$ e misto $(44,5 \%)$. Os pacientes são submetidos, em sua maioria, a artroscopia do quadril (50,4\%), enquanto 34,4\% são submetidos a luxação cirúrgica do quadril. Observam-se lesões condro-labiais em mais de $90 \%$ das cirurgias, realiza-se osteoplastia femoral em $91,6 \%$ dos procedimentos, acetabuloplastia em $36,7 \%$, reparo labial em $47,8 \%$, desbridamento labial em $16,3 \%$ e condroplastia acetabular em $40,1 \%$. 


\subsection{Lábio acetabular}

Paterson, ${ }^{33}$ em 1957, publica pela primeira vez um relato de lesão do lábio acetabular. O autor relata sobre dois pacientes com luxação coxofemoral, que, após redução da articulação, apresentam articulação incongruente à radiografia. Durante o ato operatório, encontra-se uma lesão labial encarcerada na articulação. $O$ tratamento realizado é a ressecção do lábio acetabular interposto.

Dameron, ${ }^{34}$ em 1959, também reporta sobre um paciente com uma lesão do lábio acetabular impedindo a redução concêntrica da articulação do quadril. Porém, o autor, durante o procedimento cirúrgico, realiza a reinserção do lábio acetabular através de pontos trans-ósseos com o auxílio de fio absorvível. O autor refere que, após um ano, o paciente encontra-se de volta às suas atividades habituais e sem dor.

Altenberg ${ }^{35}$ em 1977, publica sobre dois pacientes com dor no quadril secundária a lesão labial. Num dos pacientes, erosões na cartilagem articular femoral e acetabular próximas a lesão labial são encontradas. A excisão do lábio leva a alívio dos sintomas. No outro caso, uma lesão labial é encontrada em um procedimento cirúrgico para tratamento de osteoartrite do quadril. $\mathrm{O}$ autor sugere que a lesão labial pode ser uma causa de degeneração articular do quadril, quando outra causa não é encontrada. 
Harris et al., ${ }^{36}$ em 1979, relatam oito casos de osteoartrite do quadril. Durante a cirurgia, encontram o lábio acetabular entre a cabeça femoral e o acetábulo. Os autores sugerem que o lábio intra-articular é uma alteração do desenvolvimento e uma causa de osteoartrite do quadril.

Lage et al., ${ }^{37}$ em 1996, propõem uma classificação artroscópica para as lesões labiais. O estudo é baseado em 37 pacientes submetidos a artroscopia de quadril. As lesões são classificadas segundo a etiologia: traumática (18,9\% dos casos), degenerativa $(48,6 \%)$, idiopática $(27,1 \%)$ e congênita (5,4\%); e segundo a morfologia: flap radial (56,8\%), fibrilado radial (21,6\%), periférico longitudinal (16,2\%) e instável (5,4\%).

Weigel e Callaghan, ${ }^{38}$ em 1997, descrevem pela primeira vez o reparo labial com o uso de âncoras. Nesse relato, um menino de nove anos é vítima de luxação posterior do quadril. Após redução, a radiografia demonstra um quadril não concêntrico. Uma via póstero-lateral é realizada, e visualiza-se uma avulsão labial com pequeno fragmento ósseo. O lábio é então reinserido com âncoras metálicas colocadas no ísquio e coluna posterior. Os autores consideram o reparo labial do quadril análogo ao reparo do ombro; e o reparo com âncoras de mais fácil realização que pontos trans-ósseos.

Ferguson et al., ${ }^{18}$ em 2000 , estudam a capacidade do lábio acetabular de atuar como selante da articulação do quadril por meio de modelo de elementos finitos. Após compressão de 1.200 N, o lábio é capaz de manter na articulação um filme líquido, que previne o contato das superfícies articulares, mantendo pressão uniforme na articulação. Sem essa camada líquida, há contato direto entre a cartilagem do fêmur e o acetábulo, 
resultando numa distribuição de força menos uniforme entre as camadas de cartilagem. Além disso, sem a camada líquida, há aumento da pressão na cartilagem do acetábulo próxima ao lábio (3\% versus $20 \%$ ). Os autores sugerem que a ressecção do lábio acetabular durante o tratamento de quadros de osteoartrite inicial pode acelerar o processo degenerativo devido à perda da capacidade de selamento da articulação.

Ferguson et al., ${ }^{19}$ em 2000, demonstram que o lábio acetabular constitui uma barreira importante para a saída de líquido das camadas cartilaginosas da articulação. Um parâmetro estudado é a consolidação da cartilagem, definida como a compressão da cartilagem causada pela saída de líquido de sua estrutura. A consolidação da cartilagem foi $40 \%$ mais rápida na ausência do lábio. Após a remoção do lábio, o contato sólidosólido entre o fêmur e o acetábulo aumenta cerca de 92\%. Sem o lábio acetabular, o centro de rotação desloca-se em direção da borda acetabular. O lábio também contribui na resistência ao movimento lateral da cabeça femoral, aumentando a estabilidade e congruência articular.

Seldes et al., ${ }^{39}$ em 2001, analisam as características da lesão do lábio acetabular em 67 cadáveres. Dos quadris estudados, 96\% (53 de 55) apresentam lesão labial, sendo $74 \%$ dessas lesões localizadas no quadrante ântero-superior. Histologicamente, o lábio fibro-cartilaginoso é contínuo com a cartilagem acetabular, através de uma zona de transição de 1 a $2 \mathrm{~mm}$. Observa-se uma projeção óssea na substânca do lábio. Os autores sugerem uma classificação de lesão labial. O "tipo 1 de Seldes" caracteriza-se por um destacamento do lábio fibro-cartilaginoso da cartilagem hialina na zona de 
transição. Já o "tipo 2 de Seldes" caracteriza-se por um ou mais planos de clivagem de profundidade variável na substância labial. Ambos os tipos possuem uma vascularização aumentada próximo a lesão.

Ferguson et al.. ${ }^{40}$ em 2003, avaliam a função labial em 6 articulações coxo-femorais de cadáveres. Os autores demonstram taxa de consolidação inicial da cartilagem (o quanto a cartilagem se comprime quando sofre carga) $22 \%$ maior após a ressecção labial. A pressurização do fluido intra-articular é maior com o lábio presente, aumentando a lubrificação articular. Os autores sugerem que o trabalho confirma as suspeitas dos trabalhos prévios do mesmo grupo com modelos finitos, demonstrando a importância do lábio acetabular.

Miozzari et al.. ${ }^{41}$ em 2004, estudam a influência da ressecção do lábio acetabular no desenvolvimento de osteoartrite do quadril. Utilizam um modelo animal ovino, no qual 18 ovelhas são submetidas a ressecção de um segmento labial de $2 \mathrm{~cm}$. Os animais são sacrificados após 24 semanas, e os autores encontram, em todos quadris, alterações degenerativas leves. Em 16 dos 18 quadris, o lábio apresenta regeneração parcial, por meio de um tecido fibroso denso preenchendo o defeito labial.

Philippon et al., ${ }^{42}$ em 2007, avaliam a capacidade de cicatrização do lábio acetabular após reinserção artroscópica em um modelo animal. Dez ovelhas fêmeas adultas são submetidas a artroscopia de quadril. Durante o procedimento, uma lesão labial de $1,5 \mathrm{~cm}$ é criada, e em seguida reparada com o auxílio de uma âncora. Após 12 semanas, as ovelhas são sacrificadas, e o reparo labial é avaliado histologicamente. O lábio acetabular da ovelha apresenta aparência anatômica semelhante ao lábio 
humano. Todos os lábios examinados estão estáveis e cicatrizados macroscopicamente após 12 semanas. A cicatrização labial ocorre por meio da formação de um tecido fibro-vascular originário da cápsula articular, e/ou por meio de neo-formação óssea proveniente do rebordo ósseo acetabular exposto. Entretanto, todos os animais apresentam cicatrização incompleta, permanecendo uma pequena fenda superficial entre o lábio e a superfície articular do acetábulo.

Crawford et al., ${ }^{17}$ em 2007, testam a estabilidade articular em um estudo biomecânico. Três estados são avaliados: articulação intacta, selo articular rompido após inserção de uma agulha na articulação e lesão labial (desinserção labial de $15 \mathrm{~mm}$ por meio de uma incisão com lâmina de bisturi). Em todos os estados, a cápsula articular foi preservada. Comparado com o estado intacto, $43 \%$ menos força foi necessária para distrair o quadril $3 \mathrm{~mm}$ no estado com o selo rompido, e $60 \%$ menos força no estado com lesão labial. Um torque de rotação externa gerou rotação $1,5^{\circ}$ e $7,1^{\circ}$ maior no estado de selo rompido e lesão labial respectivamente, além de deslocamento da cabeça femoral 1,21 $\mathrm{mm}$ e $0,67 \mathrm{~mm}$ maior.

Myers et al., ${ }^{20}$ em 2011, avaliam a influência da lesão do ligamento ilio-femoral e do lábio, assim como o reparo dessas estruturas na rotação do quadril em diferentes ângulos de flexão. Quinze quadris de cadáveres são utilizados nesse estudo biomecânico. A avaliação é feita por meio da implantação de marcadores de tântalo nas peças anatômicas, auxiliada por um sistema de fluoroscopia bi-planar que possibilita a reconstrução tridimensional das peças anatômicas. Os autores demonstram aumento da 
rotação lateral e da translação da cabeça femoral com a lesão dessas estruturas. Após o reparo, houve retorno à condição base. Os autores sugerem que, em casos nos quais a capsulotomia é realizada durante o tratamento artroscópico da IFA, esta capsulotomia deve ser reparada, com o intuito de evitar um aumento da rotação lateral do quadril e translação anterior da cabeça femoral. $\mathrm{O}$ estudo também conclui que o lábio possui função na estabilidade articular em rotação.

Audenaert et al., ${ }^{43}$ em 2012, publicam sobre a avaliação histológica do reparo labial. Biópsias são realizadas do lábio acetabular de pacientes submetidos a artroplastia total do quadril, que haviam sido submetidos a artroscopia do quadril previamente, com utilização de âncoras para reparo labial. Macroscopicamente e histologicamente, todos os lábios preservam seu formato triangular e apresentam-se cicatrizados. Apresentam também um aspecto típico fibro-cartilaginoso. Um lábio apresenta calcificação, e três lábios apresentam neovascularização próxima às suturas. Pequenas fendas são observadas em todos os casos. Os autores concluem que o lábio acetabular possui boa capacidade de cicatrização após o reparo artroscópico.

Vawklang e Lertwanich, ${ }^{44}$ em 2012, estudam a prevalência e localização de lesões labiais e sulco sublabiais em cadáveres. Este artigo inclui 50 quadris de 25 cadáveres com idade média de 55 anos. Lesões labiais foram encontradas em $66 \%$ dos 50 quadris, e 8 sulcos sublabiais foram visualizados bilateralmente em 8 quadris de 4 cadáveres. 
Abrams et al., ${ }^{45}$ em 2013, estudam o possível recrescimento labial espontâneo após desbridamento. A população estudada inclui 24 pacientes submetidos a luxação cirúrgica do quadril, nos quais foi realizado desbridamento labial. Após dois anos do procedimento inicial, os pacientes necessitam de retirada do material de síntese, e artroscopia de quadril é realizada simultaneamente para avaliação articular. Todos os pacientes apresentam regeneração do lábio acetabular, embora os mais velhos apresentem tecido de pior qualidade.

Miozzari et al., ${ }^{46}$ em 2015 , discordam sobre a possível regeneração do lábio acetabular após excisão cirúrgica. Nove pacientes submetidos a luxação cirúrgica, em que ressecção labial extensa foi realizada (maior que $60^{\circ}$ ), são avaliados por meio da artro-ressonância magnética. Em nenhum caso foi observado crescimento de um novo lábio. O escore Harris Hip Score foi menor nessa coorte quando comparado a estudos prévios do mesmo grupo. Os autores sugerem que a reconstrução labial seja realizada em casos nos quais o reparo não seja possível.

Lertwanich et al., ${ }^{47}$ em 2015, relatam um estudo biomecânico sobre o efeito da lesão labial na estabilidade do quadril. Dez quadris são testados em 4 situações: carga axial (80 N) e carga axial associada a translação anterior, posterior e lateral. Os estados testados são: intacto, capsulotomia de $1,5 \mathrm{~cm}$ e ressecção do lábio ântero-superior. O deslocamento da cabeça femoral foi maior nos quadris com lesão labial e capsulotomia $(9,6 \pm 2,5$ $\mathrm{mm})$, do que nos quadris apenas com capsulotomia $(5,6 \pm 4,1 \mathrm{~mm}, \mathrm{p}=$ $0,005)$ e nos quadris intactos $(5,2 \pm 3,8 \mathrm{~mm}, \mathrm{p}=0,005)$. Os autores 
concluem que o reparo labial pode ser crucial para o restabelecimento da biomecância do quadril e prevenção da osteoartrite do quadril.

\subsection{Análise radiológica do impacto fêmoro-acetabular}

Terjesen et al., ${ }^{48}$ em 1982, medem o valor da anteversão femoral em 50 pacientes com osteoartrite primária do quadril e 30 indivíduos da mesma idade sem acometimento do quadril. A mediana do grupo com osteoartrite foi $17,5^{\circ}$, enquanto a mediana do grupo controle foi $13,0^{\circ}$. O maior valor de anteversão encontrado no grupo controle foi $25,0^{\circ}$, enquanto 18 pacientes do grupo acometido apresentaram valores acima de $25,0^{\circ}$. Os autores concluem que valores aumentados de anteversão femoral predispõem a osteoartrite do quadril.

Reikerås et al., ${ }^{49}$ em 1983, comparam a versão acetabular e femoral em pacientes portadores de osteoartrite do quadril, com controles portadores de quadril normal, utilizando a TC. Não encontram diferenças na anteversão acetabular entre pacientes e controles. Já no lado femoral, os pacientes com osteoartrite apresentam em média ângulos de anteversão $6^{\circ}$ maiores que os controles. Os autores sugerem que a anteversão femoral aumentada pode ser um fator contribuinte para a osteoartrite do quadril.

Tönnis e Heinecke, ${ }^{50}$ em 1999, avaliam alterações anatômicas em 356 quadris de 181 pacientes com o auxílio da TC. Os autores investigam a 
relação da variação anatômica com achados de exame físico, presença de dor, presença de osteoartrite do quadril e resultados de cirurgias preservadoras. Os autores estipulam que o ângulo normal de anteversão, tanto acetabular quanto femoral, é de $15^{\circ}$ a $20^{\circ}$. Eles também determinam que o índice de instabilidade de McKibbin, que é calculado através da soma entre a anteversão acetabular e femoral, tem o valor normal entre $30^{\circ}$ e $40^{\circ}$. Como conclusão, os autores sugerem que valores menores de anteversão acetabular e femoral, com um índice de McKibbin menor que $20^{\circ}$, são uma causa importante de dor no quadril e osteoartrite. Há uma suspeita de que índices aumentados também causariam dor, mas o número de pacientes com essa condição não é suficiente para uma conclusão definitiva.

Ito et al., ${ }^{51} \mathrm{em} 2001$, analisam a anatomia femoral em exames de RM de pacientes portadores de dor no quadril e assintomáticos. Os autores encontram diminuição significativa da anteversão femoral nos pacientes sintomáticos $\left(9,7^{\circ}\right.$ no grupo sintomático e $15,7^{\circ}$ no grupo controle). Sugerem que a anteversão diminuída predispõe ao IFA devido a um menor espaço disponível para flexão do quadril, e um espaço ainda menor durante a flexão associada a rotação interna.

Nötzli et al., ${ }^{9}$ em 2002, descrevem uma forma de quantificar a deformidade femoral em pacientes com IFA tipo came por meio do ângulo alfa, mensurado na RM. Nesse trabalho, o ângulo alfa de 39 pacientes com IFA é comparado com o ângulo alfa de 35 controles assintomáticos. 0 ângulo alfa médio do grupo com IFA é $74,0^{\circ}$, enquanto o ângulo alfa médio do grupo voluntário é $42,0^{\circ}$. 
Nouh et al., ${ }^{52}$ em 2008, investigam se o ângulo alfa pode ser estimado subjetivamente. Exames de RM de 50 pacientes foram avaliados por três examinadores. Dois examinadores avaliam subjetivamente se consideravam o ângulo alfa normal, enquanto o terceiro mede objetivamente o ângulo alfa. Os autores encontram baixa correlação entre a opinião subjetiva dos dois examinadores, e baixa correlação entre a opinião subjetiva e a objetiva. Concluem que o ângulo alfa não deve ser avaliado subjetivamente.

Miguel et al., ${ }^{53}$ em 2012, comparam os achados radiográficos em pacientes com dor no quadril e assintomáticos. Uma prutuberância femoral foi encontrada mais comumente em casos sintomáticos (24\% versus $41 \%$ ). Os autores não encontram diferenças quanto à versão acetabular. Medem o ângulo alfa nas incidências ântero-posterior, Dunn, Dunn $45^{\circ}$ e Ducroquet. Em todas incidências, o ângulo alfa é maior na população sintomática.

Register et al., ${ }^{54}$ em 2012, avaliam a presença de alterações no quadril em 45 voluntários assintomáticos por meio da RNM. Encontram ângulo alfa médio de $60,7^{\circ} \pm 7,3^{\circ}$, centro-borda médio de $31,0^{\circ} \pm 5,5^{\circ}$, e anteversão femoral média de $16,3^{\circ} \pm 8,1^{\circ}$. Lesões labiais são descritas em $69,0 \%$ dos participantes.

Monazzam et al. ${ }^{55}$ em 2013, comparam os valores do ângulo centroborda lateral mensurado na radiografia e na TC. Os ângulos são medidos por três avaliadores. Os autores encontram uma correlação entre os três avaliadores tanto na radiografia quanto na TC. Além disso, correlação entre a radiografia e a TC também é reportada. 
Scheidt et al., ${ }^{56}$ em 2014, realizam estudo com 82 voluntários com idade entre 40 e 60 anos, sendo $66 \%$ mulheres. Encontram ângulo alfa médio de $45^{\circ} \pm 8,6^{\circ}$. Valores acima de $50^{\circ}$ são encontrados em $34 \%$ dos homens e $11,1 \%$ das mulheres. Os autores relatam que $58,5 \%$ dos voluntários não apresentam alterações sugestivas de IFA, 25\% apresentavam alterações tipo came, 12,65\% apresentam alterações tipo pincer e 3,7\% portadores apresentam ambas alterações (tipo misto).

\subsection{Relação entre aspectos radiológicos e lesões labiais no IFA}

Beck et al., ${ }^{57}$ em 2005, investigam a relação entre o tipo de IFA e o padrão de lesão articular. A partir de uma amostra inicial de 302 quadris, consideram-se apenas 26 pacientes como came isolado e 16 como pincer isolado, sendo o restante considerado misto. Os casos de IFA tipo came apresentam lesão ântero-superior com separação entre o lábio e a cartilagem, porém o lábio permanece sadio. Os casos de IFA tipo pincer apresentam lesão circunferencial no acetábulo, sendo o lábio degenerado e ossificado.

Johnston et al. ${ }^{58}$ em 2008 , publicam sobre a relação entre a gravidade da lesão came e lesões condro-labiais em pacientes com IFA. São incluídos 82 pacientes. A deformidade came é avaliada por meio do ângulo alfa na radiografia simples em perfil. Amplitude de movimento pré-operatória, e lesões condro-labiais intra-operatórias são avaliadas. Ângulo alfa aumentado 
é relacionado ao gênero masculino e diminuição da amplitude de movimento do quadril. Pacientes portadores de ângulos alfa maiores apresentam mais defeitos condrais do rebordo acetabular e destacamento da base do lábio.

Kohl et al., ${ }^{22}$ em 2011, avaliam as diferenças histológicas nas lesões condro-labiais encontradas nos diferentes tipos de IFA. Os autores utilizam a classificação de Mankin para avaliação da degradação articular. Vinte pacientes foram incluídos no estudo, sendo seis casos de came, cinco casos de pincer e nove casos mistos. Os casos de IFA tipo pincer apresentam uma área focal e bem circunscrita de lesão condro-labial grave. Já os casos de IFA tipo came apresentam uma área de acometimento difuso envolvendo uma área de cartilagem acetabular maior, com sinais de degeneração e erosões superficiais. O osso subcondral nos casos de IFA tipo pincer demonstra áreas de necrose e formação de calo ósseo, enquanto o osso subcondral nos casos de IFA tipo came não apresenta alteração. Os casos de IFA tipo misto apresentam características concomitantes dos tipos came e pincer.

Beaulé et al., ${ }^{59} \mathrm{em}$ 2012, demonstram a influência dos ângulos do IFA em achados intraoperatórios de 167 pacientes submetidos a cirurgia preservadora do quadril. Pacientes portadores de IFA tipo came e ângulo alfa maior que $65^{\circ}$ apresentam maior risco de lesão condral grave, enquanto o aumento da cobertura acetabular (determinado pelo ângulo centro-borda) apresenta efeito protetor.

Ejnisman et al., ${ }^{60}$ em 2013, discorrem sobre a relação entre o IFA e a anteversão do colo femoral. A anteversão femoral média dos pacientes é $9^{\circ}$ (variação de $-10^{\circ}$ a $27^{\circ}$ ). $\mathrm{O}$ valor de anteversão femoral é correlacionado ao 
tamanho da lesão labial; quanto maior o grau de anteversão, maior o tamanho da lesão labial. Pacientes com anteversão femoral maior que $15^{\circ}$ apresentam chance 2,2 vezes maior de possuir uma lesão labial que se estende além da posição de 3 horas (anterior) no acetábulo.

Zilkens et al., ${ }^{61}$ em 2013, estudam a influência do ângulo beta na lesão da cartilagem. $O$ ângulo beta é mensurado entre a transição colo-cabeça femoral e o rebordo acetabular, e por este motivo representa simultaneamente a deformidade femoral e acetabular. São incluídos 10 pacientes e 15 voluntários. Os autores afirmam que os ângulos alfa e beta são reprodutíveis. O ângulo beta relaciona-se com os valores encontrados do índice dGEMRIC (delayed gadolinium-enhanced MRI of cartilage), que avalia a cartilagem articular; enquanto o ângulo alfa não apresenta relação com o dGEMRIC.

Redmond et al.. ${ }^{62}$ em 2015, investigam a relação entre características demográficas e radiográficas com o tamanho da lesão labial encontrada durante a artroscopia de quadril. O tamanho da lesão labial está associado a gênero, idade e ângulo alfa. Nas pacientes do sexo feminino, a classificação de Tönnis e o ângulo cérvico-diafisário também se relacionam com o tamanho da lesão labial. Porém, esse modelo estima apenas $26 \%$ das características responsáveis pelo tamanho da lesão labial. 


\subsection{Tratamento do impacto fêmoro-acetabular}

Burman, ${ }^{63}$ em 1931, reporta sua experiência com a artroscopia em diversas articulações. Sobre o quadril, o autor diz ser impossível colocar uma agulha entre a cabeça do fêmur e o acetábulo. Portanto, seria possível visualizar apenas parte da cabeça femoral, a junção da cabeça femoral e o colo, e a região intracapsular do colo femoral.

Glick et al., ${ }^{64}$ em 1987, desenvolvem uma nova técnica para realização da artroscopia do quadril. A artroscopia é feita com o paciente em decúbito lateral com auxílio de tração. A técnica cirúrgica é utilizada em 11 casos. As indicações são: dor no quadril sem diagnóstico, remoção de corpos livres articulares, exploração e desbridamento após fratura e/ou luxação, e avaliação do quadril com osteoartrite previamente à cirurgia definitiva.

Ikeda et al., ${ }^{65}$ em 1988, publicam sobre sete casos nos quais a artroscopia do quadril revela lesão do lábio acetabular. Todos os pacientes apresentam dor à flexão e rotação medial do quadril. A maior parte das lesões labiais localiza-se no lábio póstero-superior.

Byrd, ${ }^{66}$ em 1994, descreve uma técnica para realização da artroscopia de quadril na posição supina. O procedimento é realizado numa mesa ortopédica convencional com controle fluoroscópico. O quadril é operado por meio da tração, utilizando três portais artroscópicos. Vinte pacientes consecutivos são operados com essa técnica. $O$ autor considera a 
técnica efetiva e reprodutível, utilizando equipamento já presente habitualmente na sala cirúrgica.

Ganz et al., ${ }^{67}$ em 2001, relatam a técnica de luxação cirúrgica controlada do quadril. Baseado em estudos prévios do mesmo grupo, os autores descrevem uma técnica utilizada para acesso completo da articulação do quadril por meio de uma incisão de pele tipo KocherLangenbeck e uma osteotomia do trocânter maior, sem necessidade de desinserção dos rotadores laterais do quadril. Os autores descrevem os resultados em 213 pacientes operados por luxação cirúrgica do quadril, sem nenhum caso de osteonecrose da cabeça femoral.

Espinosa et al., ${ }^{68}$ em 2006, analisam os resultados clínicos após o tratamento aberto do IFA. Nos primeiros 25 quadris, o lábio lesado é ressecado, e nos 35 quadris seguintes, o lábio é reinserido com auxílio de âncoras. Os autores utilizam como ferramenta de comparação o escore clínico de Merle d'Aubigné e o escore radiográfico de Tönnis. O grupo em que o lábio é preservado apresenta melhores resultados clínicos e radiográficos após um e dois anos de cirurgia. Os autores sugerem que o lábio acetabular deve ser preservado no tratamento cirúrgico do IFA.

Larson e Giveans, ${ }^{69}$ em 2009 comparam os resultados obtidos após artroscopia de quadril em pacientes nos quais é realizada sutura labial (39 pacientes) e pacientes nos quais é realizado desbridamento labial (36 pacientes). Os escores clínicos utilizados são o Harris modificado, SF-12 (Short Form 12) e escala visual analógica de dor. Após um ano de acompanhamento, ambos os grupos apresentam melhora dos escores, 
entretanto, o grupo no qual o lábio é reparado apresenta resultados significativamente melhores no escore de Harris. O SF-12 e a escala visual analógica de dor não apresentam diferenças.

Philippon et al., ${ }^{6}$ em 2009, avaliam os resultados da artroscopia do quadril para tratamento do IFA em 112 pacientes com seguimento mínimo de dois anos. Três pacientes apresentam IFA tipo pincer, 23 IFA tipo came e 86 IFA tipo misto. O escore de Harris modificado apresenta melhora significativa, de 58 para 84 pontos. Já a mediana da satisfação do paciente em uma escala de 1 a 10 é 9 . Dez pacientes são submetidos a artroplastia do quadril após a artroscopia. Os preditores de bom resultado são o escore de Harris modificado pré-operatório, espaço articular maior que $2 \mathrm{~mm}$ e reparo labial ao invés de desbridamento. Os autores recomendam o reparo labial em pacientes submetidos a cirurgia por IFA.

Polesello et al.. ${ }^{70}$ em 2009, publicam sobre os resultados clínicos da artroscopia de quadril em 49 atletas. A taxa de retorno ao esporte foi de $96,0 \%$, sendo que os pacientes classificam subjetivamente o retorno como satisfatório em $73 \%$ dos casos, e insatisfatório em $27 \%$ dos casos.

Byrd e Jones, ${ }^{71}$ em 2010, relatam o seguimento de longo prazo de uma série de pacientes submetidos a artroscopia do quadril. Essa coorte inclui 50 pacientes (52 quadris). A idade média dos pacientes é 38 anos, sendo 27 homens e 23 mulheres. A mediana de melhora do Harris Hip Score é de 25 pontos. Quatorze pacientes são convertidos a artroplastia total do quadril. A presença de osteoartrite do quadril é um preditor de mau prognóstico. 
Ejnisman et al., ${ }^{72}$ em 2011, reportam os resultados clínicos da artroscopia de quadril em 35 atletas federados. Após seguimento médio de 2,8 anos, o Western Ontario and McMaster Universities Osteoarthritis Index (WOMAC) apresenta melhora, de uma média pré-operatória de 68,4 para uma média pós-operatória de 89,5.

Domb et al., ${ }^{73}$ em 2013, comparam os resultados da cirurgia para IFA em pacientes submetidos a artroscopia do quadril ou luxação cirúrgica. A decisão do procedimento a ser realizado é feita pelo próprio paciente após o médico explicar as vantagens e desvantagens de cada técnica. Dez pacientes são incluídos no grupo da luxação cirúrgica e 20, no grupo artroscópico. O seguimento médio é de 24 meses. Os escores clínicos utilizados são o Harris Hip Score modificado, Non-Arthritic Hip Score (NAHS), Hip Outcome Score (HOS) subdividido em atividades da vida diária e esporte específico, escala visual análogica de dor e satisfação com o procedimento. Todos os escores apresentam melhora significativa nos dois grupos. Ao comparar os resultados, o NAHS apresenta escore maior no grupo artroscópico (94,2 contra 85,7) e o incremento no escore HOS subescala esporte específico é maior no grupo artroscópico $(42,8$ contra 23,5).

Geyer et al., ${ }^{74}$ em 2013, relatam os resultados clínicos após reconstrução labial utilizando enxerto autólogo de fáscia lata. São incluídos 75 pacientes (76 quadris). Destes quadris, 19 são convertidos para artroplastia total do quadril após 59,1 meses em média. Dos pacientes não artroplásticos, o Harris Hip Score modificado e o HOS melhoram significativamente após seguimento médio de 49 meses. A satisfação com o 
procedimento apresenta mediana de 8. Espaço articular menor que $2 \mathrm{~mm}$ é fator prognóstico ruim para sobrevivência do quadril.

Krych et al., ${ }^{75}$ em 2013, avaliam os resultados da artroscopia de quadril em pacientes do sexo feminino com lesão labial secundária a impacto tipo pincer. Dezoito pacientes são randomizadas para desbridamento do lábio acetabular, e 18 pacientes são randomizadas para reparo labial. Após seguimento mínimo de um ano, o grupo em que o lábio é reparado apresenta resultados clínicos superiores no escore HOS.

Domb et al., ${ }^{76}$ em 2015, comparam os resultados de pacientes submetidos a artroscopia de quadril em dois grupos: capsulotomia não reparada (235 pacientes) e capsulotomia reparada (168 pacientes). As características dos pacientes dos dois grupos não são semelhantes. O grupo onde a capsulotomia não foi reparada é mais velho e apresenta IMC maior, mais lesões condrais e piores escores clínicos pré-operatórios. Além disso, mais mulheres são submetidas a reparo capsular. Após dois anos de seguimento mínimo, todos os escores clínicos dos dois grupos melhoram. Os resultados do grupo onde se realiza o reparo capsular são significativamente melhores, porém a significância se perde ao se realizar a correção por variáveis de confusão. Os autores concluem que o reparo capsular é seguro e não influencia negativamente os resultados clínicos da artroscopia do quadril.

Steppacher et al., ${ }^{77}$ em 2015, publicam os resultados da luxação cirúrgica do quadril após 10 anos de seguimento. São relatados os resultados de 93 quadris de 72 pacientes. A prevalência do sinal do impacto anterior diminui de $95 \%$ para $38 \%$. O escore Merle d'Aubigné Postel melhora 
de 15,3 para 16,9. O índice de sobrevivência é de $80 \%$, sendo considerado falha: conversão para artroplastia total, evidência de progressão radiográfica de osteoartrite, ou escore de Merle d'Aubigné-Postel menor que 15. Preditores de falha são: idade maior que 40 anos, IMC maior que 30, ângulo centro-borda menor que $22^{\circ}$ ou maior que $32^{\circ}$, e cobertura acetabular posterior menor que $34 \%$. 
3. MÉTODOS 


\subsection{Desenho do estudo}

Este é um estudo observacional. Realizamos TCs de bacia e joelho em cadáveres do Serviço de Verificação de Óbitos da Capital da Universidade de São Paulo (SVOC-USP). As TCs são parte do projeto PISA (Plataforma de Imagem na Sala de Autópsia) da Faculdade de Medicina da Universidade de São Paulo (FMUSP). Após a TC, o acetábulo do cadáver foi ressecado para avaliação histológica do lábio acetabular. A descrição deste estudo foi realizada segundo as orientações do protocolo Strengthening the Reporting of Observational Studies in Epidemiology (STROBE).$^{78}$

\subsection{Aprovação na comissão de ética}

O presente estudo foi aprovado pela Comissão de Ética para Análise de Projetos de Pesquisa do Hospital das Clínicas da Faculdade de Medicina da Universidade de São Paulo (HC-FMUSP), em sessão do dia 19 de setembro de 2012, como protocolo de pesquisa 296/12 (Anexo A). O presente estudo também foi aprovado pelo SVOC-USP (Anexo B). 


\subsection{Características e locação do estudo}

Este estudo foi realizado no SVOC-USP e no Laboratório de Investigação Médica 41 (LIM/41) do Instituto de Ortopedia e Traumatologia do HCFMUSP (IOT-HCFMUSP).

\subsection{Participantes}

Os cadáveres foram incluídos de maneira consecutiva de acordo com a disponibilidade do SVOC-USP. O lado dissecado foi alternado sequencialmente. A amostra estudada foi de 20 cadáveres. O tamanho da amostra baseou-se no número de TCs disponibilizadas pelo PISA para este estudo. Antes do início do projeto, um caso foi estudado como piloto, com o objetivo de averiguar a viabilidade do projeto.

Dados demográficos analisados foram: idade, gênero, peso, altura, índice de massa corpórea, e lado estudado. 


\subsection{Critérios de seleção}

\subsubsection{Critérios de inclusão}

Potenciais participantes foram incluídos caso apresentassem todos os seguintes critérios:

1. Idade entre 18 e 60 anos, de ambos os gêneros;

2. Ausência de deformidades visíveis nos membros inferiores;

3. Ausência de cicatrizes no quadril indicativas de cirurgia prévia na região.

\subsubsection{Critérios de exclusão}

Participantes foram excluídos do estudo ou deixaram de ser incluídos caso apresentassem um dos seguintes critérios:

1. Osteoartrite avançada segundo avaliação macroscópica da articulação após dissecção;

2. Osteoartrite avançada do quadril na TC; 
3. Casos em que ocorreram complicações durante a dissecção, como fraturas intra-articulares durante osteotomia da peça e/ou lesão iatrogênica do lábio acetabular.

\subsection{Técnica tomográfica}

Todas as TCs foram realizadas no SVOC-USP. Após a liberação pelo técnico do SVOC-USP, o cadáver foi encaminhado à sessão de radiologia. Utilizou-se um aparelho tomográfico de 16 canais (SOMATOM Emotion, Siemens HealthCare, Alemanha) com colimação de 6,0 x 16,0 x 0,5 mm e 0,6 $\mathrm{mm}$, "pitch" de 0,8, rotação do tubo de 1,0 segundos, FOV de $370 \mathrm{~mm}$, filtro "detail", matriz de 512, dosagem de radiação CTDI vol de 58,3 mGy ou DLP de 291,5 mGy-cm. O cadáver foi posicionado no tomógrafo em decúbito dorsal, com o tronco centralizado, membros superiores para cima e com os pés próximos do aparelho (Figura 1). As pernas foram presas para evitar movimentação dos membros pela rolagem da esteira do aparelho durante o exame. 


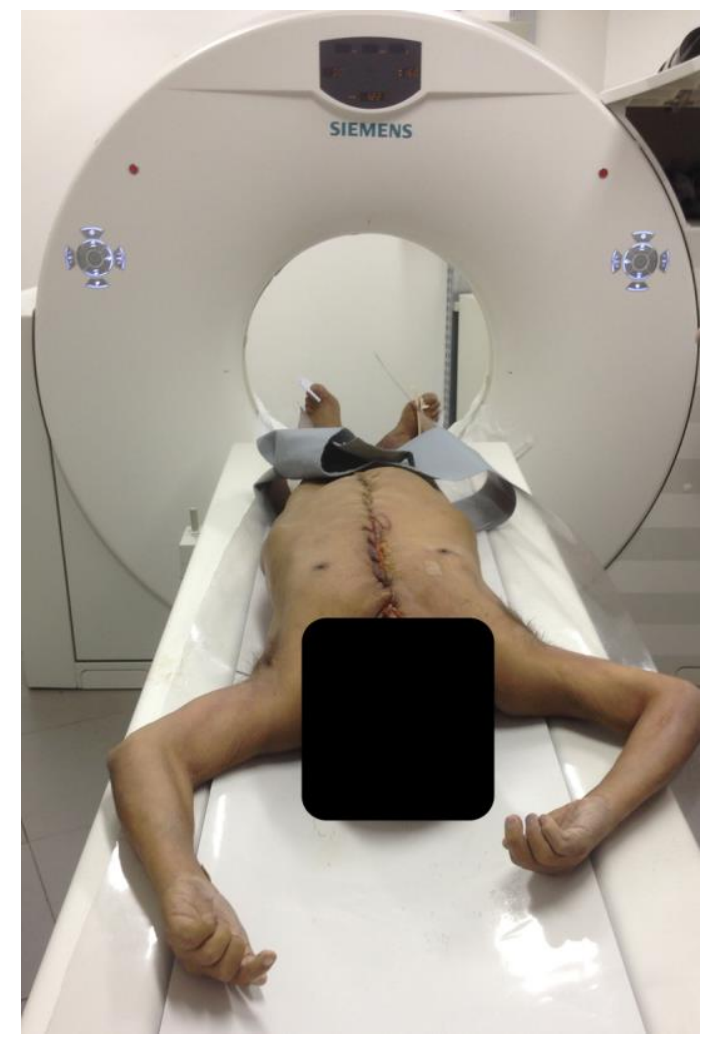

Figura 1. Posicionamento do cadáver durante o exame de tomografia computadorizada: decúbito dorsal horizontal, pés presos próximos ao aparelho e membros superiores elevados.

A técnica do aparelho para adquirir as imagens foi a "multislice", na qual o tubo tomográfico roda e adquire múltiplas imagens simultâneas enquanto a mesa varia de posição. Para as imagens da bacia foram obtidos cortes axiais de $1,5 \mathrm{~mm}$ de espessura com interposição de $50 \%$ entre eles, permitindo reconstrução multiplanar detalhada nos três eixos ortogonais (coronal, axial e sagital), iniciando proximalmente acima da crista ilíaca e finalizando distalmente ao trocânter menor. A mesma técnica foi usada no joelho ipsilateral ao lado estudado sem mudar o posicionamento do paciente. Tais imagens foram armazenadas em arquivos formato DICOM (Digital Imaging and Communications in Medicine). 


\subsection{Técnica de dissecção}

Após obtenção da TC, o cadáver foi encaminhado à sessão de dissecções do SVOC-USP e foi dissecado em decúbito dorsal horizontal em mesa de dissecção. Uma incisão de aproximadamente $20 \mathrm{~cm}$ na região anterior do quadril foi realizada (Figura 2) ${ }^{79} \mathrm{~A}$ incisão foi iniciada na face lateral da crista ilíaca, curvando-se levemente sobre a espinha ilíaca ânterosuperior e estendendo-se à face lateral da coxa. No aspecto proximal da ferida, o músculo ilíaco foi dissecado sub-periostealmente da tábua interna do osso ilíaco. No aspecto distal da ferida, a dissecção superficial foi entre o músculo sartório e o músculo tensor da fáscia lata. A dissecção profunda continuou entre o músculo glúteo médio e o músculo reto femoral, expondo a cápsula articular. Em alguns casos, o músculo sartório e o reto femoral foram desinseridos para facilitar a via de acesso. 


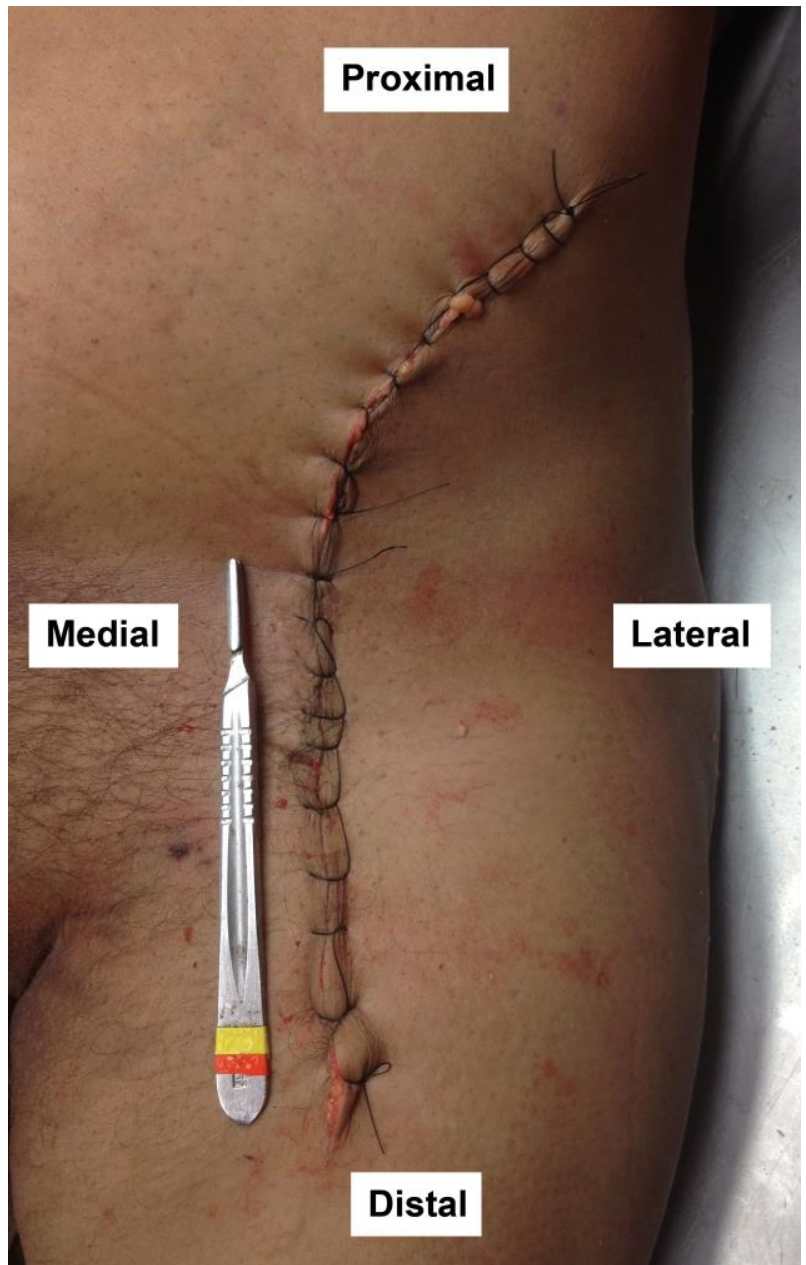

Figura 2. Incisão suturada com nylon 2,0 na região anterior do quadril (caso 8, lado esquerdo).

A cápsula articular foi aberta através de uma incisão em "T" invertido com base na linha inter-trocantérica. Realizou-se este passo com muito cuidado para evitar lesões iatrogênicas ao lábio acetabular. Com a cápsula aberta, o colo do fêmur era osteotomizado, e a cabeça do fêmur, ressecada. O acetábulo era ressecado através de uma osteotomia tripla, utilizando formões. A primeira osteotomia realizada era a do ísquio, feita logo abaixo do fim do acetábulo. A osteotomia púbica era a segunda realizada, medialmente ao fim do acetábulo, com direção oblíqua de ântero-lateral para 
póstero-medial. Por último, a osteotomia do ilíaco foi realizada entre as espinhas ilíacas, direcionada à incisura isquiática maior (Figura 3). Após as três osteotomias, observou-se a mobilidade do fragmento, as partes moles eram liberadas e o acetábulo era ressecado.

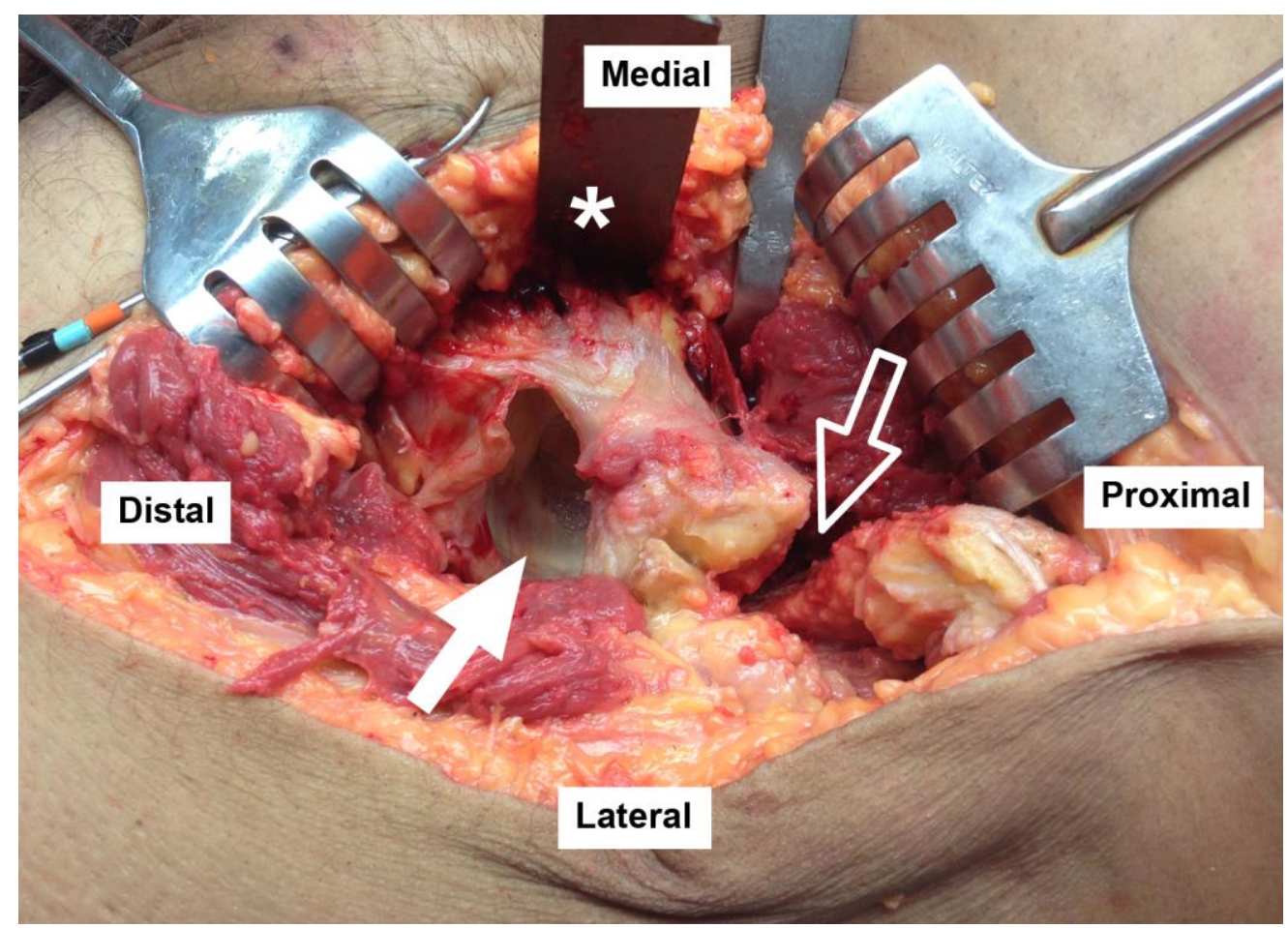

Figura 3. Dissecção acetabular (caso 8, lado esquerdo). Asterisco: osteótomo no púbis; seta cheia: cavidade acetabular; seta vazia: osteotomia ilíaca. 


\subsection{Preparação das lâminas}

Após a ressecção do acetábulo, um fio de nylon 2,0 foi colocado na porção anterior da peça para demarcação da posição anatômica das estruturas (Figura 4). Neste momento, realizou-se uma avaliação macroscópica. Avaliouse: presença de lesão macroscópica do lábio acetabular, presença de sulcos sublabiais posteriores e presença de lesões cartilaginosas macroscópicas. A peça foi levada ao LIM/41 do IOT-HCFMUSP, onde foi fixada em solução de formalina $10 \%$ por 5 dias. Após a fixação, as peças foram submetidas a descalcificação com ácido nítrico $10 \%$ por 7 dias.

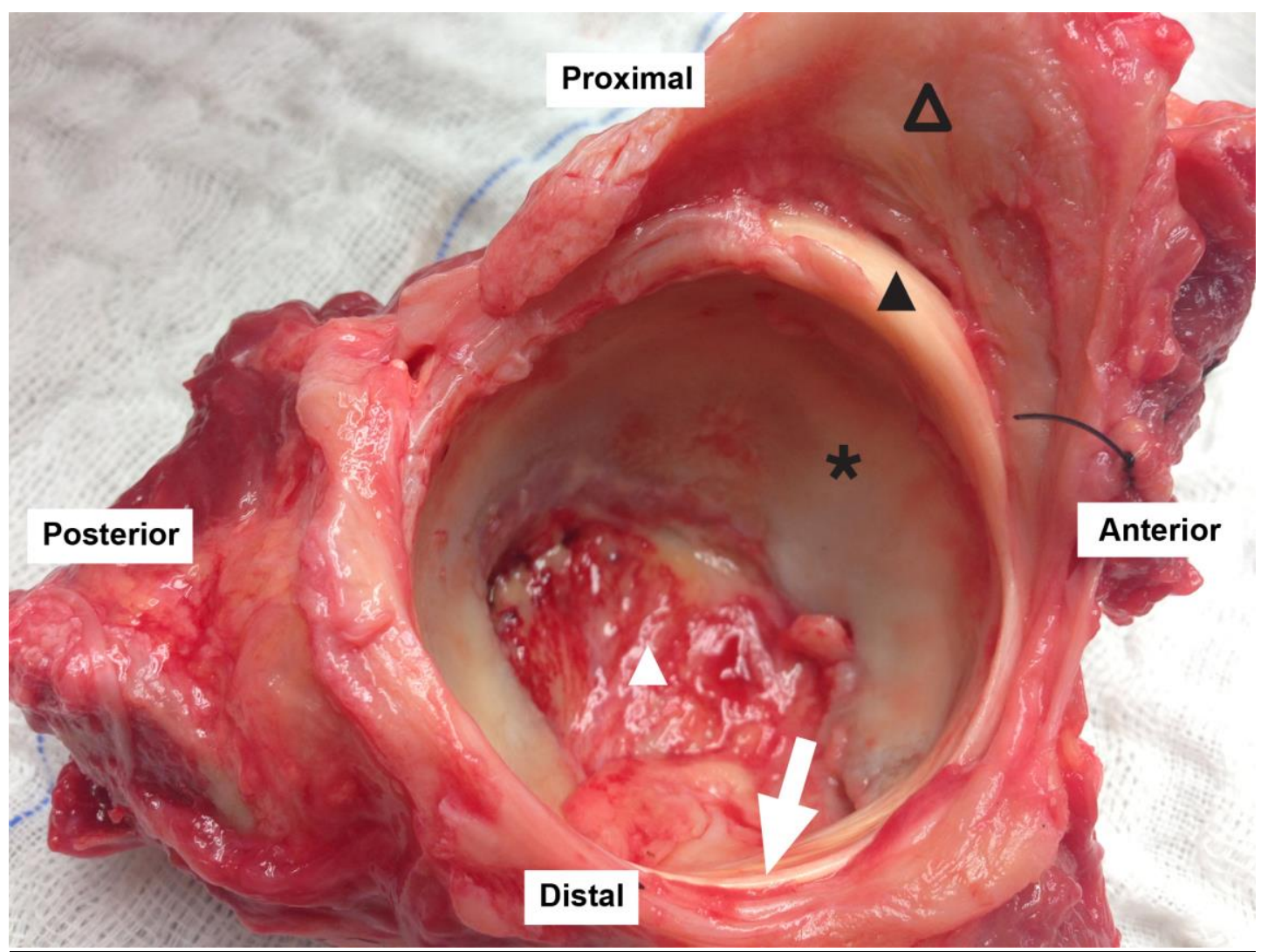

Figura 4. Peça acetabular (caso 7, lado direito). Triângulo preto: lábio ântero-superior; seta branca: ligamento transverso; triângulo vazio: cápsula articular; triângulo branco: pulvinar; asterisco preto: cartilagem acetabular. 
As peças foram cortadas com auxílio de uma serra manual no sentido radial da articulação segundo a face de um relógio (Figuras 5 e 6). ${ }^{80}$ Considerou-se a porção média da fossa acetabular como 6 horas, e a posição imediatamente superior como 12 horas. Foram realizados cortes de modo a obter três fragmentos de cada peça, sendo um fragmento ântero-superior (próximo a região de 2 horas em um quadril direito, ou 10 horas em quadril esquerdo), um fragmento superior (próximo a região de 12 horas) e um fragmento póstero-superior (próximo a região de 10 horas em quadril direito, ou 2 horas em um quadril esquerdo). O fragmento continha osso acetabular, cartilagem articular, lábio acetabular e cápsula articular (Figura 7).

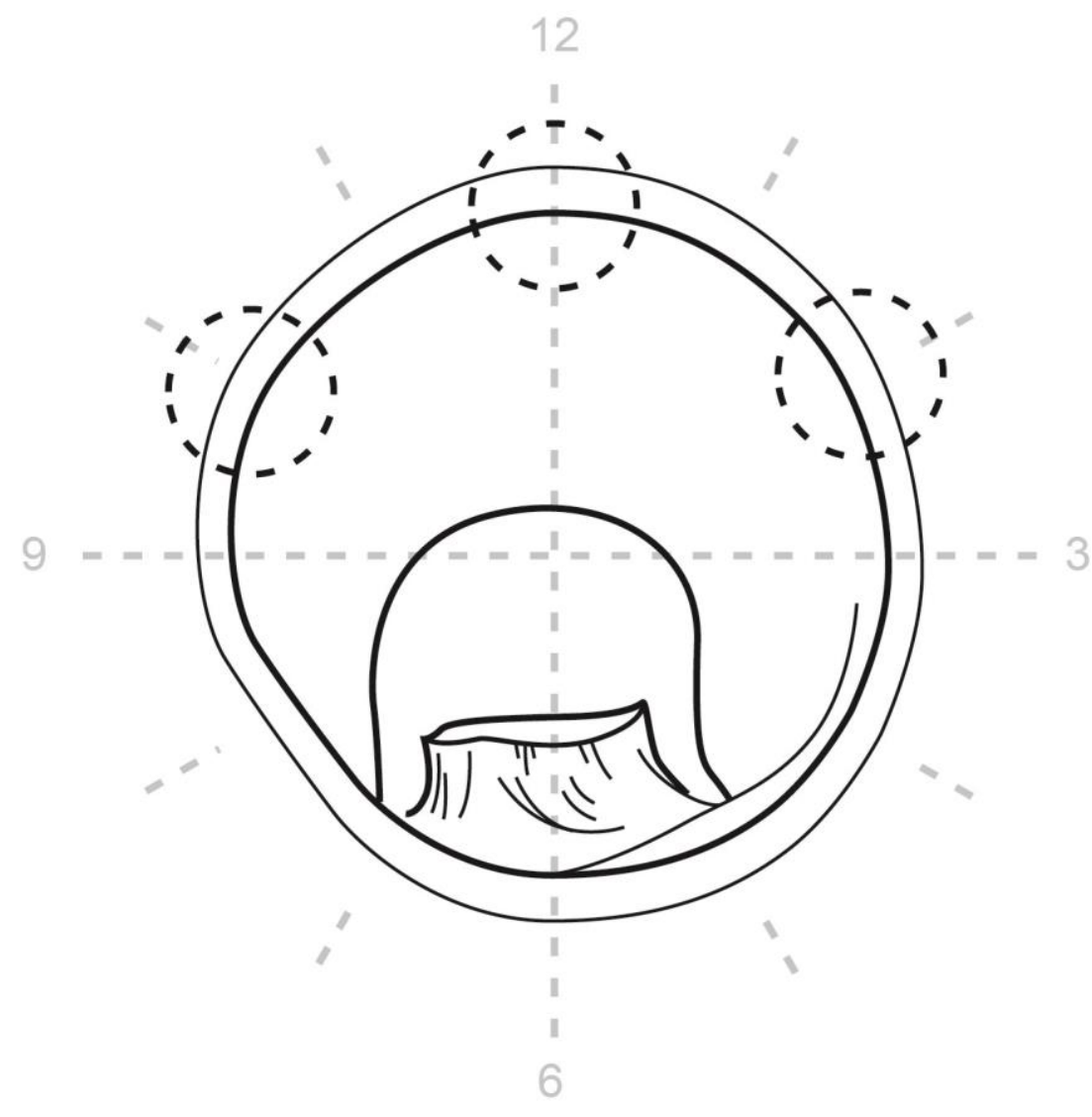

Figura 5. llustração demonstrando a orientação dos cortes acetabulares segundo as horas do relógio. Os círculos pontilhados demonstram o local de retirada dos fragmentos, equivalente as posições de 10, 12 e 2 horas. 


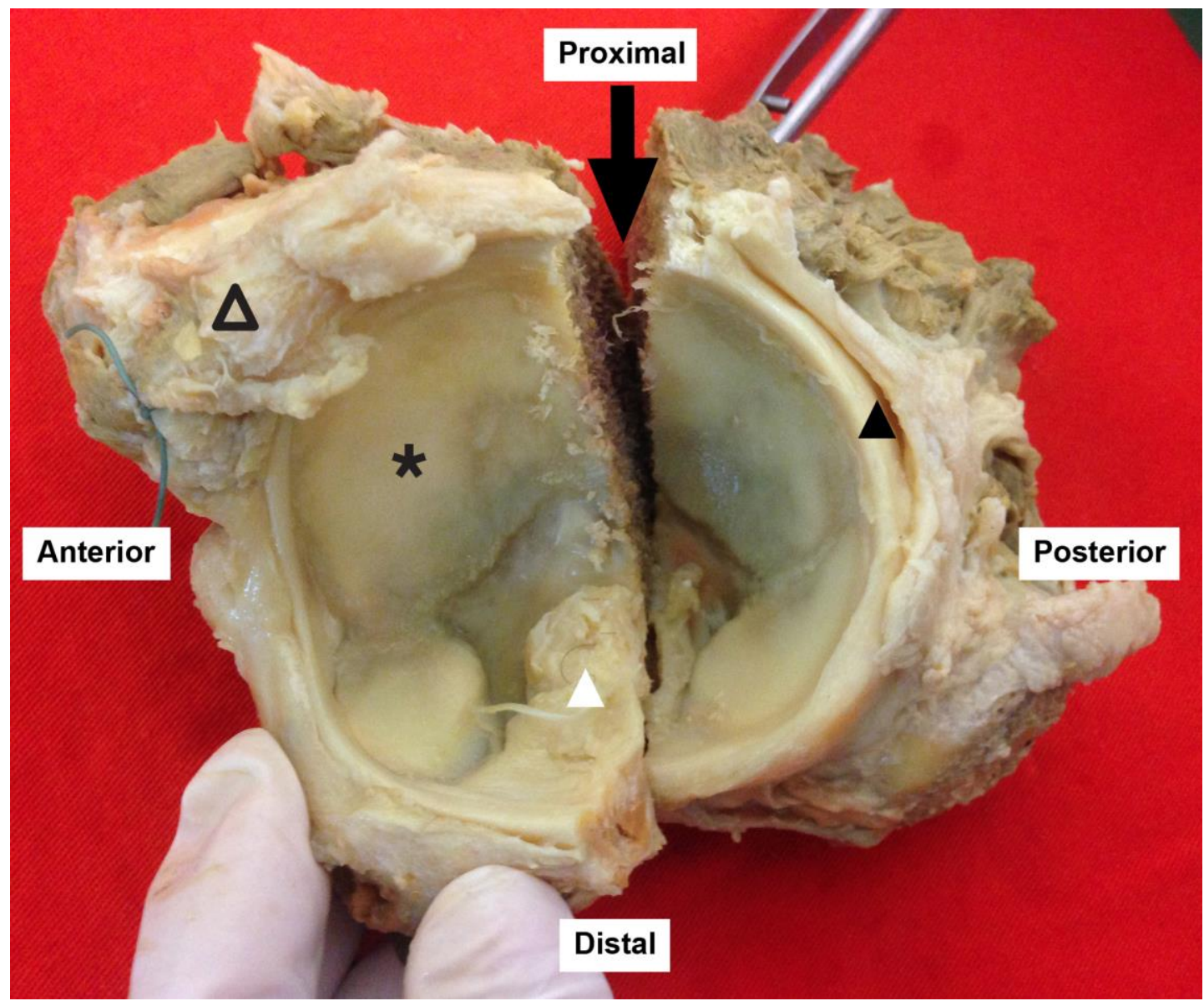

Figura 6. Peça acetabular (caso 8, lado esquerdo) após realização do primeiro corte. Seta preta: corte entre 6 e 12 horas; triângulo preto: lábio póstero-superior; triângulo vazio: cápsula articular; triângulo branco: pulvinar; asterisco preto: cartilagem acetabular. 


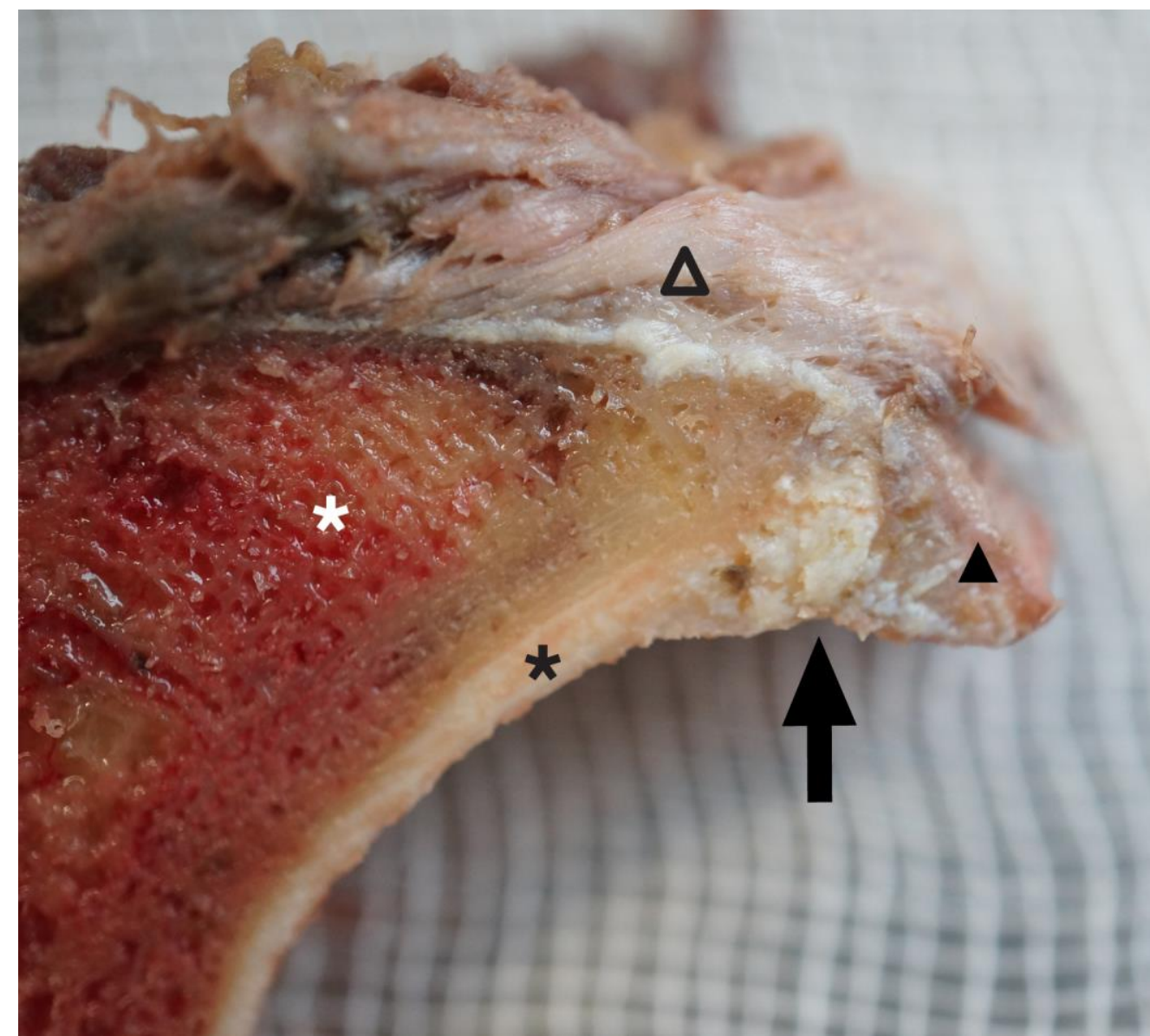

Figura 7. Fragmento acetabular superior (caso 1, lado esquerdo) previamente à rotina histológica. Triângulo preto: lábio acetabular; triângulo vazio: cápsula articular; asterisco preto: cartilagem acetabular; asterisco branco: osso acetabular; seta: transição condro-labial íntegra.

As peças foram então submetidas à rotina histológica. Inicialmente foram desidratadas em série crescente de álcoois, clareadas em xilol e em seguida emblocadas em parafina. Foram obtidos cortes histológicos com 5 micrômetros de espessura dos blocos de parafina. Estes cortes foram corados por hematoxilina e eosina (HE) e pelo tricrômico de Masson. A avaliação das alterações histológicas foi realizada sob microscópio (Axio-lab, 
Zeiss, Oberkochen, Alemanha) de luz Zeiss e os achados foram documentados em fotografia.

A estação de trabalho consiste de microscópio Zeiss trinocular, vídeocâmera colorida (CCD-IRIS SONY modelo DXC-107 A, Tóquio, Japão) com placa digitalizadora de imagens, um microcomputador com processador Pentium $133 \mathrm{MHz}$, IBM-PC (IBM, Armonk, Estados Unidos) compatível, operando em ambiente Windows 95-32 bits. As imagens obtidas dos campos microscópicos foram digitalizadas. Cada campo microscópico foi avaliado com objetiva de 4 aumentos e ocular de 10 aumentos.

\subsection{Avaliação histológica}

Todas as avaliações histológicas foram realizadas pelo mesmo médico patologista, que é membro do IOT-HCFMUSP. O médico patologista desconhecia os valores das medidas tomográficas.

As lâminas foram avaliadas por meio dos seguintes parâmetros:

1. Presença de lesão do lábio acetabular;

2. Classificação de Seldes et al. ${ }^{39}$ para lesão do lábio acetabular em casos positivos quanto ao item 1 (Figura 8):

2.1. Seldes 1: destacamento do lábio da cartilagem articular 
2.2. Seldes 2: um ou mais planos de clivagem na substância do lábio.

2.3. Seldes 3: modificou-se a classificação original de Seldes com a inclusão do tipo 3, caracterizado por um padrão misto que apresenta destacamento do lábio acetabular associado a um ou mais planos de clivagem na substância labial.
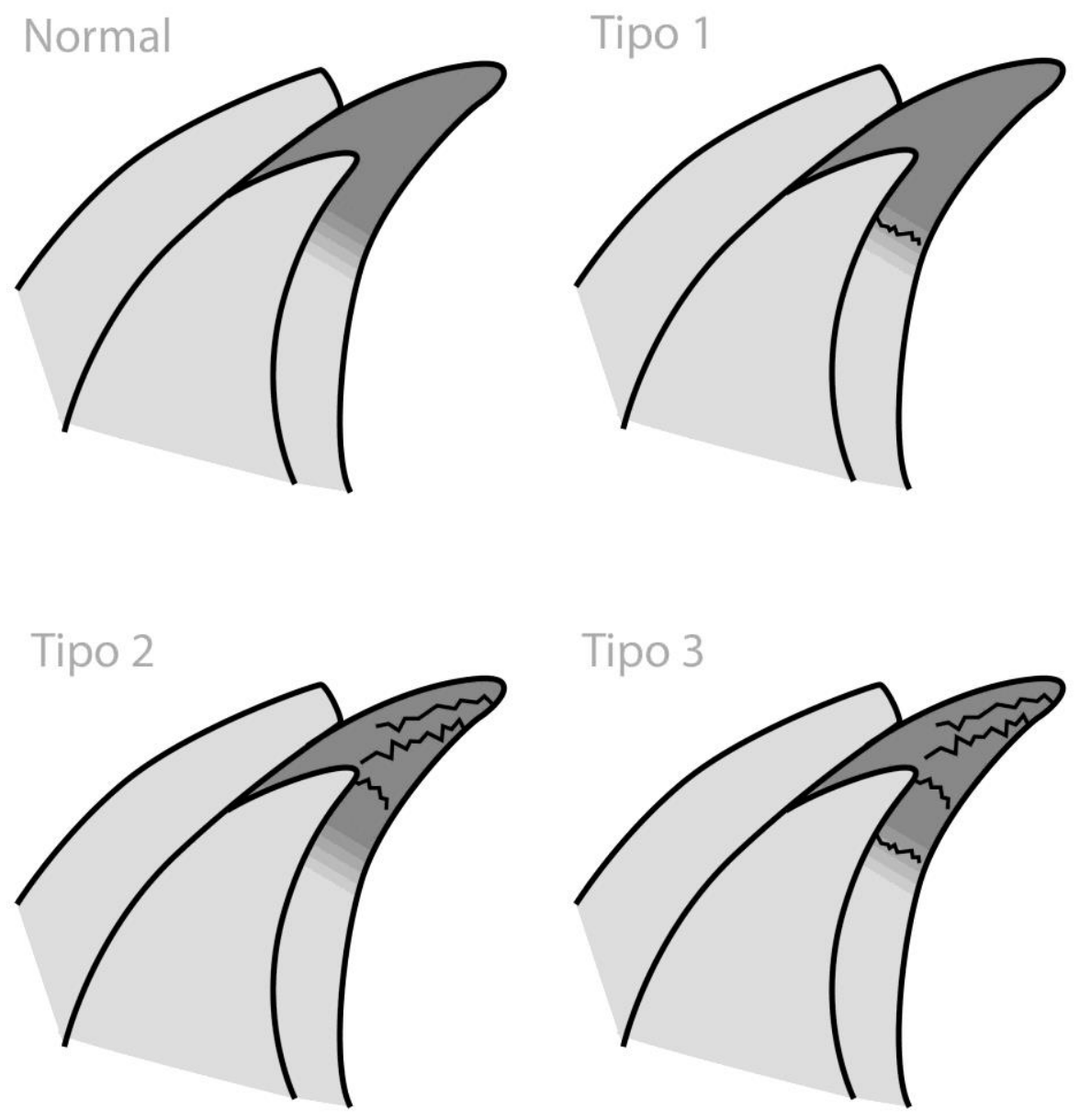

Figura 8. Classificação de $\operatorname{Seldes}^{39}$ modificada. O tipo 1 apresenta destacamento do lábio da cartilagem acetabular, o tipo 2 apresenta um ou mais planos de clivagem na substância labial, e o tipo 3 apresenta um padrão misto que apresenta destacamento do lábio e lesões intrasubstanciais. 


\subsection{Avaliação das imagens tomográficas}

Os arquivos em formato DICOM foram importados para o programa Osirix (Osirix Foundation, Genebra, Suíça), utilizado para processamento de imagens médicas. Por meio deste programa, é possível a reformatação das imagens em diversos planos e a mensuração de ângulos. As medidas tomográficas foram realizadas por médico radiologista, membro do IOTHCFMUSP, que desconhecia os resultados da avaliação histológica.

O ângulo alfa femoral foi medido por meio da técnica descrita por Nötzli et al. ${ }^{9}$ (Figura 9). Foi obtida uma reconstrução chamada axial oblíqua, por meio de cortes obliquos paralelos ao colo do fêmur passando pelo centro da cabeça femoral. A seguir, foi encontrado o centro da cabeça femoral e desenhado um círculo com o diâmetro aproximado da cabeça. Foi traçada uma linha passando pelo centro da cabeça femoral e o centro do colo femoral. Uma linha foi obtida entre o centro da cabeça femoral e o ponto onde o osso femoral excedeu o círculo desenhado previamente. $\mathrm{O}$ ângulo alfa foi determinado pelo ângulo entre essas duas linhas. 


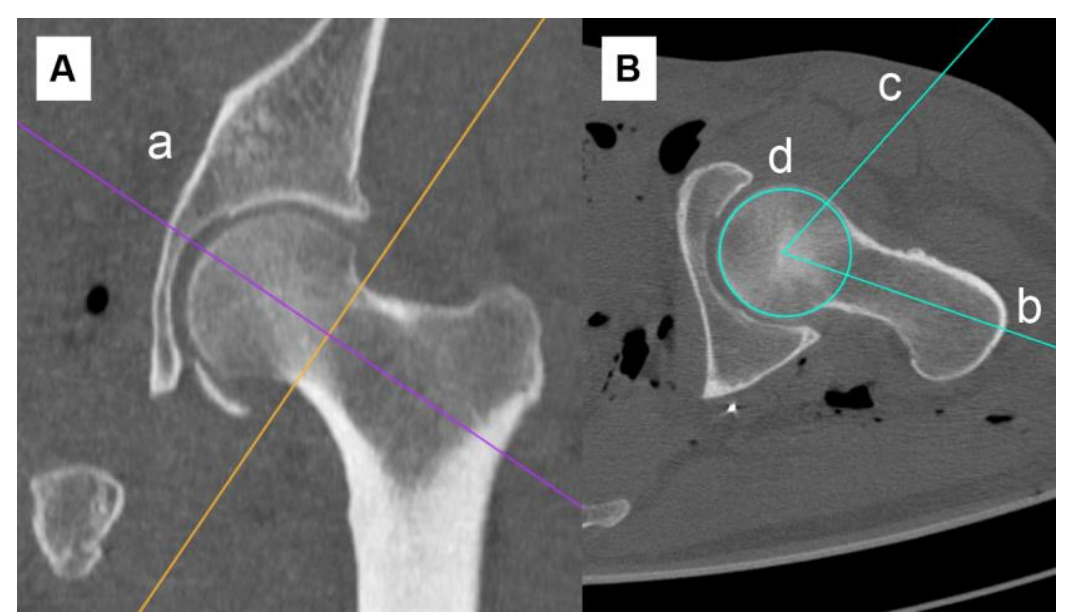

Figura 9. Medida do ângulo alfa femoral (caso 1, lado esquerdo). A: Determinação do plano axial oblíquo por meio da linha "a", que passa pelo centro do colo e cabeça femoral. B: Medida do ângulo alfa compreendido pelas linha "b" que passa pelo centro do colo e cabeça femoral, e "c" que passa pelo centro da cabeça femoral e o ponto onde a cabeça perde a esfericidade, determinada pelo círculo "d".

Foi determinado o ângulo de anteversão femoral segundo técnica descrita por Tomczak et al. ${ }^{81}$ Foi criada uma imagem sobreposta entre um corte tomográfico contendo o eixo do colo femoral e um corte tomográfico contendo o ponto mais posterior dos côndilos femorais. Nessa imagem sobreposta, o ângulo de anteversão femoral foi medido (Figura 10). Casos de anteversão femoral foram considerados como valores positivos e casos de retroversão femoral foram considerados como valores negativos. 


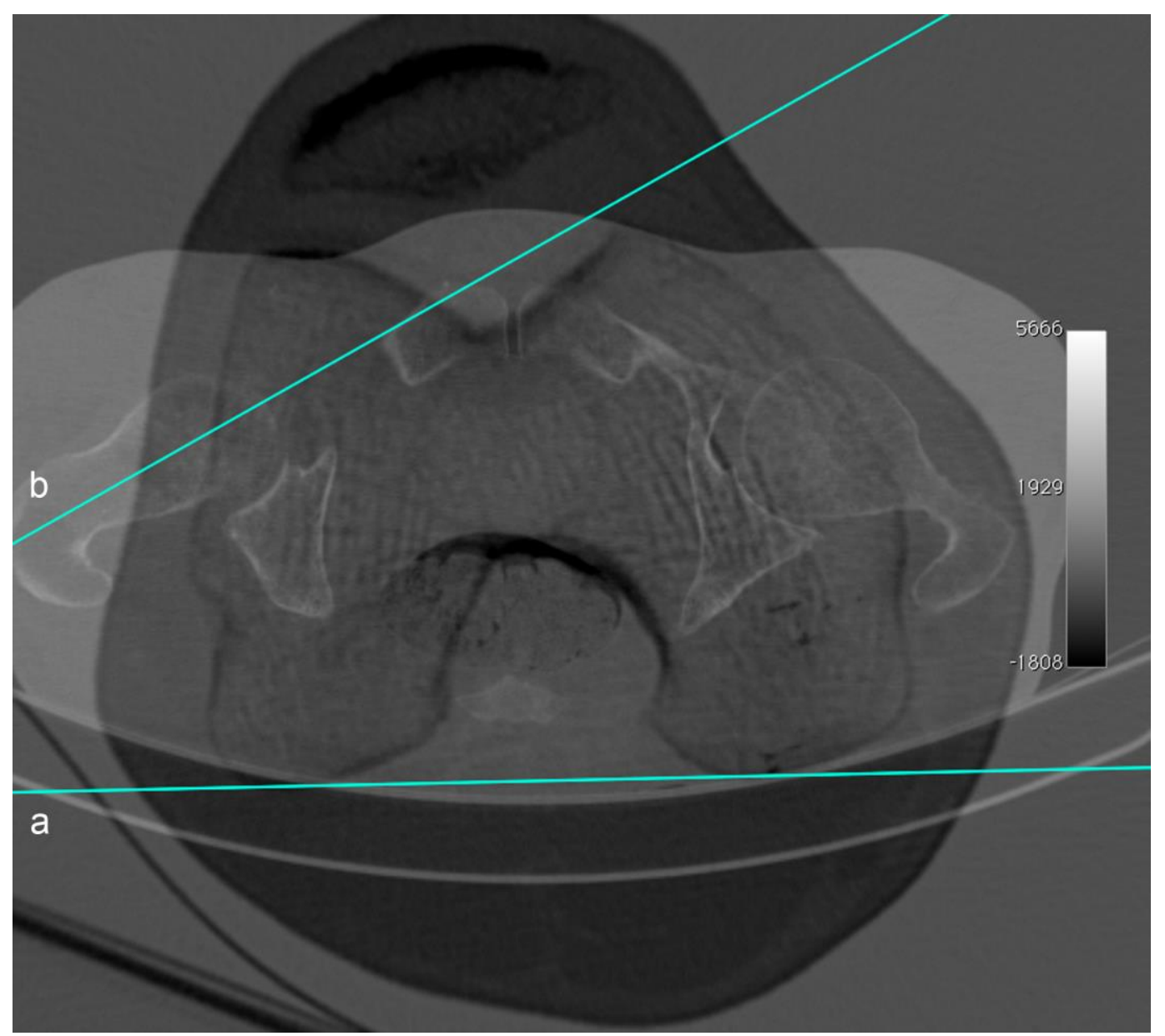

Figura 10. Medida do ângulo de versão femoral (caso 3, lado direito) por meio da sobreposição de duas imagens: centro do colo femoral e ponto mais posterior dos côndilos femorais. A versão femoral é medida entre as linhas "a", formada pelos pontos mais posteriores dos côndilos femorais, e a linha "b" formada pelo centro do colo femoral.

Previamente à medida dos ângulos referentes ao acetábulo, a bacia foi alinhada conforme o plano pélvico anterior (Figura 11) ${ }^{82,83} \mathrm{O}$ ângulo centro-borda foi medido conforme técnica descrita por Monazzam et al. ${ }^{55}$ Foi obtida uma reconstrução coronal correspondente ao centro do acetábulo no plano axial. O eixo horizontal foi determinado através de uma linha passando no centro das duas cabeças femorais. Uma segunda linha foi determinada como uma linha perpendicular ao eixo horizontal, passando pelo centro da 
cabeça femoral. Uma terceira linha foi encontrada passando pelo centro da cabeça femoral e a porção mais lateral da superfície articular do acetábulo. O ângulo centro-borda foi considerado como o ângulo entre estas duas últimas linhas (Figura 12). Os ângulos centro-borda encontrados foram classificados da seguinte maneira: normal entre $25^{\circ}$ e $40^{\circ}$, sobrecobertura acima de $40^{\circ}$, limítrofe entre $20^{\circ}$ e $25^{\circ}$ e displasia abaixo de $20^{\circ}$.

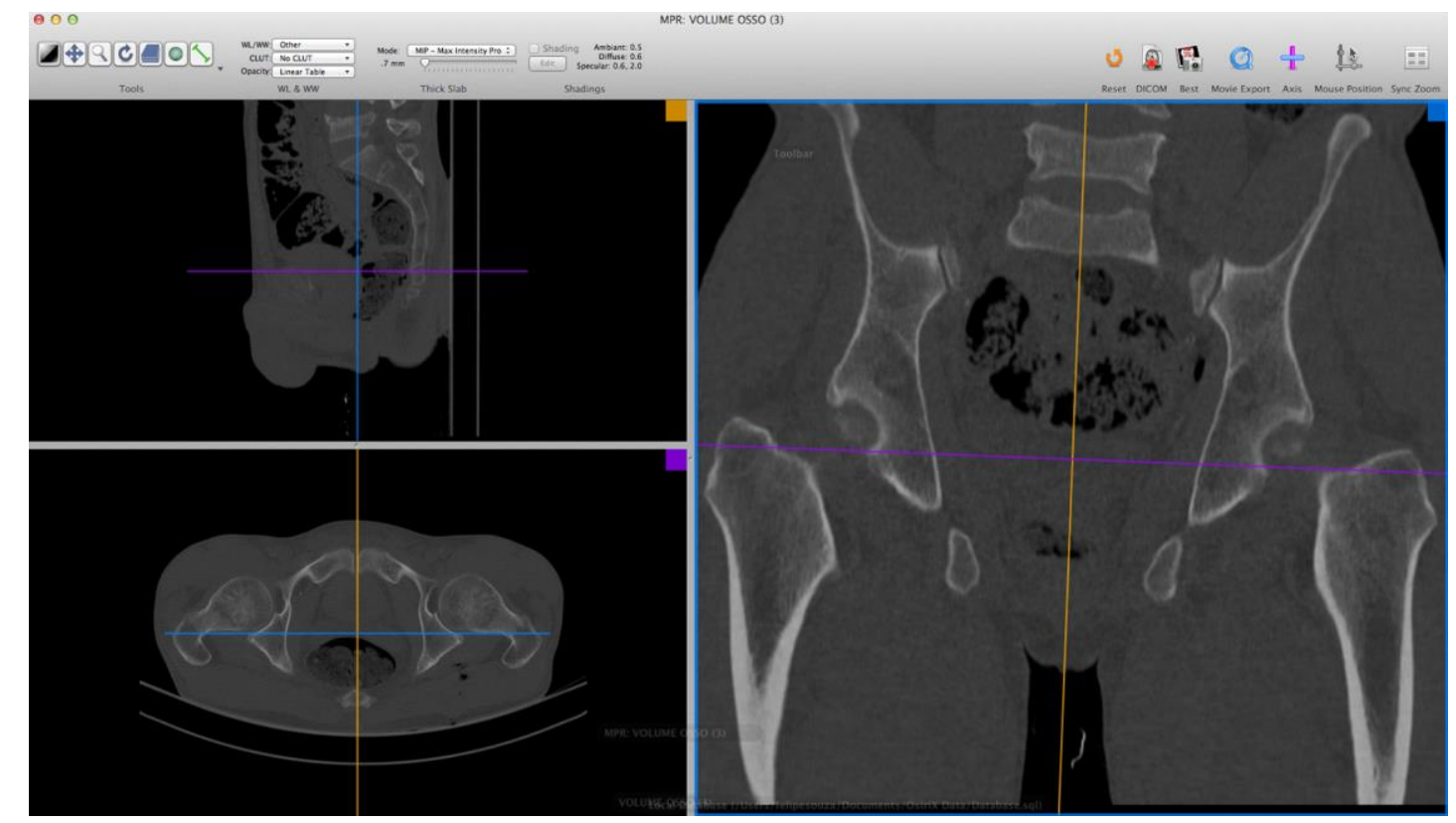

Figura 11. Alinhamento da bacia no plano pélvico anterior previamente a medida dos ângulos acetabulares (caso 3). 


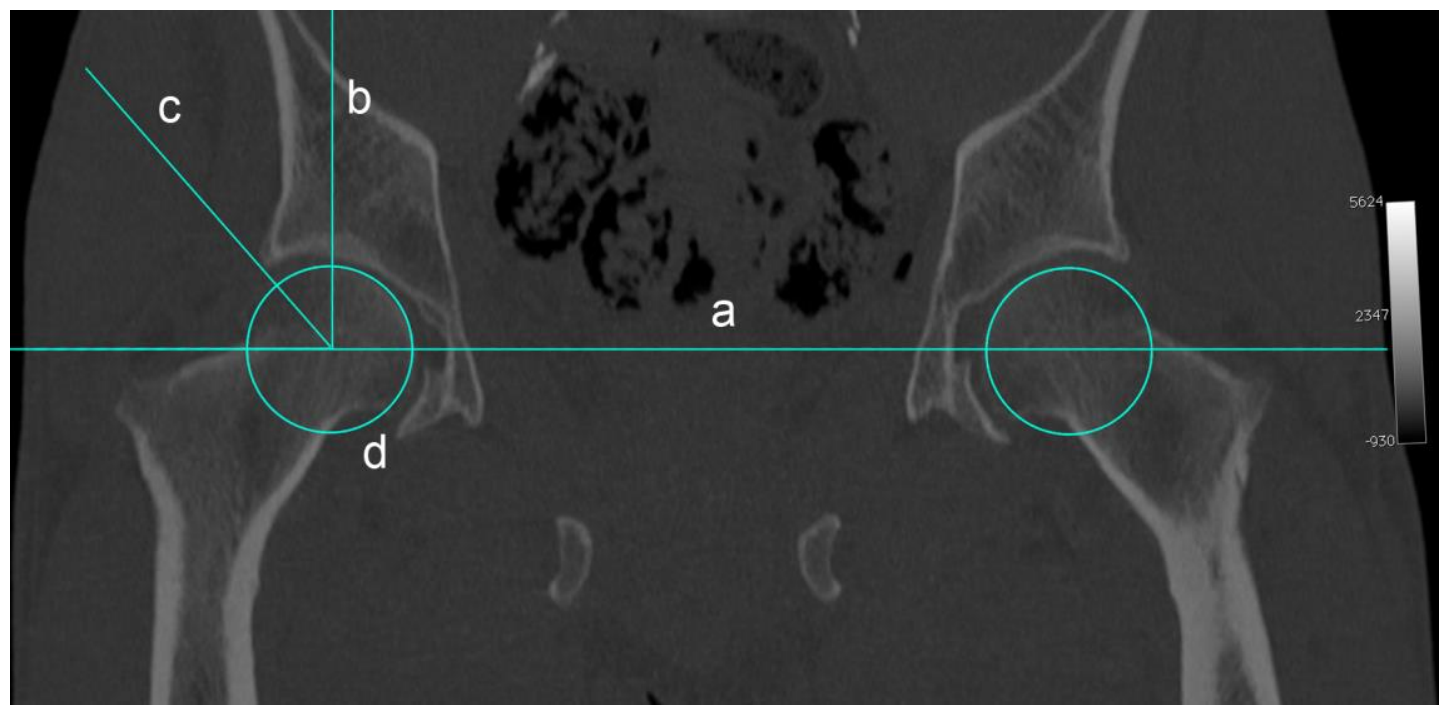

Figura 12. Medida do ângulo centro-borda acetabular (caso 3, lado direito). A linha "a" passa entre o centro das duas cabeças femorais e determina o plano horizontal, o círculo "d" determina o centro da cabeça femoral, a linha "b" é perpendicular à linha "a" e passa pelo centro da cabeça femoral, e a linha "c" passa pelo centro da cabeça femoral e o ponto mais lateral da borda acetabular. 0 ângulo centro-borda é determinado pelas linhas "b" e "c".

A versão acetabular foi determinada por meio de cortes axiais da bacia conforme técnica descrita por Dandachli et al. ${ }^{82} \mathrm{O}$ corte axial escolhido foi o segundo corte superior (cranial), onde ocorre abertura da cavidade acetabular. Uma linha foi determinada contendo a porção mais posterior dos dois acetábulos. A seguir, foi determinada uma linha contendo a borda anterior e posterior do acetábulo. O ângulo entre estas duas linhas foi considerado o ângulo de versão acetabular (Figura 13). Valores positivos foram considerados como anteversão e valores negativos foram considerados como retroversão. 


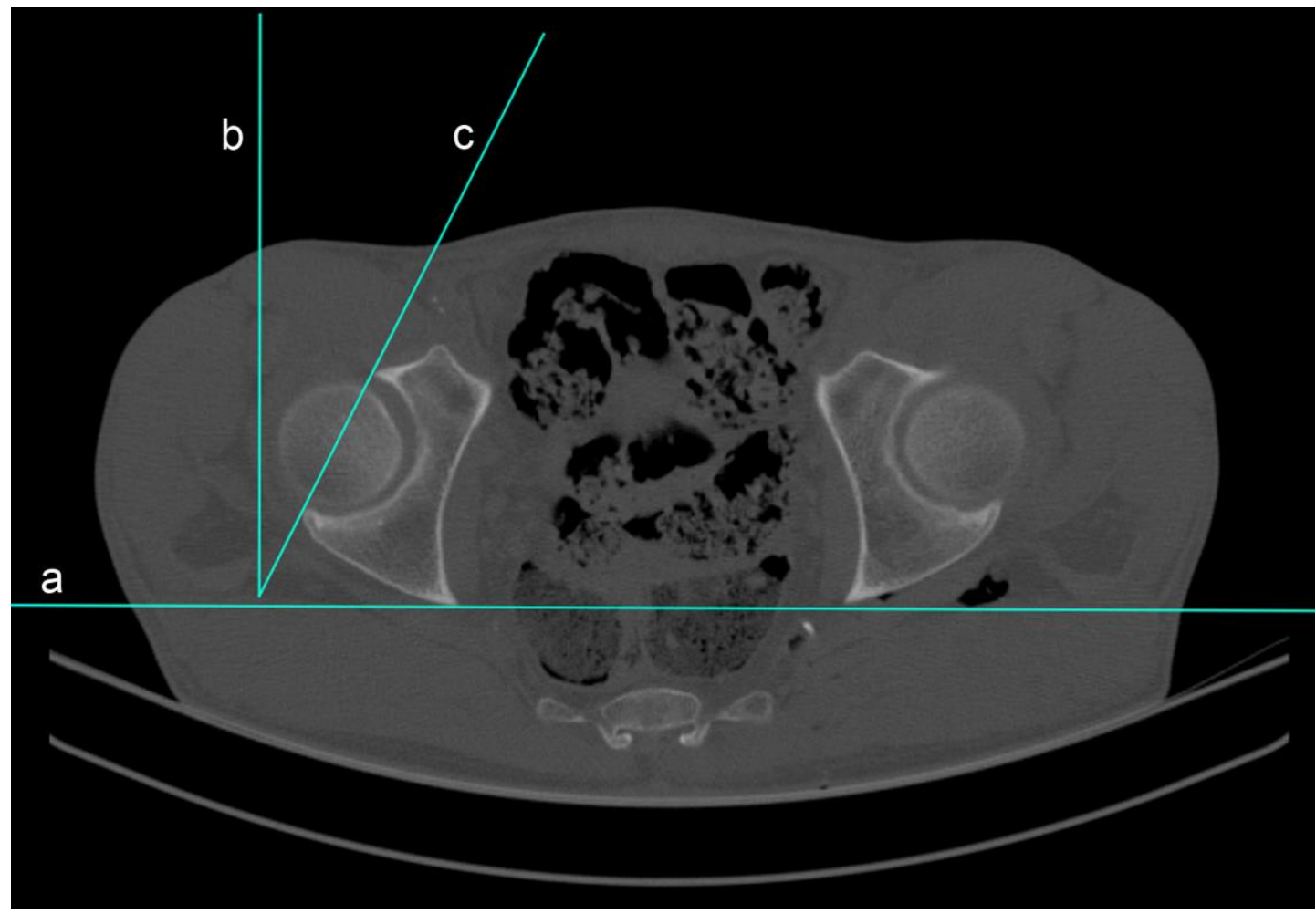

Figura 13. Medida da versão acetabular (caso 3, lado direito). A linha "a" passa pelos pontos mais posteriores dos dois acetábulos, a linha "c" passa pela parede anterior e posterior do acetábulo, e a linha "b" é perpendicular à linha "a" no ponto onde as linhas "a" e "c" cruzamse. A versão acetabular é determinada pelas linhas "b" e "c".

O ângulo de Tönnis foi determinado conforme técnica descrita por Monazzam et al. ${ }^{83}$ Foi utilizado o mesmo corte coronal adotado para medida do ângulo centro-borda. Uma linha entre a porção medial da área de carga acetabular (zona esclerótica) e a porção lateral do acetábulo foi estabelecida. O ângulo entre esta linha e a linha horizontal foi considerado o ângulo de Tönnis (Figura 14). 


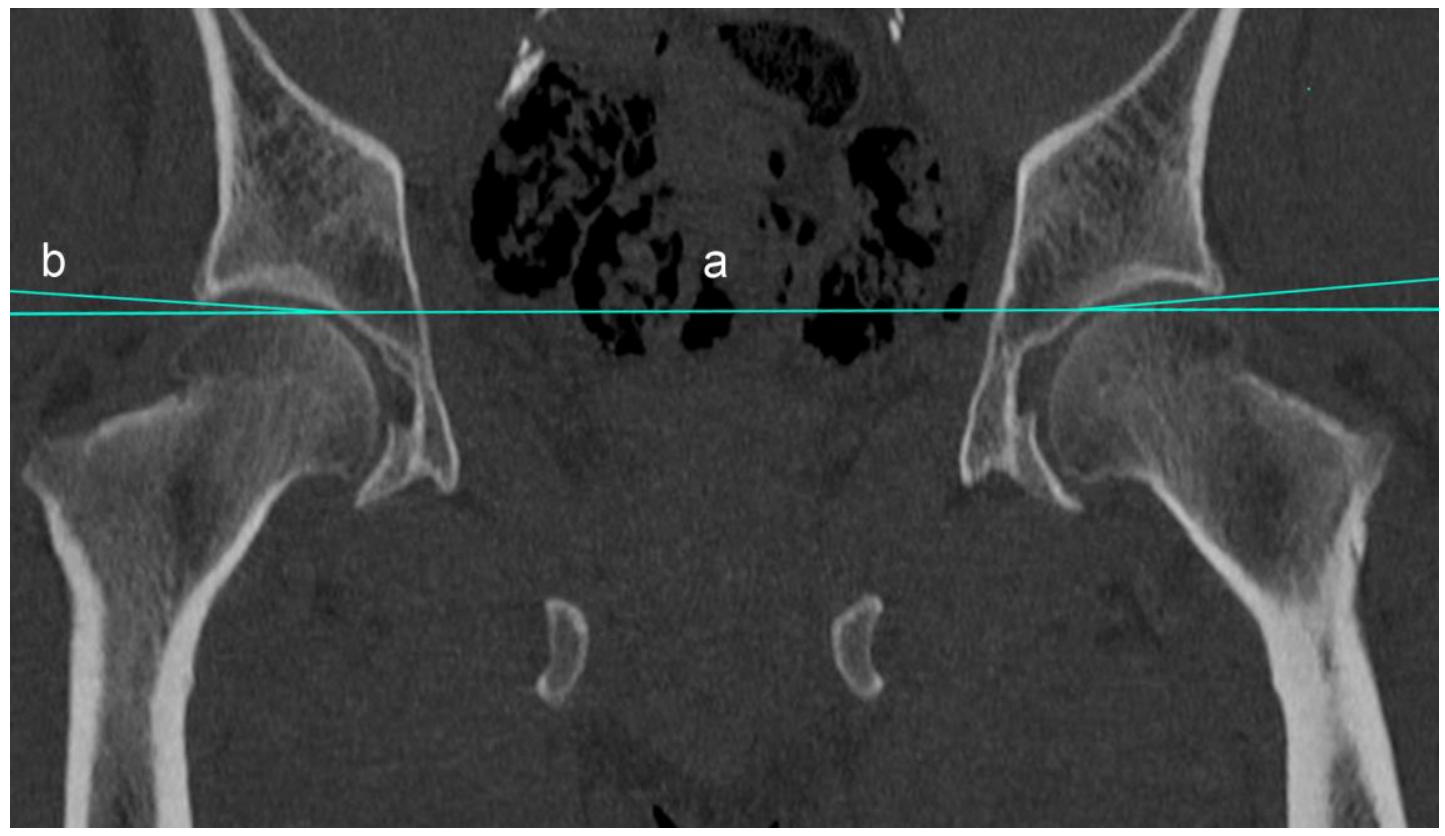

Figura 14. Medida do ângulo de Tönnis (caso 3, lado direito). A linha "a" determina o plano horizontal (paralela à linha que liga as duas cabeças femorais) passando pelo ponto mais medial da zona de carga acetabular, e a linha "b" liga os pontos mais medial e mais lateral da zona de carga acetabular. O ângulo de Tönnis é determinado pelas linhas "a" e "b".

Os casos foram considerados como portadores de IFA tipo came quando apresentaram ângulo alfa maior ou igual a 50,0 ${ }^{84,85}$ Foram considerados portadores de IFA tipo pincer quando apresentaram: ${ }^{83}$ versão acetabular menor ou igual a $0^{\circ}$ associada a ângulo centro-borda $\geq 30^{\circ},{ }^{86}$ ou ângulo centro-borda maior ou igual a $40,0^{\circ}, 87$ ou ângulo de Tönnis menor ou igual a $0^{\circ} .^{88}$ Casos portadores de deformidade came e pincer foram considerados mistos. 


\subsection{Análise estatística}

Os dados quantitativos foram apresentados como média, desvio padrão, mediana, valores mínimo e máximo. As medidas qualitativas foram apresentadas como frequências absolutas e relativas (porcentagens). A normalidade dos dados quantitativos foi avaliada pelo teste de Kolmogorov-Smirnov.

Na comparação dos desfechos quantitativos, utilizou-se o teste $t$ de Student, quando a distribuição foi paramétrica, ou o teste $U$ de MannWhitney, quando a distribuição foi não paramétrica.

$\mathrm{Na}$ comparação dos dados qualitativos, utilizou-se o teste chiquadrado, quando havia cinco ou mais observações esperadas em cada grupo de comparação, ou o teste exato de Fisher, quando havia menos de cinco observações esperadas em cada grupo.

O teste de correlação de Pearson foi utilizado para avaliação da correlação entre os ângulos tomográficos (centro-borda, versão acetabular e Tönnis).

O nível de significância de 5\% foi utilizado em todas as comparações, sendo os valores de $p<0,05$ considerados estatisticamente significantes. Todos os testes utilizados foram bicaudais. Quando o valor de $p$ foi $0,01 \leq p$ $\leq 0,10$; o valor exato de $p$ foi descrito. Valores fora desta faixa foram descritos como $p<0,05$ ou $p>0,05$.

A análise estatística foi realizada com o software Statistical Package for Social Sciences version 22.0 for Mac (SPSS Inc., Chicago, IL, Estados Unidos). 
4. RESULTADOS 


\subsection{Caracterização da amostra}

Vinte e um cadáveres foram estudados. Um cadáver foi excluído do estudo, pois, durante a dissecção, ocorreu uma fratura do acetábulo com lesão subsequente do lábio. Os dados demográficos dos 20 indivíduos incluídos estão descritos na Tabela 1 e no Anexo C.

Tabela 1. Dados demográficos dos cadáveres incluídos

\begin{tabular}{lccccc}
\hline & Média & Desvio-padrão & Mediana & Mínimo & Máximo \\
\hline \hline Idade (anos) & 50,2 & 7,4 & 53,0 & 34,0 & 58,0 \\
Altura (cm) & 167,7 & 9,8 & 167,5 & 150,0 & 187,0 \\
Peso (kg) & 63,6 & 10,6 & 66,6 & 37,2 & 77,0 \\
IMC $\left(\mathrm{kg} / \mathrm{m}^{2}\right)$ & 22,7 & 4,1 & 21,6 & 15,9 & 29,6 \\
\hline \hline IMC = índice de massa corpórea & & & & \\
\hline
\end{tabular}

Incluiram-se 14 (70,0\%) casos masculinos e 6 (30,0\%) casos femininos. Dividindo os cadáveres quanto ao gênero, não houve diferença estatística entre os grupos quanto à idade $(p>0,05)$, altura $(p=0,08)$, peso $(p>0,05)$, e IMC $(p>0,05)$. Com relação à lateralidade, foram estudados em $10(50,0 \%)$ casos o lado direito, e em $10(50,0 \%)$ casos o lado esquerdo. 


\section{2. Ângulos tomográficos}

Os resultados da análise dos ângulos tomográficos são apresentados na Tabela 2 e no Anexo D.

Tabela 2. Ângulos tomográficos

\begin{tabular}{lccccc}
\hline & Média & Desvio-padrão & Mediana & Mínimo & Máximo \\
\hline \hline Alfa $\left(^{\circ}\right)$ & 52,5 & 3,1 & 52,6 & 45,9 & 58,3 \\
Centro-borda $\left(^{\circ}\right)$ & 35,7 & 7,9 & 36,0 & 22,6 & 51,2 \\
Versão acetabular $\left(^{\circ}\right)$ & 14,1 & 5,6 & 14,7 & 3,7 & 23,2 \\
Tönnis $\left(^{\circ}\right)$ & 6,1 & 3,6 & 6,2 & 0 & 15,0 \\
Versão femoral $\left(^{\circ}\right)$ & 12,1 & 9,9 & 12,9 & $-8,0$ & 30,0 \\
\hline \hline
\end{tabular}

Ao se analisar se houve diferença na medida dos ângulos tomográficos entre os gêneros, foi encontrado que apenas o ângulo centroborda apresentou diferença significativa (Tabela 3, Figura 15). 
Tabela 3. Diferença entre gêneros em relação aos ângulos tomográficos

\begin{tabular}{lccc}
\hline & Masculino & Feminino & p \\
\hline \hline Alfa $\left(^{\circ}\right)$ & 52,6 & 52,2 & $p>0,05$ \\
Centro-borda $\left(^{\circ}\right)$ & 33,1 & 41,7 & $p=0,02$ \\
Versão acetabular $\left(^{\circ}\right)$ & 14,4 & 13,4 & $p>0,05$ \\
Tönnis $\left(^{\circ}\right)$ & 6,5 & 5,4 & $p>0,05$ \\
Versão femoral $\left(^{\circ}\right)$ & 11,7 & 12,8 & $p>0,05$ \\
\hline \hline
\end{tabular}

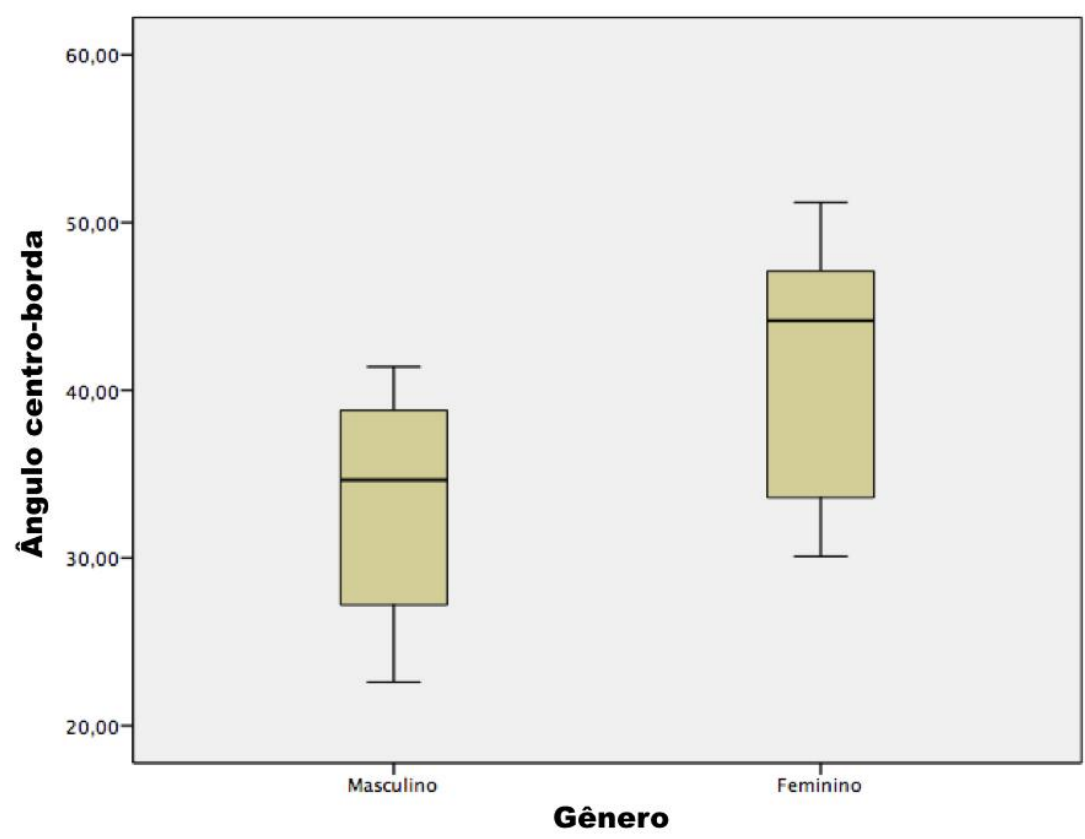

Figura 15. Ângulo centro-borda estratificado por gênero. 
Ao serem classificados os cadáveres segundo os ângulos tomográficos, foram encontrados um $(5,0 \%)$ cadáver portador de ângulo centro-borda de $22,6^{\circ}$, considerado limítrofe para displasia, e seis $(30,0 \%)$ com ângulo centro-borda maior que $40^{\circ}$ considerado sobrecobertura. Nenhum caso apresentou versão acetabular negativa. Dois $(10,0 \%)$ casos apresentaram ângulo de Tönnis de $0^{\circ}$, e dois (10,0\%) apresentaram ângulo maior que $10^{\circ}$. Três (15,0\%) cadáveres apresentaram retroversão femoral.

Ao se classificarem os quadris quanto ao tipo de IFA, foi encontrado que $16(80,0 \%)$ cadáveres foram considerados came positivos. Não encontramos diferença entre os gêneros (homens: 85,7\% versus mulheres: $66,7 \%, p>0,05)$. Oito (40\%) espécimes foram considerados pincer positivos. Mulheres apresentaram IFA tipo pincer mais frequentemente que homens (homens: $21,4 \%$ versus mulheres: $83,3 \%, p=0.02)$. Seis $(30,0 \%)$ cadáveres apresentaram alteração tipo came e pincer, sendo considerados portadores de IFA tipo misto. Desses 6 casos com IFA misto, 3 eram homens e 3 eram mulheres $(p>0,05)$. Desta forma, $4(20,0 \%)$ cadáveres não apresentaram alterações de IFA, 10 (50,0\%) foram considerados came, 2 (10,0\%) foram considerados pincer e $6(30,0 \%)$ foram considerados mistos.

Ao se analisar se havia relação entre os seguintes ângulos tomográficos, nenhuma relação foi significativa: versão acetabular e ângulo de Tönnis $(p=0,06)$, versão acetabular e ângulo centro-borda $(p>0,05)$ e ângulo de Tönnis e ângulo centro-borda $(p=0,08)$. 


\subsection{Histologia}

$\mathrm{Na}$ avaliação macroscópica, $10(50,0 \%)$ casos apresentaram lesão labial (Figura 16). Três (15\%) acetábulos apresentaram sulco sublabial posterior (Figura 17, Anexo E). Três (15\%) cadáveres apresentaram lesão condral acetabular com osso subcondral exposto (Figura 18). Estes três acetábulos apresentaram lesão labial macroscópica associada à lesão condral. Não houve diferença quanto à presença de lesão labial macroscópica entre os gêneros ( $p>0,05)$.

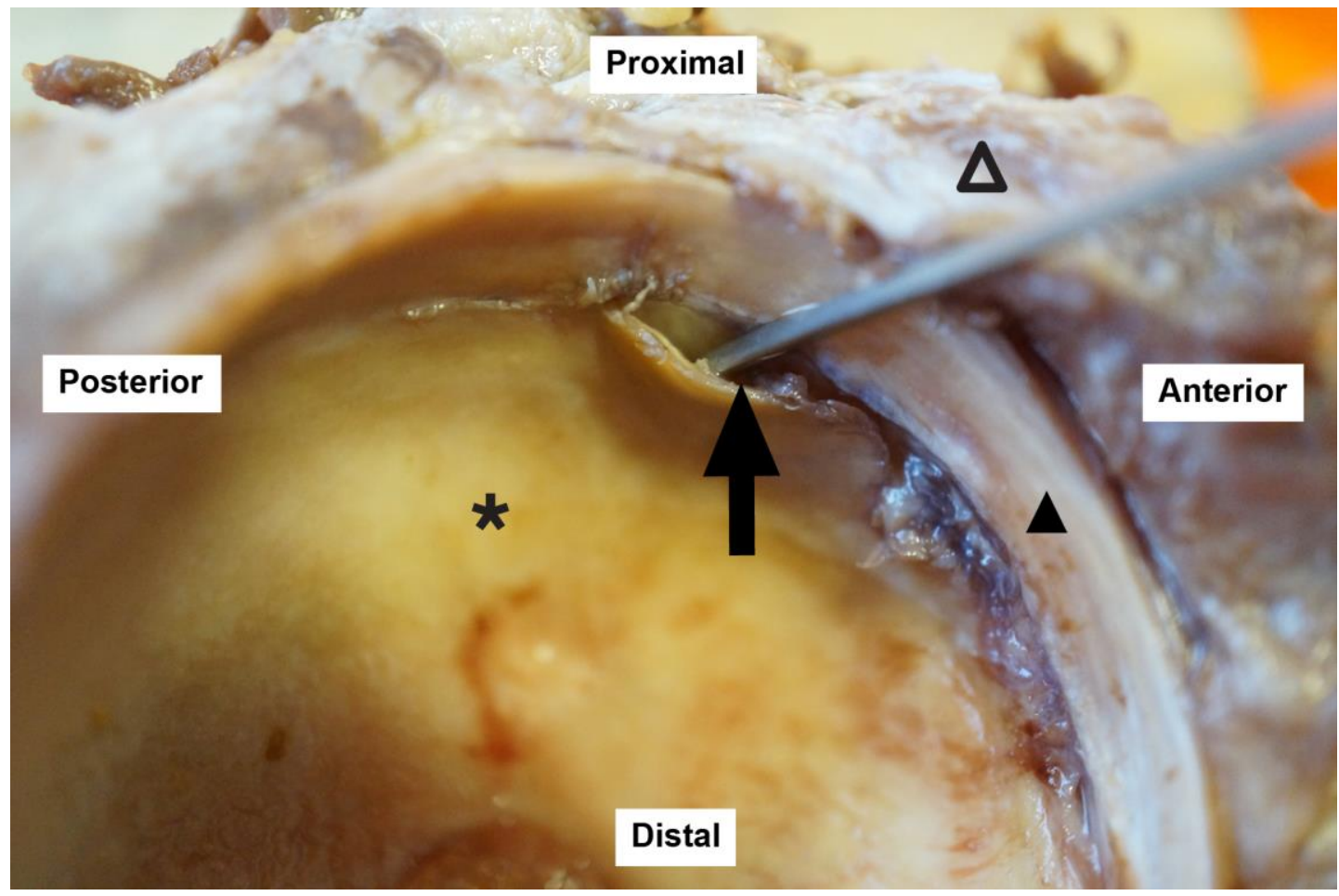

Figura 16. Lesão labial macroscópica (caso 3, lado direito). Triângulo preto: lábio acetabular; triângulo vazio: cápsula articular; asterisco preto: cartilagem acetabular; seta: probe colocado na lesão labial associada a lesão em carpete da cartilagem. 


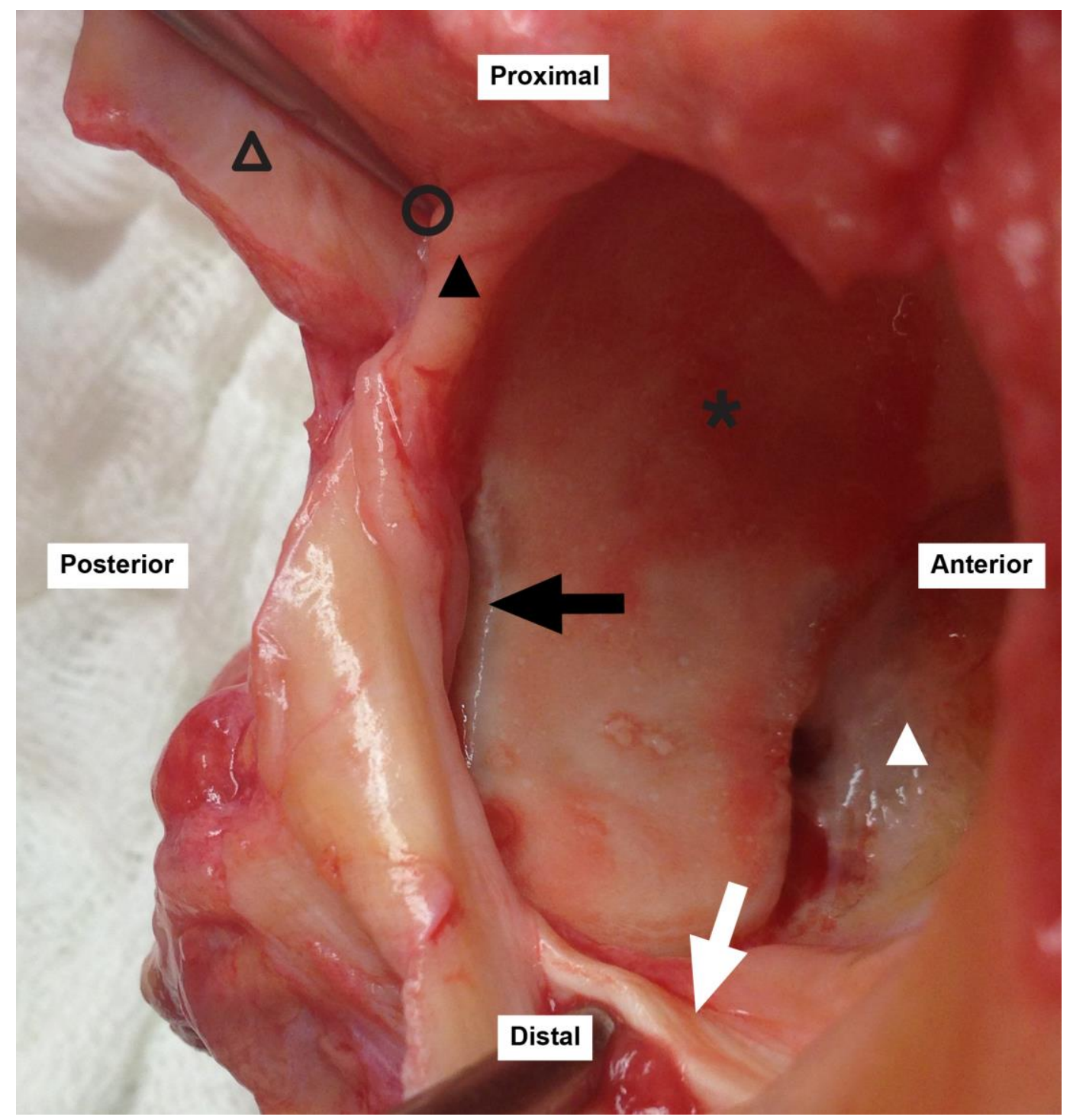

Figura 17. Sulco sublabial posterior (caso 9, lado direito). Triângulo preto: lábio póstero-superior, triângulo vazio: cápsula articular; círculo: pinça cirúrgica entre o lábio e cápsula articular; asterisco: cartilagem acetabular; triângulo branco: pulvinar; seta preta: sulco sublabial posterior; seta branca: ligamento transverso. 


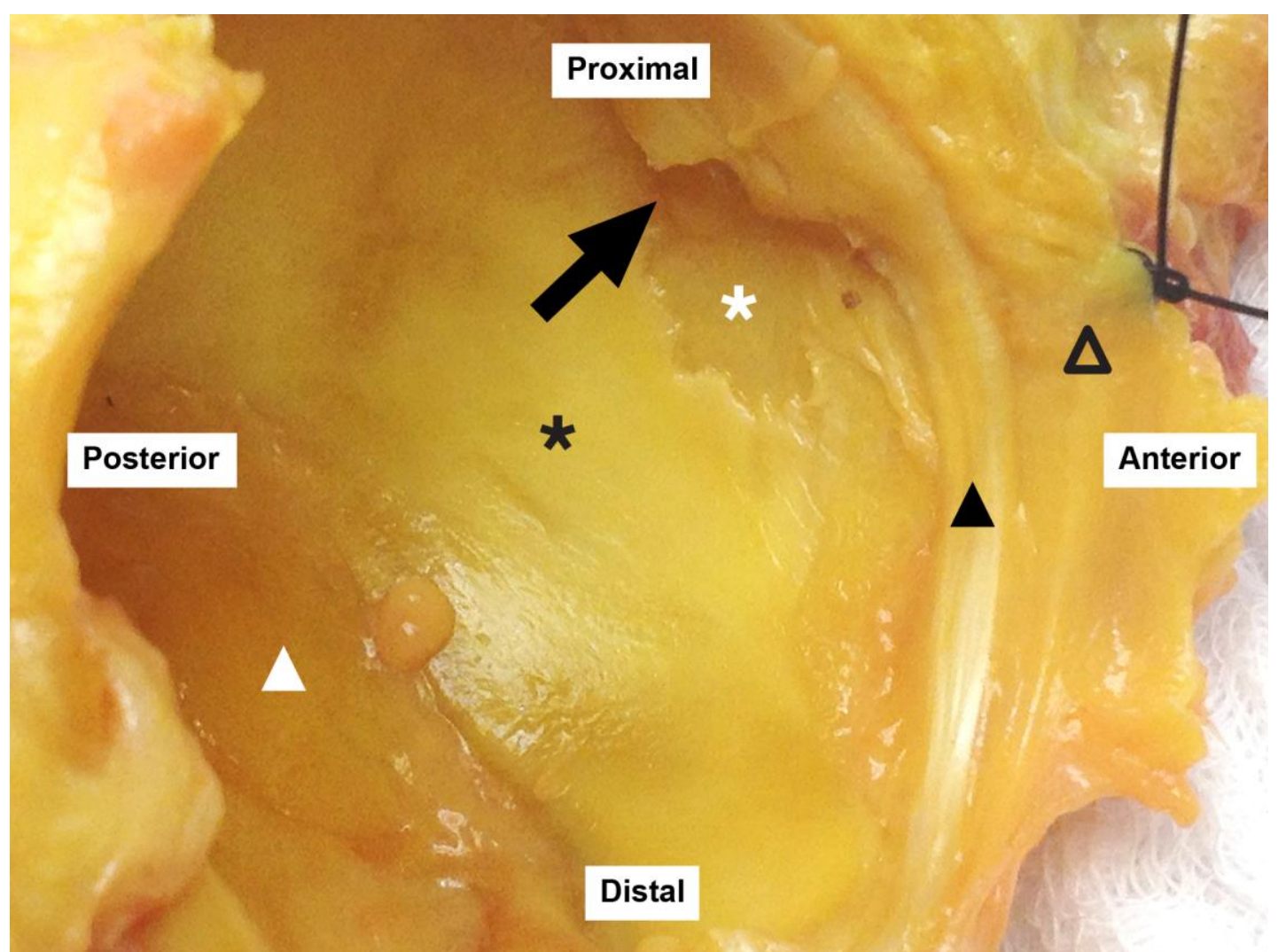

Figura 18. Lesão condral macroscópica (caso 17, lado direito). Triângulo preto: lábio acetabular anterior; triângulo vazio: cápsula articular; triângulo branco: pulvinar; asterisco preto: cartilagem acetabular; asterisco branco: osso acetabular exposto por lesão condral; seta preta: lesão labial.

Na análise microscópica, $16(80,0 \%)$ dos cadáveres apresentaram lesão labial em pelo menos uma localização acetabular (Figuras 19 a 23). Não houve diferença significativa de idade entre os grupos com e sem lesão labial microscópica em qualquer posição (sem lesão: $54 \pm 2,4$ anos versus com lesão: $49 \pm 7,9$ anos, $p>0,05)$. Não houve diferença entre os sexos quanto à presença de lesão labial microscópica $(p>0,05)$. Das 60 lâminas analisadas, $28(46,7 \%)$ apresentaram lesões labiais. Quando dividido por região acetabular; $13(65,0 \%)$ lábios anteriores apresentaram lesão; 10 (50,0\%) lábios superiores apresentaram lesão, e 5 (25,0\%) dos lábios 
posteriores apresentaram lesão. Houve diferença estatistica entre a incidência de lesões por localização ( $p=0,04)$.

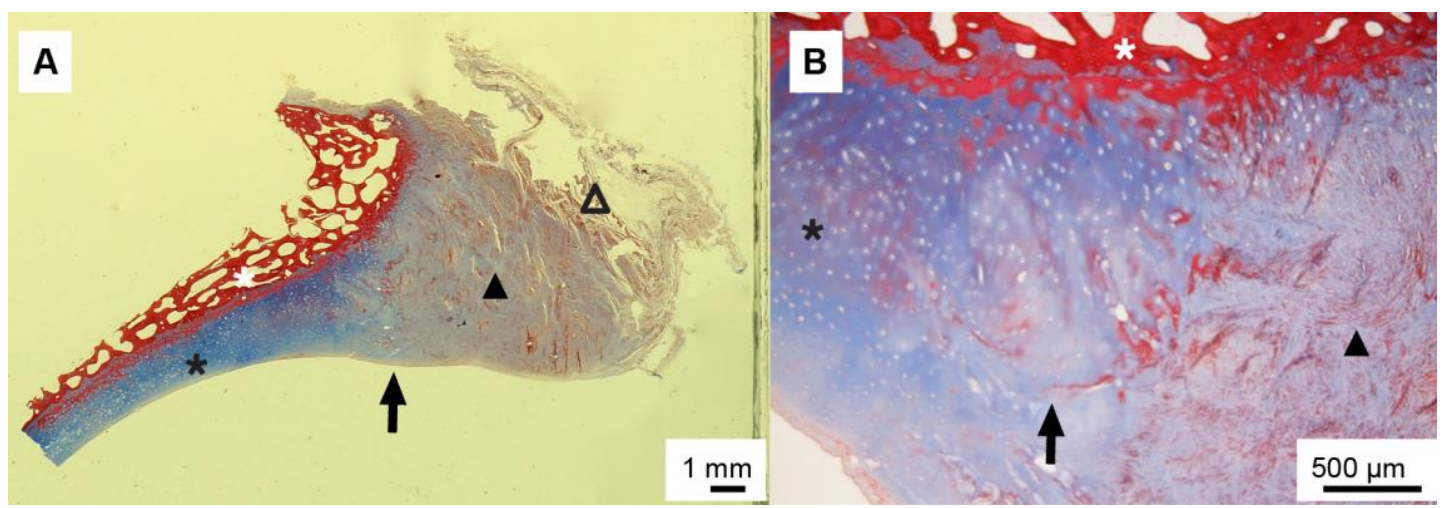

Figura 19. Lábio acetabular sem lesão (caso 1, lábio superior), coloração por tricrômico de Masson. A: objetiva com aumento original de uma vez demonstra transição entre lábio e cartilagem íntegra. B: objetiva com aumento original de quatro vezes demonstra zona de transição entre cartilagem e lábio acetabular, com características mistas de cartilagem hialina e tecido conjuntivo fibro-elástico. Triângulo preto: lábio acetabular; triângulo vazio: cápsula articular, asterisco preto: cartilagem acetabular; asterisco branco: osso acetabular; seta: indica zona de transição entre cartilagem e lábio.
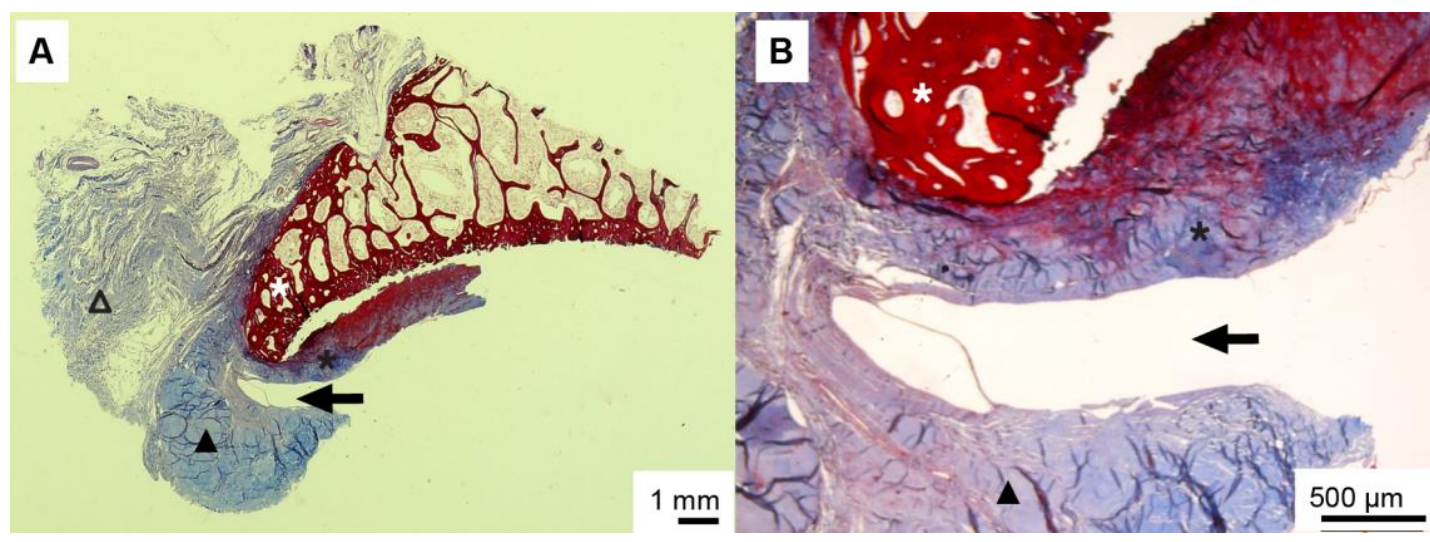

Figura 20. Lábio acetabular com lesão Seldes tipo 1 (caso 4, lábio anterior), coloração por tricrômico de Masson. A: objetiva com aumento original de uma vez, B: objetiva com aumento original de quatro vezes. Triângulo preto: lábio acetabular; triângulo vazio: cápsula articular; asterisco preto: cartilagem acetabular destacada do osso subcondral; asterisco branco: osso acetabular; seta preta: separação entre o lábio e a cartilagem acetabular. 


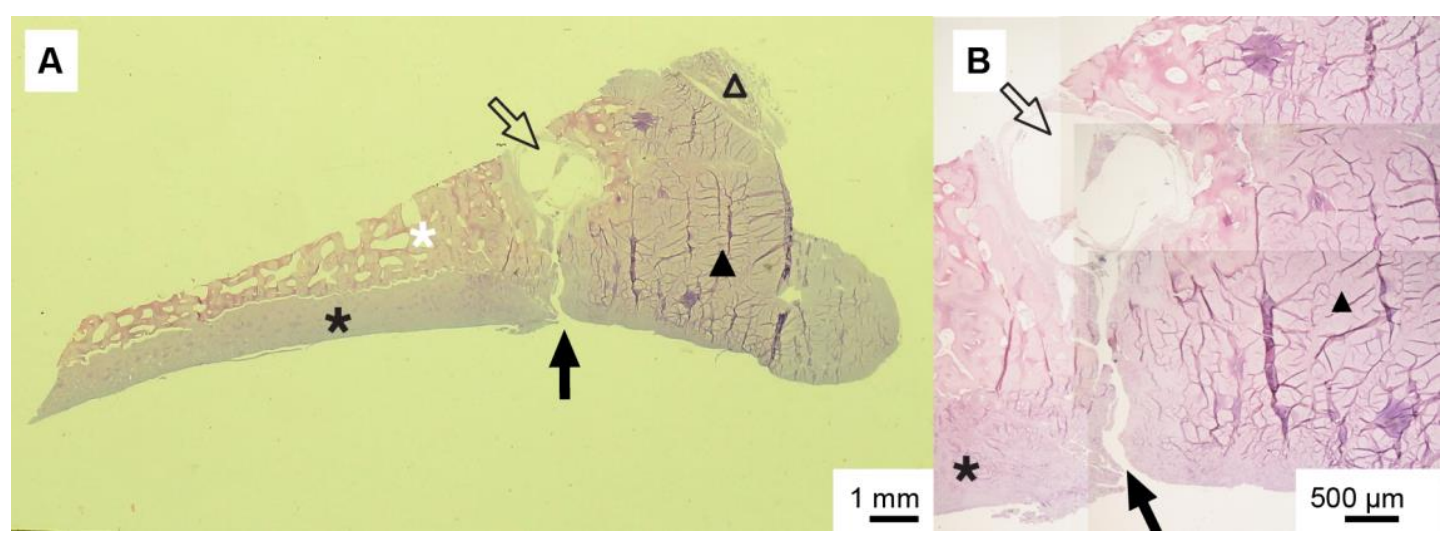

Figura 21. Lábio acetabular com lesão Seldes tipo 1 (caso 13, lábio posterior) associado a formação de cisto ósseo, coloração por hematoxilina e eosina. A: objetiva com aumento original de uma vez; B: objetiva com aumento original de quatro vezes. Triângulo preto: lábio acetabular; triângulo vazio: cápsula articular; asterisco preto: cartilagem acetabular; asterisco branco: osso acetabular; seta preta: separação entre o lábio e a cartilagem acetabular; seta vazia: cisto ósseo.

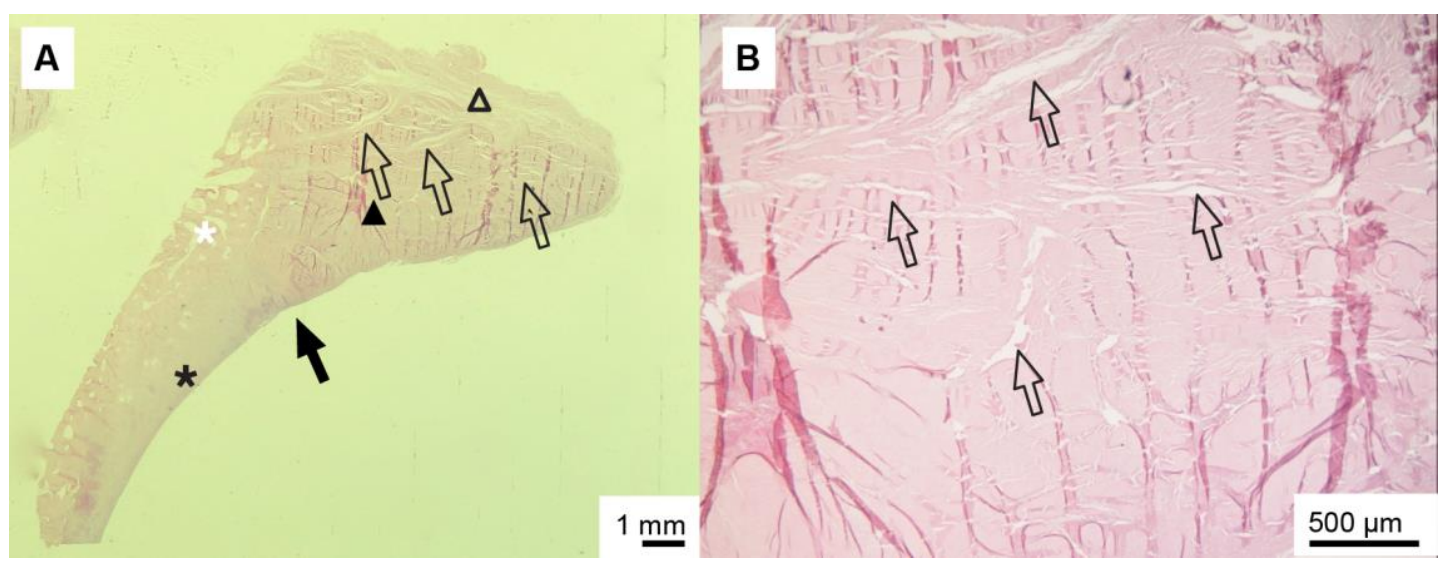

Figura 22. Lábio acetabular com lesão Seldes tipo 2 (caso 11, lábio superior), coloração por hematoxilina e eosina. A: objetiva com aumento original de uma vez, B: objetiva com aumento original de quatro vezes. Triângulo preto: lábio acetabular; triângulo vazio: cápsula articular; asterisco preto: cartilagem acetabular; asterisco branco: osso acetabular; seta preta: transição íntegra entre o lábio e a cartilagem acetabular; setas vazias: planos de clivagem na substância do lábio. 
A

B

$\Delta$

$\Delta$

$1 \underline{\mathrm{mm}}$

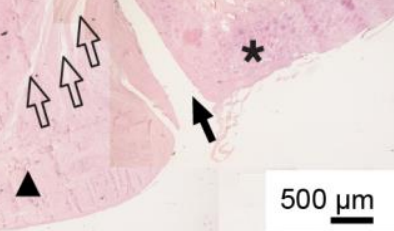

Figura 23. Lábio acetabular com lesão Seldes tipo 3 (caso 6, lábio anterior), coloração por hematoxilina e eosina. A: objetiva com aumento original de uma vez, B: objetiva com aumento original de quatro vezes. Triângulo preto: lábio acetabular; triângulo vazio: cápsula articular; asterisco preto: cartilagem acetabular; asterisco branco: osso acetabular; seta preta: separação entre o lábio e a cartilagem acetabular; setas vazias: planos de clivagem na substância do lábio.

Segundo a classificação de Seldes, 17 (60,7\%) lesões labiais foram consideradas tipo $1,8(28,6 \%)$ foram consideradas tipo 2 e $3(10,7 \%)$ foram consideradas tipo 3 (Tabela 4). Ao se analisar o lábio posterior, dos 3 casos onde um sulco sublabial posterior foi visualizado, em apenas 1 (33,3\%) lesão labial (Seldes 1) foi observada (Figura 24). 
Tabela 4. Lesão labial segundo classificação de Seldes

\begin{tabular}{cccc}
\hline Seldes & Anterior & Superior & Posterior \\
\hline 1 & $9(45,0 \%)$ & $4(20,0 \%)$ & $4(20,0 \%)$ \\
2 & $2(10,0 \%)$ & $5(25,0 \%)$ & $1(5,0 \%)$ \\
3 & $2(10,0 \%)$ & $1(5,0 \%)$ & 0 \\
Total & $13(65,0 \%)$ & $10(50,0 \%)$ & $5(25,0 \%)$ \\
\hline \hline
\end{tabular}

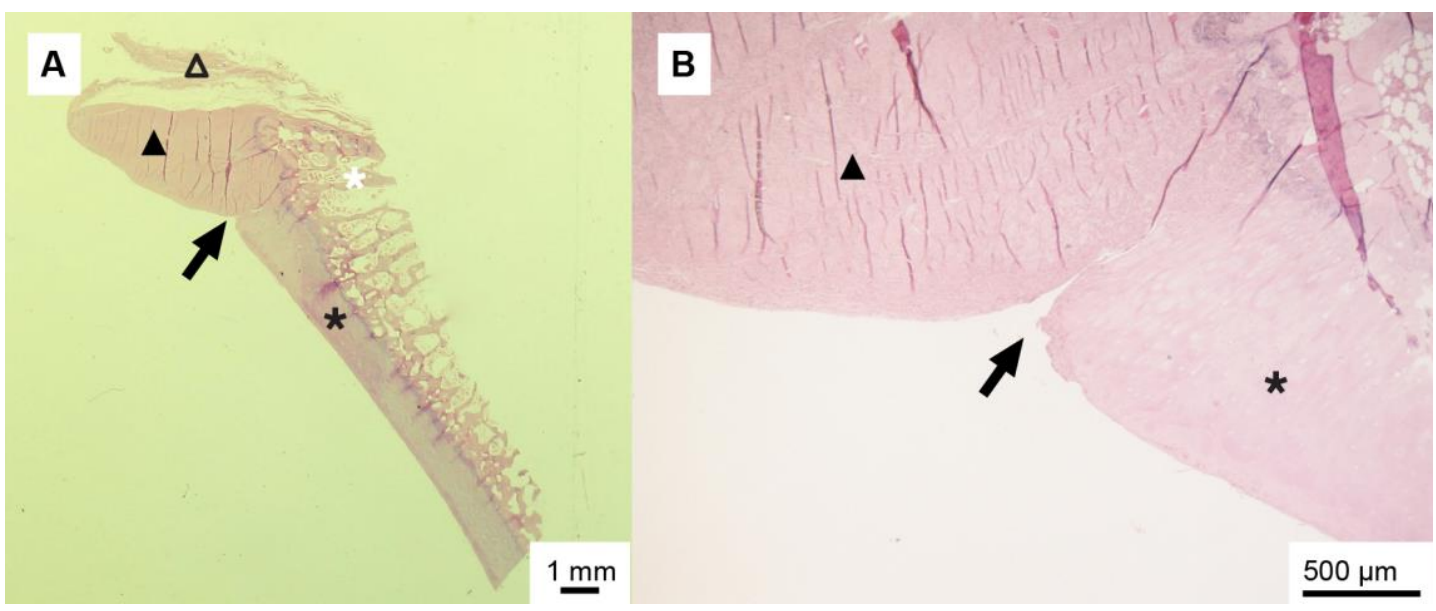

Figura 24. Sulco sublabial posterior (caso 10, lábio posterior), coloração por hematoxilina e eosina. A: objetiva com aumento original de uma vez, B: objetiva com aumento original de quatro vezes. Triângulo preto: lábio acetabular; triângulo vazio: cápsula articular; asterisco preto: cartilagem acetabular; asterisco branco: osso acetabular; seta preta: sulco entre a cartilagem e lábio acetabular. 
Não houve associação entre a lesão macroscópica e a microscópica. Dos 10 casos que não apresentaram lesão macroscópica, 8 (80,0\%) apresentaram lesão microscópica; enquanto dos 10 casos que apresentaram lesão macroscópica, $2(20,0 \%)$ não tinham lesão microscópica ( $p>0,05)$.

\subsection{Relação entre achados tomográficos e histológicos}

Não foi encontrada associação significativa entre a presença de lesão labial macroscópica e o ângulo alfa $(p>0,05)$. Ao se analisar a presença de lesão labial, avaliada microscopicamente, em relação ao ângulo alfa, foi encontrado que cadáveres com lesão labial apresentaram ângulo alfa maior (com lesão: $53,3^{\circ}$ versus sem lesão: $49,3^{\circ}, p=0,01$ ) (Figura 25). Indivíduos

que apresentaram lesão tipo came possuíram maior prevalência de lesão labial $(p=0,01)$. 


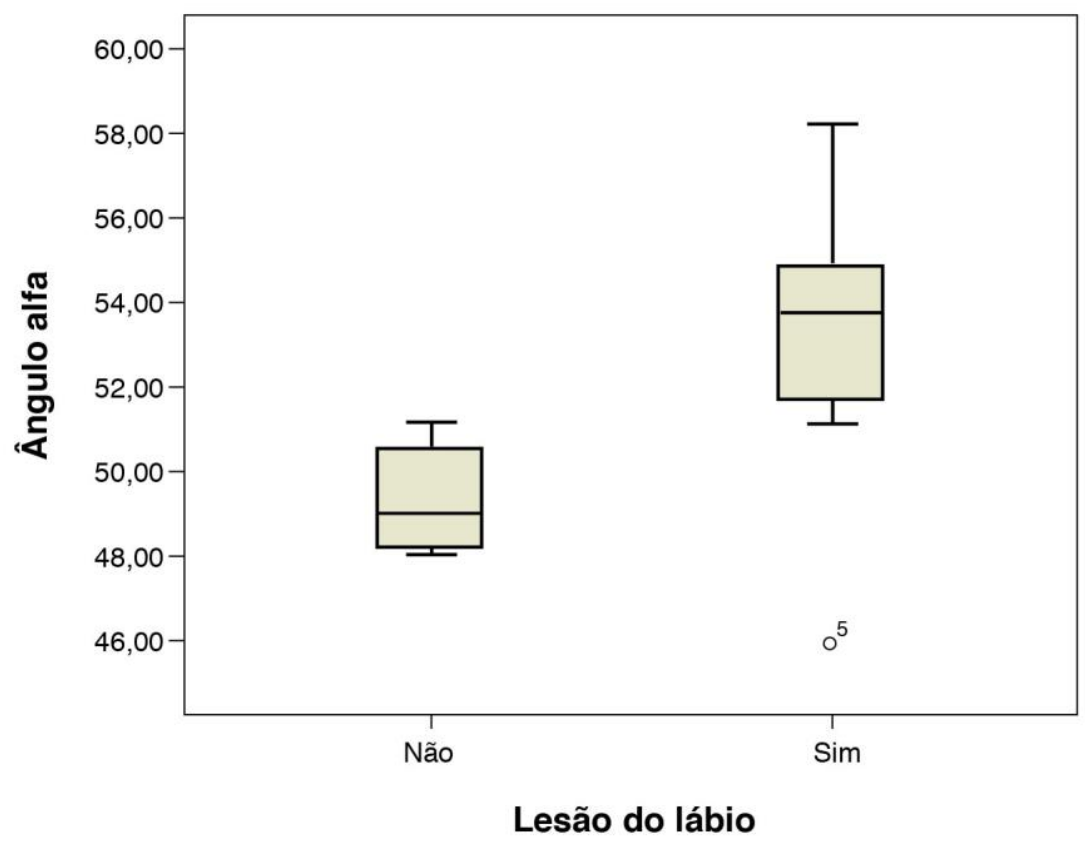

Figura 25. Ângulo alfa e sua relação com a presença de lesão labial.

O ângulo alfa não se associou com a presença de lesão labial macroscópica, ou presença de lesão labial tipo Seldes 1 ( $p>0,05)$.

Ao se analisar a presença de lesão labial avaliada microscopicamente em cadáveres em relação ao pincer, não foi encontrada diferença significativa $(p>0,05)$. O IFA tipo pincer também não se associou com a lesão Seldes tipo $2(p>0,05)$.

A versão femoral, ângulo centro-borda, versão acetabular e ângulo de Tönnis não apresentaram relação com a lesão labial microscópica ( $p$ > 0,05).

O tipo de IFA (came ou pincer) não apresentou relação com a classificação da lesão labial segundo Seldes ( $p>0,05)$. 
5. DISCUSSÃO 
O presente estudo avaliou a relação entre ângulos tomográficos do IFA e achados histológicos do lábio acetabular em cadáveres. Encontrou-se uma relação entre o ângulo alfa femoral e a presença de lesão labial avaliada na histologia. Não foi observada relação entre os demais ângulos estudados e a presença de lesão labial. O tipo de IFA não se relacionou com o tipo de lesão labial segundo a classificação de Seldes.

A nomenclatura dos tipos de IFA ainda não é estabelecida no Brasil. O termo pincer é proveniente da língua inglesa, e pode ser traduzido como pinça torquesa. Na literatura nacional, encontramos o termo IFA tipo torquês. $^{72,89}$ Optamos por utilizar, nesta dissertação, o termo pincer, por acreditar que é o mais utilizado em nosso meio. ${ }^{70,90,91}$ Já no IFA tipo came, encontramos essa grafia utilizada mais comumente. ${ }^{70,72,89-91}$ Porém o termo cam, com a mesma grafia da língua inglesa, também é encontrado na literatura nacional. ${ }^{92}$

Nosso estudo incluiu 20 cadáveres, amostra baseada na quantidade de exames de TC disponibilizada para este projeto pela equipe do projeto PISA da FMUSP. Acreditamos que esta amostra está em acordo com a literatura. Pesquisa realizada por Kohl et al., ${ }^{22}$ semelhante ao nosso estudo, foi realizada com amostra de 20 pacientes. Outros estudos sobre a histologia labial apresentam amostra menor, variando de 6 a 10 casos. ${ }^{42,43}$

Diversos artigos relatam a prevalência de IFA em populações assintomáticas. Uma revisão sistemática publicada em 2015 por Frank et al. ${ }^{93}$ resume os achados de IFA em populações assintomáticas, e inclui 26 estudos, com 2.114 quadris (57,2\% são homens). O ângulo alfa médio é 
$54,1^{\circ} \pm 5,1^{\circ}$. A prevalência de IFA tipo came é $37 \%$, variando de 7 a $100 \%$ dentre os estudos, sendo que atletas apresentam maior prevalência de alterações came que a população geral (54,8\% versus $23,1 \%)$. A prevalência de IFA tipo pincer é $67 \%$, variando de 61 a $76 \%$ nos estudos. Os autores fazem uma ressalva de que a deformidade tipo pincer é mal definida nos artigos, ocorrendo muita variação em sua definição. O ângulo centro-borda médio é $30^{\circ}$. Sete estudos dessa revisão reportam a prevalência de lesões labiais pela RM, encontrando uma prevalência de $68,1 \%$.

No presente estudo, encontramos uma prevalência de $80,0 \%$ de alterações tipo came e 40,0\% de alterações tipo pincer. O ângulo alfa médio foi $52,5^{\circ} \pm 3,1^{\circ}$, o centro-borda médio foi $35,7^{\circ} \pm 7,9^{\circ}$ e a anteversão femoral foi $12,1^{\circ} \pm 9,9^{\circ}$. Ao comparar nossos achados com a revisão sistemática de Frank et al., ${ }^{93}$ vimos que encontramos ângulo alfa semelhante, porém prevalência de IFA tipo came maior que a média. Esta diferença possivelmente se deve às diferentes definições de came. Encontramos ângulo centro-borda médio maior, porém prevalência menor de IFA tipo pincer. Acreditamos que essa diferença também esteja relacionada às diferentes definições do pincer.

Uma ressalva importante em relação aos estudos em assintomáticos, incluindo o presente, é que o IFA é um diagnóstico clínico. ${ }^{94,95}$ Para um paciente ser considerado portador de IFA, deve apresentar sintomas, exame físico condizente e achados nos exames de imagem. ${ }^{95}$ Portanto, a denominação de IFA em pessoas assintomáticas seria contraditória, pois o IFA não poderia estar presente em indivíduos assintomáticos. Entretanto, 
como todos os ângulos estudados são relacionados ao IFA, e não portadores de IFA também apresentam estas alterações radiográficas, optamos por esta nomenclatura. Essa opção está em acordo com diversos estudos que também a utilizam. . $^{53,54,93,96}$

A definição do IFA é discutida na literatura. Diversos ângulos e diversos valores são encontrados. Do lado femoral, o ângulo alfa é o mais comumente utilizado. ${ }^{4}$ Porém, outras medidas podem ser utilizadas, como a razão entre o offset colo-cabeça, ${ }^{7,97}$ presença de protuberância femoral

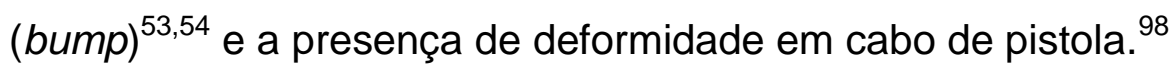

Na literatura encontramos valores de corte do ângulo alfa variando de $42^{\circ}$ a $63^{\circ} .4,7,9,99$ Pollard et. al. ${ }^{99}$ realizam um estudo em voluntários com intuito de determinar o valor normal do ângulo alfa. Neste estudo, os autores medem o ângulo alfa em 83 indivíduos por meio da radiografia em perfil cross-table. Encontram um ângulo alfa médio de $48^{\circ} \mathrm{em}$ homens e $47^{\circ} \mathrm{em}$ mulheres. Determinam o intervalo de referência $95 \%$, com valor de $32^{\circ}$ a $62^{\circ}$ e, por essa razão, propõem que o valor de corte do ângulo alfa seja $62^{\circ}$. Em um estudo mais recente com 2.038 voluntários, Laborie et al., ${ }^{100}$ encontram um valor médio do ângulo alfa de $47^{\circ}$ para homens, e $42^{\circ}$ em mulheres, sendo os percentis 97,5 de $68^{\circ}$ e $56^{\circ}$ respectivamente; porém não propõem um valor de corte para o ângulo alfa.

No presente estudo, consideramos a deformidade came como $50^{\circ} .84,85$ Optamos por esta medida porque objetivamos avaliar se a lesão labial ocorreria mesmo em quadris com ângulo alfa não tão aumentado. Além disso, na avaliação da relação entre o ângulo alfa e a lesão labial, 
avaliamos não apenas a presença de came como uma variável categórica (came presente ou ausente), mas também avaliamos o came por meio do ângulo alfa como variável numérica contínua.

Ademais, ao encontrarmos um aumento na prevalência de lesões labiais em indivíduos portadores de ângulo alfa próximo de $50^{\circ}$, confirmamos nossa hipótese de que o corte do ângulo alfa em $50^{\circ}$ é adequado. Os indivíduos portadores de lesão labial tiveram em média um ângulo alfa igual a $53,3^{\circ}$, enquanto não portadores de lesão labial apresentaram um ângulo alfa médio de $49,3^{\circ}$.

A metodologia da medida do ângulo alfa é motivo de debate. A medida do ângulo alfa no plano axial oblíquo, que é a mais utilizada, analisa o ângulo alfa na porção mais anterior do colo femoral. Entretanto, alguns estudos indicam que a região na qual o ângulo alfa seria mais acentuado é o quadrante ântero-superior. ${ }^{101-103}$ Por esse motivo, a medida em diversos planos radiais seria mais precisa na determinação do ângulo alfa. Rakhra et al. ${ }^{103}$ relatam, em uma série de pacientes submetidos a cirurgia por IFA, que em $54 \%$ dos indivíduos o ângulo alfa foi menor que $55^{\circ}$ no plano axial oblíquo convencional, porém maior que $55^{\circ} \mathrm{em}$ planos radiais.

No presente estudo, optamos por realizar a medida do ângulo alfa no plano axial oblíquo por dois motivos. Primeiro, acreditamos que, no dia a dia, a medida em diversos planos é possivelmente pouco prática. Grande parte dos cirurgiões ortopédicos e radiologistas têm por costume medir o ângulo alfa apenas no plano axial oblíquo e, desta maneira, a medida em diversos planos poderia distanciar este projeto da clínica diária. Segundo, devido ao reduzido 
tamanho da amostra, o aumento no número de variáveis poderia incorrer em um erro do tipo 1. Diversas análises estatísticas poderiam aumentar a chance de encontrar um valor estatisticamente significativo ao acaso.

A confiabilidade da medida do ângulo alfa descrita na literatura é variável. Mast et al. ${ }^{104}$ relatam índices altos de coeficiente de correlação intraclasses para o ângulo alfa, tanto interexaminadores $(0,83)$ quanto intraexaminadores $(0,90)$. Carlisle et al. ${ }^{105}$ encontram índices semelhantes para o coeficiente intraexaminadores $(0,76)$, mas relatam índices mais baixos para coeficientes interexaminadores $(0,21)$. Clohisy et al. ${ }^{106}$ demonstram que a avaliação radiográfica do quadril tem baixa confiabilidade, mesmo entre avaliadores experientes. $O$ ângulo alfa, por ser uma medida em duas dimensões de uma deformidade tridimensional, apresenta limitações. Por esse motivo, alguns programas de computador foram desenvolvidos com o objetivo de aprimorar a avaliação da deformidade came e inclusive auxiliar no planejamento da correção durante a cirurgia, abrindo um promissor campo de pesquisa no IFA. ${ }^{107,108}$

Diversos artigos relacionam alterações na anteversão femoral à dor no quadril e osteoartrite. ${ }^{48-50,109,110}$ Entretanto, não é consenso na literatura se valores aumentados ou diminuídos da anteversão estariam relacionados ao IFA, ou se a anteversão influenciaria resultados clínicos no tratamento do IFA.

Ito et al. ${ }^{51}$ encontram índices diminuídos de anteversão femoral comparando portadores de IFA com controles, enquanto Ejnisman et al. ${ }^{60}$ encontram valores de anteversão femoral similares entre portadores de IFA e controles da literatura. Com relação a resultados clínicos após o 
tratamento do IFA, a influência da versão femoral não é estabelecida. Fabricant et al. ${ }^{111}$ reportam resultados clínicos piores em pacientes com anteversão femoral menor que $5^{\circ}$. O estudo também avalia a influência do índice de McKibbin (versão acetabular e femoral combinada) que não apresenta relação com resultados clínicos. Já Ferro et al.. ${ }^{112}$ não encontram diferença nos resultados clínicos de pacientes submetidos a artroscopia do quadril com diferentes versões femorais. Os autores consideram que anteversão femoral maior que $30^{\circ}$ é uma contraindicação relativa para a artroscopia do quadril. Nosso estudo encontrou um valor médio da versão femoral de $12,1^{\circ}$ (mínimo $-8,0^{\circ}$ e máximo $30,0^{\circ}$ ). Estes valores são similares aos encontrados na literatura e demonstram a grande variação encontrada na versão femoral.

O presente estudo não encontrou associação entre a versão femoral e a presença de lesão labial, que pode estar relacionada não apenas a fatores anatômicos, mas também a fatores dinâmicos. Um dos possíveis mecanismos da influência da versão femoral sobre a lesão labial é o impacto do psoas (psoas impingement em inglês). ${ }^{113}$ Este impacto gera lesões mais anteriores no lábio acetabular, causadas pela compressão local do tendão do psoas ao cruzar o rebordo acetabular anterior. O impacto do psoas poderia ser mais frequente em pacientes ativos, visto que apresenta relação com a contração muscular. Lembrando que não conhecemos o histórico dos cadáveres estudados nesta tese, eventualmente o impacto do psoas pode não ter sido identificado por termos avaliado uma população menos ativa fisicamente. Outra possível causa da falta de associação é o local do lábio 
estudado. $\mathrm{O}$ impacto do psoas ocorre principalmente na região de três horas do acetábulo (em um acetábulo direito). Nesta tese, a posição estudada do lábio anterior foi correspondente a posição de duas horas (em um acetábulo direito). Pesquisas futuras avaliando regiões acetabulares mais anteriores poderão fornecer mais informações sobre o impacto do psoas.

Quanto ao lado acetabular do IFA, a determinação da presença da deformidade pincer também apresenta peculiaridades. No trabalho original de Ganz et al., ${ }^{1}$ a determinação do IFA tipo pincer é realizada por meio da radiografia de bacia. Alguns sinais são descritos para este diagnóstico, como o sinal do cruzamento, espinha isquiática proeminente e a coxa profunda. ${ }^{1,13,114}$ Entretanto, os sinais sugestivos de pincer apresentam grande variação, dependendo da posição na pelve do paciente. ${ }^{115,116}$ Por conseguinte, alguns estudos sugerem que a TC é o melhor método para determinar a anatomia acetabular por padronizar a posição pélvica. ${ }^{82,117}$ Por esse motivo, utilizamos a TC no presente estudo.

Optamos pela técnica descrita por Dandachli et al. ${ }^{82}$ para determinação da versão acetabular, que tem como vantagem a correção da bacia para um plano padrão conhecido como plano pélvico anterior. Desta maneira, a variabilidade causada pela posição da pelve é reduzida. Medimos a versão na porção superior do acetábulo, conforme os mesmos autores descrevem. A medida da versão acetabular varia conforme o local da mensuração, sendo que os cortes mais caudais apresentam anteversão aumentada. A principal localização da retroversão e pinçamento é na região 
mais superior do acetábulo, sendo a mensuração em regiões mais craniais mais importante no contexto do IFA.

Com o intuito de aumentar a sensibilidade na determinação do IFA tipo pincer, além da versão acetabular, utilizamos também o ângulo centroborda e o ângulo de Tönnis, conforme descrito por Monazzam et al. ${ }^{83} \mathrm{O}$ ângulo centro-borda é confiável na determinação da deformidade tipo pincer. Kutty et al. $^{87}$ demonstraram sensibilidade de $84,2 \%$ e especificidade de $100 \%$ do ângulo centro-borda maior que $40^{\circ}$ na detecção de IFA tipo pincer. O ângulo centro-borda, assim como a versão acetabular, apresentam variação a depender da posição da pelve do paciente. Pullen et al. ${ }^{118}$ demonstram variações significativas entre os valores do ângulo centro-borda e do ângulo de Tönnis em radiografias de bacia em posição supina e ortostática. Desta forma, a correção da posição da pelve é importante também na medida desses ângulos.

Encontramos apenas um indivíduo (caso 6) com ângulo centro-borda limítrofe para displasia, e que apresentou ângulo de Tönnis maior que $10^{\circ}$. Seu ângulo alfa foi de $53,1^{\circ}$. Este indíviduo, de 38 anos, apresentou lesão labial na porção anterior (Seldes 3). A displasia acetabular é uma causa importante de degeneração articular do quadril. O mecanismo é distinto do IFA, e é relacionado a aumento da pressão sobre a cartilagem, devido à diminuição da área de carga acetabular. É interessante notar que este caso apresentou lesão labial Seldes 3, sendo um dos poucos com esse padrão, possivelmente denotando a diferença na fisiopatologia da lesão labial na displasia. No tratamento da lesão labial, identificar a displasia é essencial, pois a correção da 
lesão labial em acetábulos displásicos, sem correção da deformidade óssea, produz resultados desastrosos, com rápida progressão para osteoartrite. ${ }^{119,120}$ Um estudo semelhante ao atual, com foco específico na displasia acetabular, possivelmente elucidaria questões na fisiopatologia da displasia.

Uma dificuldade no estudo do IFA é a alta taxa de presença de mais de uma deformidade concomitante. Por exemplo, encontramos uma prevalência de $30 \%$ de IFA tipo misto, e o único caso limítrofe para displasia apresentou ângulo alfa aumentado. Além disso, devido ao tamanho da nossa amostra, casos de IFA misto foram avaliados duas vezes, tanto no grupo pincer quanto came. Desta forma, a avaliação do efeito da presença de uma deformidade isolada fica prejudicada.

Encontramos prevalência de $80 \%$ de lesões labiais. Há discordância dessa prevalência ao compararmos com outros estudos em cadáveres. Seldes et al. $^{39}$ relatam prevalência de $96 \%$, enquanto Vawklang e Lertwanich $^{44}$ relatam prevalência de $66 \%$. Uma possível causa para essa diferença é a idade dos indivíduos estudados. O presente estudo apresentou idade média de 50 anos, o estudo de Seldes et al. ${ }^{39}$ apresenta idade média de 78 anos, e Vawklang e Lertwanich ${ }^{44}$ apresentam idade média de 55 anos. É possível que o próprio envelhecimento seja uma causa de lesão labial, explicando a maior prevalência da lesão em estudos com indivíduos mais velhos. Por esta razão, no presente estudo optou-se por incluir apenas indivíduos com menos de 60 anos; visando diminuir a influência da idade na lesão labial. Entretanto, na nossa amostra, não se encontrou diferença de idade entre cadáveres portadores e não portadores de lesão labial. 
A classificação de Seldes et al. ${ }^{39}$ considera dois tipos de lesão labial: no tipo 1, ocorre uma avulsão do lábio da junção condro-labial, enquanto no tipo 2, planos de clivagem são encontrados na substância labial. No presente estudo, descrevemos um novo tipo de lesão labial; que combina as lesões tipo 1 e 2, que denominamos tipo 3. Em teoria, a lesão Seldes 1 é relacionada ao IFA tipo came, e a lesão Seldes 2 é relacionada ao IFA tipo pincer. ${ }^{57}$ Frente a essa teoria, faz sentido que exista uma lesão tipo 3 , que corresponderia ao IFA tipo misto. Kohl et al. ${ }^{22}$ também demonstram que há diferenças histológicas no padrão de lesão da cartilagem encontrada em pacientes portadores de diferentes tipos de IFA.

Entretanto, nosso estudo não encontrou relação entre o tipo de IFA e a classificação de Seldes. Pode ser que estejamos frente a um erro tipo 2 e nossa casuística não tenha sido suficiente para detectarmos essa relação. Outra possibilidade é de que o mecanismo de lesão labial seja mais complexo do que apenas a relação entre esfericidade da cabeça femoral e a versão do acetábulo. Com o desenvolvimento do conhecimento das afecções do quadril não artrítico, novas doenças vêm sendo estudadas, como o impacto do psoas, impacto subespinal e a instabilidade do quadril. ${ }^{113,121,122} \mathrm{O}$ mecanismo de lesão labial pode ser multifatorial, com diversos aspectos anatômicos e dinâmicos influenciando na presença e padrão da lesão.

Outrossim, possivelmente não só fatores mecânicos sejam causadores de lesões labiais e degeneração articular. Há uma discussão sobre a relação de fatores inflamatórios, não avaliados no presente estudo, com a fisiopatologia do IFA e lesão labial. Biópsias labiais e de cartilagem de pacientes portadores de 
IFA demonstram importante infiltrado inflamatório e neo-vascularização, assim como maior expressão de interleucinas e genes relacionados a aumento da atividade metabólica. ${ }^{123,124}$ Estudos futuros poderão avaliar se os fatores mecânicos ou inflamatórios são os mais importantes na lesão labial.

No presente estudo, não houve concordância entre os achados da lesão labial macroscópica e microscópica. Uma possível explicação para esse achado é a localização da lesão labial. Padronizamos a localização da retirada da peça a ser estudada histologicamente, e possivelmente alguns casos apresentaram lesão macroscópica em local diferente do padronizado para estudo histológico. Essa hipótese explicaria os casos falsos negativos (presença de lesão macroscópica, ausência de lesão microscópica). A possibilidade de ausência de lesão macroscópica em casos de lesão microscópica reforça a importância da anamnese e exame físico em pacientes com dor no quadril. Possivelmente, alguns pacientes com dor no quadril sejam comparáveis aos cadáveres deste estudo, com lesão labial apenas microscópica, e apresentariam exames de imagem negativos, demonstrando a relevância clínica do presente estudo.

Nosso estudo possui algumas limitações. Uma limitação é a idade média da amostra estudada, que foi de 50 anos. O IFA acomete principalmente pacientes jovens, portanto estudar uma população jovem de 20 a 40 anos seria ideal. Porém, no SVOC-SP a disponibilidade de cadáveres abaixo de 40 anos é pequena. Incluímos apenas indivíduos com menos de 60 anos, com objetivo de tentar manter a idade média o menos avançada possível. Outra limitação é o desconhecimento da história clínica do paciente. Seria de grande valia 
conhecer se os cadáveres apresentavam dor no quadril em vida e seu nível de atividade física e profissional. Conhecendo essas características, poderíamos investigar possíveis relações entre alterações histológicas e nível de atividade, tema que poderá ser investigado futuramente.

A pesquisa do IFA é um campo do conhecimento em expansão. Recentemente, ocorreu aumento de cinco vezes no número de publicacões relacionadas ao IFA, porém a maior parte é de estudos nível de evidência IV e V. ${ }^{125}$ Há necessidade de estudos de ciência básica relacionada ao IFA e estudos clínicos com maior nível de evidência.

Vemos o presente estudo como um seguimento da pesquisa em IFA iniciada em um estágio internacional em 2010 no Steadman Philippon Research Institute, sendo continuada na nossa instituição. Planejamos manter essa linha de pesquisa translacional no IOT-HCFMUSP, que acreditamos poderá trazer contribuição para o conhecimento do IFA e no entendimento da fisiopatologia da dor no quadril não artrítico. 
6. CONCLUSÕES 
1. Quadris portadores de ângulo alfa femoral aumentados apresentam maior prevalência de lesões labiais.

2. O ângulo de versão acetabular ou femoral, o ângulo de Tönnis e o ângulo centro-borda não apresentam associação com a lesão labial.

3. A presença de IFA tipo came associa-se com a maior prevalência de lesão labial, enquanto a presença de IFA tipo pincer não se associa com a lesão labial.

4. O tipo de IFA não se relaciona com o tipo de lesão labial segundo a classificação de Seldes. 


\section{Anexos}


Anexo A. Carta de aprovação da Comissão de Ética para Análise de Projetos de Pesquisa.

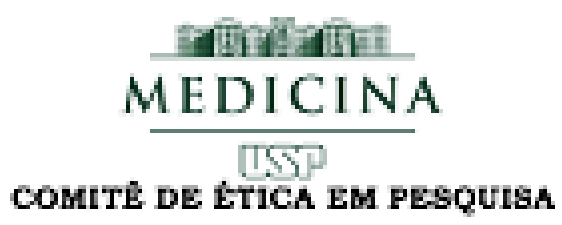

\section{APROVAÇÃo}

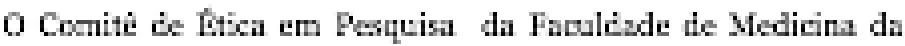
Univerdade de sào Paulo, en 19/09/2012, ApRovou ad neforetum o Protocnlo di Pesquisa $\mathrm{n}^{\circ}$ 296/12 intitulado "EsTUDO HISTOMORFOMETRICO DA LESTO DO LAEIO ACETABLLAR E CARTILAGEM ARTICULAR DO QUADRIT FM RELACAO OOM O AMGULO AIPHA FEMORAL E O IMPACTO FEMORO-ACETABULAR" aprestedo pilo Departamento de ORTOFEDLA E TRALMATOLOGLA

Cabe to pesquisador elaborar e apresentar ag cr.p. FMUSP, os relatórios parciats ef final sobre a pesquisa cResoluçán do Conselho Nacional de Suúde $n^{\circ} 196$, de 10/10/1996, inciso IX.2, letra "c"?.

Pesquisador (a) Responsúwel: Allerto Tesconi Croei Pesquisador (a) Executante Lendro E.jnismun

CEP-PMUSP, 20 de Setembro de 2012.

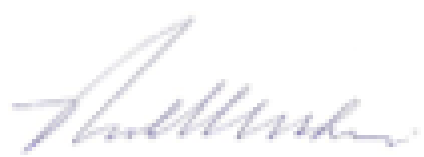

Prof. Dr. Paulo Euripedes Mardbiori Viec-Goordenador Comite de Ctica em Pesquisi 
Anexo B. Carta de aprovação do Serviço de Verificação de Óbitos da Capital (SVOC-USP).

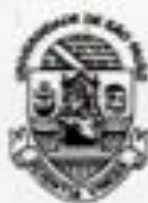

\section{UNIVERSIDADE DE SÃO PAULO} SERVICO DE VERIFICACIO DE ÓBITOS DA CAPTTAL.

\footnotetext{
Manifestaclo prèvia a respeite des aspectos técaicos relacionades ae estude para pesquisa cientifica
}

Título da pesquisa: Estude histomorfometrico da lesto do labio acetabular e cartilagem articular do quadril en relaçio com o àngulo alpha femoral e o impacto fémoro acetabular.

Pesquisader Execatante: Leandro Ejnisman

Pesquaisader Responsivel Alberto Tesconi Croci

Em relaça aos aspectos técaicos relacionsdos ao estudo para pesquisa cientifiea mescionada acima, informamos aăo maver impedimento do ponto de vista tecnico e nem risco de mutilaçăo. Com a finalidade de aprimoramento medico. 
Anexo C. Lista dos casos.

\begin{tabular}{|c|c|c|c|c|c|c|c|c|}
\hline Caso & $\begin{array}{c}\text { Número } \\
\text { SVOC-USP }\end{array}$ & Idade & Gênero & Lado & Altura & Peso & IMC & $\begin{array}{l}\text { Data da } \\
\text { dissecção }\end{array}$ \\
\hline 1 & V013-5617 & 51 & $M$ & $E$ & 1,70 & 70,4 & 24,4 & $10 / 06 / 13$ \\
\hline 2 & V013-6035 & 56 & $M$ & D & 1,80 & 65,6 & 20,3 & $17 / 06 / 13$ \\
\hline 3 & V013-6575 & 55 & $M$ & D & 1,73 & 56,0 & 18,7 & $24 / 06 / 13$ \\
\hline 4 & V013-7383 & 50 & M & $E$ & 1,53 & 37,2 & 15,9 & $11 / 07 / 13$ \\
\hline 5 & V013-7675 & 38 & $\mathrm{~F}$ & D & 1,68 & 59,0 & 20,9 & $18 / 07 / 13$ \\
\hline 6 & V013-7837 & 38 & M & $E$ & 1,87 & 76,0 & 21,7 & $25 / 07 / 13$ \\
\hline 7 & V013-9570 & 53 & M & D & 1,65 & 53,0 & 19,5 & 09/09/13 \\
\hline 8 & V013-10092 & 56 & M & $E$ & 1,50 & 66,6 & 29,6 & $16 / 09 / 13$ \\
\hline 9 & V013-10236 & 52 & $\mathrm{~F}$ & D & 1,60 & 48,0 & 18,8 & $19 / 09 / 13$ \\
\hline 10 & V013-10385 & 51 & $\mathrm{M}$ & E & 1,72 & 66,6 & 22,5 & $23 / 09 / 13$ \\
\hline 11 & V014-1023 & 53 & $M$ & D & 1,70 & 54,0 & 18,7 & $30 / 01 / 14$ \\
\hline 12 & V014-1828 & 53 & $\mathrm{~F}$ & E & 1,60 & 72,0 & 28,1 & $03 / 02 / 14$ \\
\hline 13 & V014-2035 & 34 & $\mathrm{M}$ & D & 1,66 & 77,0 & 27,9 & $27 / 02 / 14$ \\
\hline 14 & V014-3372 & 47 & M & $E$ & 1,70 & 74,0 & 25,6 & $07 / 04 / 14$ \\
\hline 15 & V014-3545 & 58 & M & D & 1,81 & 70,0 & 21,4 & $14 / 04 / 14$ \\
\hline 16 & V014-5269 & 56 & $\mathrm{~F}$ & $E$ & 1,67 & 63,0 & 22,6 & $26 / 05 / 14$ \\
\hline 17 & V014-7193 & 37 & M & D & 1,78 & 67,4 & 21,3 & $14 / 07 / 14$ \\
\hline 18 & V014-7993 & 53 & $\mathrm{~F}$ & $E$ & 1,51 & 67,0 & 29,4 & $04 / 08 / 14$ \\
\hline 19 & V014-10805 & 56 & $\mathrm{~F}$ & D & 1,65 & 75,8 & 27,8 & $20 / 10 / 14$ \\
\hline 20 & V014/12554 & 56 & $\mathrm{M}$ & E & 1,67 & 53,0 & 19,0 & $15 / 12 / 14$ \\
\hline
\end{tabular}

IMC = índice de massa corpórea 
Anexo D. Análise tomográfica.

\begin{tabular}{|c|c|c|c|c|c|c|c|}
\hline Caso & Alfa & $\begin{array}{l}\text { Versão } \\
\text { femoral }\end{array}$ & $\begin{array}{l}\text { Versão } \\
\text { acetabular }\end{array}$ & Centro-borda & Tönnis & Came & Pincer \\
\hline 1 & 51,3 & 13,9 & 17,1 & 37,1 & 0 & $(+)$ & $(+)$ \\
\hline 2 & 54,1 & 16,6 & 3,9 & 27,2 & 7,1 & $(+)$ & $(-)$ \\
\hline 3 & 54,2 & 26,9 & 18,3 & 26,7 & 6,8 & $(+)$ & $(-)$ \\
\hline 4 & 51,1 & $-8,0$ & 15,0 & 25,2 & 11,4 & $(+)$ & $(-)$ \\
\hline 5 & 45,9 & 5,4 & 18,8 & 30,1 & 0 & $(-)$ & $(+)$ \\
\hline 6 & 53,1 & 13,0 & 8,3 & 22,6 & 15,0 & $(+)$ & $(-)$ \\
\hline 7 & 51,1 & 16,8 & 23,2 & 41,0 & 2,0 & $(+)$ & $(+)$ \\
\hline 8 & 48,3 & $-4,8$ & 21,9 & 34,5 & 2,9 & $(-)$ & $(-)$ \\
\hline 9 & 54,0 & 17,1 & 14,0 & 33,6 & 8,5 & $(+)$ & $(-)$ \\
\hline 10 & 51,2 & $-1,2$ & 12,1 & 28,6 & 6,1 & $(+)$ & $(-)$ \\
\hline 11 & 51,9 & 16,9 & 14,3 & 28,8 & 9,4 & $(+)$ & $(-)$ \\
\hline 12 & 48,1 & 6,1 & 12,1 & 46,2 & 8,8 & $(-)$ & $(+)$ \\
\hline 13 & 52,1 & 12,7 & 10,7 & 37,1 & 6,7 & $(+)$ & $(-)$ \\
\hline 14 & 57,0 & 12,1 & 5,5 & 34,8 & 5,0 & $(+)$ & $(-)$ \\
\hline 15 & 58,3 & 12,5 & 17,1 & 41,4 & 6,2 & $(+)$ & $(+)$ \\
\hline 16 & 55,2 & 18,4 & 15,8 & 51,2 & 5,5 & $(+)$ & $(+)$ \\
\hline 17 & 53,6 & 7,0 & 14,4 & 38,8 & 7,2 & $(+)$ & $(-)$ \\
\hline 18 & 54,7 & 4,7 & 15,7 & 47,1 & 4,5 & $(+)$ & $(+)$ \\
\hline 19 & 55,1 & 24,9 & 3,7 & 42,1 & 4,9 & $(+)$ & $(+)$ \\
\hline 20 & 49,7 & 30,0 & 20,4 & 39,3 & 4,6 & $(-)$ & $(-)$ \\
\hline
\end{tabular}


Anexo E. Análise histológica.

\begin{tabular}{|c|c|c|c|c|c|c|}
\hline Caso & $\begin{array}{l}\text { Lesão labial } \\
\text { macroscópica }\end{array}$ & $\begin{array}{l}\text { Sulco sublabial } \\
\text { posterior }\end{array}$ & $\begin{array}{l}\text { Lesão condral } \\
\text { macroscópica }\end{array}$ & $\begin{array}{c}\text { Seldes } \\
\text { anterior }\end{array}$ & $\begin{array}{l}\text { Seldes } \\
\text { superior }\end{array}$ & $\begin{array}{l}\text { Seldes } \\
\text { posterior }\end{array}$ \\
\hline 1 & $(-)$ & $(-)$ & $(-)$ & 1 & $(-)$ & $(-)$ \\
\hline 2 & $(-)$ & $(-)$ & $(-)$ & 1 & 2 & $(-)$ \\
\hline 3 & $(+)$ & $(-)$ & $(-)$ & 1 & 2 & 1 \\
\hline 4 & $(-)$ & $(-)$ & $(-)$ & 1 & 1 & $(-)$ \\
\hline 5 & $(-)$ & $(-)$ & $(-)$ & $(-)$ & 2 & 2 \\
\hline 6 & $(-)$ & $(-)$ & $(-)$ & 3 & $(-)$ & $(-)$ \\
\hline 7 & $(+)$ & $(-)$ & $(-)$ & 2 & 3 & $(-)$ \\
\hline 8 & $(+)$ & $(-)$ & $(+)$ & $(-)$ & $(-)$ & $(-)$ \\
\hline 9 & $(+)$ & $(+)$ & $(-)$ & 1 & $(-)$ & $(-)$ \\
\hline 10 & $(-)$ & $(+)$ & $(-)$ & $(-)$ & $(-)$ & $(-)$ \\
\hline 11 & $(-)$ & $(-)$ & $(-)$ & $(-)$ & 2 & $(-)$ \\
\hline 12 & $(+)$ & $(-)$ & $(-)$ & $(-)$ & $(-)$ & $(-)$ \\
\hline 13 & $(-)$ & $(-)$ & $(-)$ & 3 & 1 & 1 \\
\hline 14 & $(+)$ & $(+)$ & $(-)$ & 1 & $(-)$ & 1 \\
\hline 15 & $(-)$ & $(-)$ & $(-)$ & 2 & 2 & 1 \\
\hline 16 & $(+)$ & $(-)$ & $(-)$ & 1 & 1 & $(-)$ \\
\hline 17 & $(+)$ & $(-)$ & $(+)$ & 1 & $(-)$ & $(-)$ \\
\hline 18 & $(+)$ & $(-)$ & $(+)$ & 1 & $(-)$ & $(-)$ \\
\hline 19 & $(+)$ & $(-)$ & $(-)$ & $(-)$ & 1 & $(-)$ \\
\hline 20 & $(-)$ & $(-)$ & $(-)$ & $(-)$ & $(-)$ & $(-)$ \\
\hline
\end{tabular}




\section{REFERÊNCIAS}


1. Ganz R, Parvizi J, Beck M, Leunig M, Nötzli H, Siebenrock KA. Femoroacetabular impingement: a cause for osteoarthritis of the hip. Clin Orthop Relat Res. 2003;(417):112-20.

2. Lavigne M, Parvizi J, Beck M, Siebenrock KA, Ganz R, Leunig M. Anterior femoroacetabular impingement: part I. Techniques of joint preserving surgery. Clin Orthop Relat Res. 2004;(418):61-6.

3. Leunig $M$, Casillas MM, Hamlet $M$, Hersche $O$, Nötzli $H$, Slongo $T$, et al. Slipped capital femoral epiphysis: early mechanical damage to the acetabular cartilage by a prominent femoral metaphysis. Acta Orthop Scand. 2000;71(4):370-5.

4. Nepple JJ, Prather H, Trousdale RT, Clohisy JC, Beaulé PE, GlynJones $S$, et al. Diagnostic imaging of femoroacetabular impingement. J Am Acad Orthop Surg. 2013;21 Suppl 1:S20-6.

5. Oberg E. Machinery's Handbook. $29^{\text {th }}$ edition. South Norwalk: Industrial Press; 2012.

6. Philippon MJ, Briggs KK, Yen YM, Kuppersmith DA. Outcomes following hip arthroscopy for femoroacetabular impingement with associated chondrolabral dysfunction minimum two-year follow-up. J Bone Joint Surg Br. 2009;91(1):16-23.

7. Clohisy JC, Carlisle JC, Beaulé PE, Kim YJ, Trousdale RT, Sierra RJ, et al. A systematic approach to the plain radiographic evaluation of the young adult hip. J Bone Joint Surg Am. 2008;90 Suppl 4:47-66.

8. Genovese E, Spiga S, Vinci V, Aliprandi A, Di Pietto F, Coppolino F, et al. Femoroacetabular impingement: role of imaging. Musculoskelet Surg. 2013;97 Suppl 2:S117-26. 
9. Nötzli HP, Wyss TF, Stoecklin CH, Schmid MR, Treiber K, Hodler J. The contour of the femoral head-neck junction as a predictor for the risk of anterior impingement. J Bone Joint Surg Br. 2002;84(4):556-60.

10. Clohisy JC, Nunley RM, Otto RJ, Schoenecker PL. The frog-leg lateral radiograph accurately visualized hip cam impingement abnormalities. Clin Orthop Relat Res. 2007;462:115-21.

11. Beaulé PE, Zaragoza E, Motamedi K, Copelan N, Dorey FJ. Threedimensional computed tomography of the hip in the assessment of femoroacetabular impingement. J Orthop Res. 2005;23(6):1286-92.

12. Wiberg G. Studies on dysplastic acetabula and congenital subluxation of the hip joint: with special reference to the complication of osteoarthritis. Acta Chir Scand. 1939;83(Suppl 58):53-68.

13. Jamali AA, Mladenov K, Meyer DC, Martinez A, Beck M, Ganz R, et al. Anteroposterior pelvic radiographs to assess acetabular retroversion: high validity of the "cross-over-sign." J Orthop Res. 2007;25(6):758-65.

14. Kim J, Choi JA, Lee E, Lee KR. Prevalence of Imaging Features on CT Thought to Be Associated With Femoroacetabular Impingement: A Retrospective Analysis of 473 Asymptomatic Adult Hip Joints. AJR Am J Roentgenol. 2015;205(1):W100-5.

15. Ejnisman L, Philippon MJ, Lertwanich P. Acetabular labral tears: diagnosis, repair, and a method for labral reconstruction. Clin Sports Med. 2011;30(2):317-29.

16. Shindle MK, Voos JE, Nho SJ, Heyworth BE, Kelly BT. Arthroscopic management of labral tears in the hip. J Bone Joint Surg Am. 2008;90 Suppl 4:2-19. 
17. Crawford MJ, Dy CJ, Alexander JW, Thompson M, Schroder SJ, Vega CE, et al. The 2007 Frank Stinchfield Award. The biomechanics of the hip labrum and the stability of the hip. Clin Orthop Relat Res. 2007;465:16-22.

18. Ferguson SJ, Bryant JT, Ganz R, Ito K. The acetabular labrum seal: a poroelastic finite element model. Clin Biomech (Bristol, Avon). 2000;15(6):463-8.

19. Ferguson SJ, Bryant JT, Ganz R, Ito K. The influence of the acetabular labrum on hip joint cartilage consolidation: a poroelastic finite element model. J Biomech. 2000;33(8):953-60.

20. Myers CA, Register BC, Lertwanich P, Ejnisman L, Pennington WW, Giphart JE, et al. Role of the acetabular labrum and the iliofemoral ligament in hip stability: an in vitro biplane fluoroscopy study. Am $\mathrm{J}$ Sports Med. 2011;39 Suppl:85S-91S.

21. Wenger DE, Kendell KR, Miner MR, Trousdale RT. Acetabular labral tears rarely occur in the absence of bony abnormalities. Clin Orthop Relat Res. 2004;(426):145-50.

22. Kohl S, Hosalkar HS, Mainil-Varlet P, Krueger A, Buechler L, Siebenrock K. Histology of damaged acetabular cartilage in symptomatic femoroacetabular impingement: an observational analysis. Hip Int. 2011;21(2):154-62.

23. Smith-Petersen MN. Treatment of malum coxae senilis, old slipped upper femoral epiphysis, intrapelvic protrusion of the acetabulum, and coxa plana by means of acetabuloplasty. The Journal of Bone \& Joint Surgery American. 1936;18(4):869-80. Disponível em: http://jbjs.org/content/18/4/869. Acessado em 2015 (25 nov). 
24. Carlioz H, Pous JG, Rey JC. [Upper femoral epiphysiolysis]. Rev Chir Orthop Reparatrice Appar Mot. 1968;54(5):387-491.

25. Murray RO, Duncan C. Athletic activity in adolescence as an etiological factor in degenerative hip disease. J Bone Joint Surg Br. 1971;53(3):406-19.

26. Stulberg SD, Cordell LD, Harris WH, Ramsey PL, MacEwan GD. Unrecognized childhood hip disease: a major cause of idiopathic osteoarthritis of the hip. In: The Hip Proceedings of The Third Meeting of the Hip Society. Saint Louis: Mosby; 1975. p. 212-28

27. Ganz R, Klaue K, Vinh TS, Mast JW. A new periacetabular osteotomy for the treatment of hip dysplasias. Technique and preliminary results. Clin Orthop Relat Res. 1988;(232):26-36.

28. Klaue K, Durnin CW, Ganz R. The acetabular rim syndrome. A clinical presentation of dysplasia of the hip. J Bone Joint Surg Br. 1991;73(3):423-9.

29. Reynolds D, Lucas J, Klaue K. Retroversion of the acetabulum. A cause of hip pain. J Bone Joint Surg Br. 1999;81(2):281-8.

30. Myers SR, Eijer H, Ganz R. Anterior femoroacetabular impingement after periacetabular osteotomy. Clin Orthop Relat Res. 1999;(363):93-9.

31. Gautier E, Ganz K, Krügel N, Gill T, Ganz R. Anatomy of the medial femoral circumflex artery and its surgical implications. J Bone Joint Surg Br. 2000;82(5):679-83. 
32. Clohisy JC, Baca G, Beaulé PE, Kim YJ, Larson CM, Millis MB, et al. Descriptive epidemiology of femoroacetabular impingement: a North American cohort of patients undergoing surgery. Am J Sports Med. 2013;41(6):1348-56.

33. Paterson I. The torn acetabular labrum; a block to reduction of a dislocated hip. J Bone Joint Surg Br. 1957;39-B(2):306-9.

34. Dameron TB Jr. Bucket-handle tear of acetabular labrum accompanying posterior dislocation of the hip. J Bone Joint Surg Am. 1959;41-A(1):131-4.

35. Altenberg AR. Acetabular labrum tears: a cause of hip pain and degenerative arthritis. South Med J. 1977;70(2):174-5.

36. Harris $\mathrm{WH}$, Bourne RB, Oh I. Intra-articular acetabular labrum: a possible etiological factor in certain cases of osteoarthritis of the hip. $\mathrm{J}$ Bone Joint Surg Am. 1979;61(4):510-4.

37. Lage LA, Patel JV, Villar RN. The acetabular labral tear: an arthroscopic classification. Arthroscopy. 1996;12(3):269-72.

38. Weigel DP, Callaghan JJ. Use of anchor sutures to repair labral avulsions of the hip: a brief report. lowa Orthop J. 1997;17:141-3.

39. Seldes RM, Tan V, Hunt J, Katz M, Winiarsky R, Fitzgerald RH Jr. Anatomy, histologic features, and vascularity of the adult acetabular labrum. Clin Orthop Relat Res. 2001;(382):232-40.

40. Ferguson SJ, Bryant JT, Ganz R, Ito K. An in vitro investigation of the acetabular labral seal in hip joint mechanics. J Biomech. 2003;36(2):171-8. 
41. Miozzari HH, Clark JM, Jacob HA, von Rechenberg B, Nötzli HP. Effects of removal of the acetabular labrum in a sheep hip model. Osteoarthritis Cartilage. 2004;12(5):419-30.

42. Philippon MJ, Arnoczky SP, Torrie A. Arthroscopic repair of the acetabular labrum: a histologic assessment of healing in an ovine model. Arthroscopy. 2007;23(4):376-80.

43. Audenaert EA, Dhollander AA, Forsyth RG, Corten K, Verbruggen G, Pattyn C. Histologic assessment of acetabular labrum healing. Arthroscopy. 2012;28(12):1784-9.

44. Vawklang N, Lertwanich P. Prevalence of acetabular labral tears and sublabral sulci: a cadaveric study. J Med Assoc Thai. 2012;95 Suppl 9:S104-9.

45. Abrams GD, Safran MR, Sadri H. Spontaneous hip labrum regrowth after initial surgical débridement. Clin Orthop Relat Res. 2013;471(8):2504-8.

46. Miozzari HH, Celia M, Clark JM, Werlen S, Naal FD, Nötzli HP. No regeneration of the human acetabular labrum after excision to bone. Clin Orthop Relat Res. 2015;473(4):1349-57.

47. Lertwanich P, Plakseychuk A, Kramer S, Linde-Rosen M, Maeyama A, $\mathrm{Fu} \mathrm{FH}$, et al. Biomechanical evaluation contribution of the acetabular labrum to hip stability. Knee Surg Sports Traumatol Arthrosc. 2015 Mar 7. [Epub ahead of print].

48. Terjesen T, Benum P, Anda S, Svenningsen S. Increased femoral anteversion and osteoarthritis of the hip joint. Acta Orthop Scand. 1982;53(4):571-5. 
49. Reikerås $\mathrm{O}$, Bjerkreim I, Kolbenstvedt A. Anteversion of the acetabulum and femoral neck in normals and in patients with osteoarthritis of the hip. Acta Orthop Scand. 1983;54(1):18-23.

50. Tönnis D, Heinecke A. Acetabular and femoral anteversion: relationship with osteoarthritis of the hip. J Bone Joint Surg Am. 1999;81(12):1747-70.

51. Ito K, Minka MA 2nd, Leunig M, Werlen S, Ganz R. Femoroacetabular impingement and the cam-effect. A MRI-based quantitative anatomical study of the femoral head-neck offset. $J$ Bone Joint Surg Br. $2001 ; 83(2): 171-6$.

52. Nouh MR, Schweitzer ME, Rybak L, Cohen J. Femoroacetabular impingement: can the alpha angle be estimated? AJR Am J Roentgenol. 2008;190(5):1260-2.

53. Miguel OF, Cabrita HB, Rodrigues MB, Croci AT. A comparative radiographic investigation of femoroacetabular impingement in young patients with and without hip pain. Clinics (Sao Paulo). 2012;67(5):463-7.

54. Register B, Pennock AT, Ho CP, Strickland CD, Lawand A, Philippon MJ. Prevalence of abnormal hip findings in asymptomatic participants: a prospective, blinded study. Am J Sports Med. 2012;40(12):2720-4.

55. Monazzam S, Bomar JD, Cidambi K, Kruk P, Hosalkar H. Lateral center-edge angle on conventional radiography and computed tomography. Clin Orthop Relat Res. 2013;471(7):2233-7. 
56. Scheidt RB, Galia CR, Diesel CV, Rosito R, Macedo CA. Prevalence of radiographic markers of femoroacetabular impingement in asymptomatic adults. Rev Col Bras Cir. 2014;41(1):36-42.

57. Beck M, Kalhor M, Leunig M, Ganz R. Hip morphology influences the pattern of damage to the acetabular cartilage: femoroacetabular impingement as a cause of early osteoarthritis of the hip. J Bone Joint Surg Br. 2005;87(7):1012-8.

58. Johnston TL, Schenker ML, Briggs KK, Philippon MJ. Relationship between offset angle alpha and hip chondral injury in femoroacetabular impingement. Arthroscopy. 2008;24(6):669-75.

59. Beaulé PE, Hynes K, Parker G, Kemp KA. Can the alpha angle assessment of cam impingement predict acetabular cartilage delamination? Clin Orthop Relat Res. 2012;470(12):3361-7.

60. Ejnisman L, Philippon MJ, Lertwanich P, Pennock AT, Herzog MM, Briggs KK, et al. Relationship between femoral anteversion and findings in hips with femoroacetabular impingement. Orthopedics. 2013;36(3):e293-300.

61. Zilkens $\mathrm{C}$, Miese F, Krauspe R, Bittersohl B. Symptomatic femoroacetabular impingement: does the offset decrease correlate with cartilage damage? A pilot study. Clin Orthop Relat Res. 2013;471(7):2173-82.

62. Redmond JM, Gupta A, Hammarstedt JE, Stake CE, Dunne KF, Domb BG. Labral injury: radiographic predictors at the time of hip arthroscopy. Arthroscopy. 2015;31(1):51-6. 
63. Burman MS. Arthroscopy or the direct visualization of joints. The Joint of Bone \& Joint Surgery American. 1931;13(4):669-95. Disponível em: http://jbjs.org/content/jbjsam/13/4/669.full.pdf. Acessado em 2015 (25 nov).

64. Glick JM, Sampson TG, Gordon RB, Behr JT, Schmidt E. Hip arthroscopy by the lateral approach. Arthroscopy. 1987;3(1):4-12.

65. Ikeda T, Awaya G, Suzuki S, Okada Y, Tada H. Torn acetabular labrum in young patients. Arthroscopic diagnosis and management. J Bone Joint Surg Br. 1988;70(1):13-6.

66. Byrd JW. Hip arthroscopy utilizing the supine position. Arthroscopy. 1994;10(3):275-80.

67. Ganz R, Gill TJ, Gautier E, Ganz K, Krügel N, Berlemann U. Surgical dislocation of the adult hip a technique with full access to the femoral head and acetabulum without the risk of avascular necrosis. $J$ Bone Joint Surg Br. 2001;83(8):1119-24.

68. Espinosa N, Rothenfluh DA, Beck M, Ganz R, Leunig M. Treatment of femoro-acetabular impingement: preliminary results of labral refixation. J Bone Joint Surg Am. 2006;88(5):925-35.

69. Larson CM, Giveans MR. Arthroscopic debridement versus refixation of the acetabular labrum associated with femoroacetabular impingement. Arthroscopy. 2009;25(4):369-76.

70. Polesello GC, Ono NK, Bellan DG, Honda EK, Guimarães RP, Riccioli Junior W, et al. Artroscopia do quadril em atletas [Hip arthroscopy in athletes]. Rev Bras Ortop. 2009;44(1):26-31. 
71. Byrd JW, Jones KS. Prospective analysis of hip arthroscopy with 10year followup. Clin Orthop Relat Res. 2010;468(3):741-6.

72. Ejnisman L, Lipai RR, Cabrita HB, Vicente JRN, Gurgel HMC, Leonhardt MC, et al. Tratamento artroscópico de lesões do quadril em 35 atletas [Arthroscopic treatment of hip pathology in 35 athletes]. RBM Rev Bras Med. 2011;68(n. esp):4-10.

73. Domb BG, Stake CE, Botser IB, Jackson TJ. Surgical dislocation of the hip versus arthroscopic treatment of femoroacetabular impingement: a prospective matched-pair study with average 2-year follow-up. Arthroscopy. 2013;29(9):1506-13.

74. Geyer MR, Philippon MJ, Fagrelius TS, Briggs KK. Acetabular labral reconstruction with an iliotibial band autograft: outcome and survivorship analysis at minimum 3-year follow-up. Am J Sports Med. 2013;41(8):1750-6.

75. Krych AJ, Thompson M, Knutson Z, Scoon J, Coleman SH. Arthroscopic labral repair versus selective labral debridement in female patients with femoroacetabular impingement: a prospective randomized study. Arthroscopy. 2013;29(1):46-53.

76. Domb BG, Stake CE, Finley ZJ, Chen T, Giordano BD. Influence of capsular repair versus unrepaired capsulotomy on 2-year clinical outcomes after arthroscopic hip preservation surgery. Arthroscopy. 2015;31(4):643-50. 
77. Steppacher SD, Anwander H, Zurmühle CA, Tannast M, Siebenrock $K A$. Eighty percent of patients with surgical hip dislocation for femoroacetabular impingement have a good clinical result without osteoarthritis progression at 10 years. Clin Orthop Relat Res. 2015;473(4):1333-41.

78. von Elm E, Altman DG, Egger M, Pocock SJ, Gøtzsche PC, Vandenbroucke JP, et al. The Strengthening the Reporting of Observational Studies in Epidemiology (STROBE) statement: guidelines for reporting observational studies. Bull World Health Organ. 2007;85(11):867-72.

79. Smith-Petersen MN. A new supra-articular subperiosteal approach to the hip joint. Am J Orthop Surg. 1917;215(8):592-5. Disponível em: http://jbjs.org/content/s2-15/8/592. Acessado em 2015 (2 dez).

80. Philippon MJ, Stubbs AJ, Schenker ML, Maxwell RB, Ganz R, Leunig M. Arthroscopic management of femoroacetabular impingement: osteoplasty technique and literature review. Am J Sports Med. 2007;35(9):1571-80.

81. Tomczak RJ, Guenther KP, Rieber A, Mergo P, Ros PR, Brambs HJ. MR imaging measurement of the femoral antetorsional angle as a new technique: comparison with CT in children and adults. AJR Am J Roentgenol. 1997;168(3):791-4.

82. Dandachli W, UI Islam S, Tippett R, Hall-Craggs MA, Witt JD. Analysis of acetabular version in the native hip: comparison between 2D axial CT and 3D CT measurements. Skeletal Radiol. 2011;40(7):877-83. 
83. Monazzam S, Bomar JD, Dwek JR, Hosalkar HS, Pennock AT. Development and prevalence of femoroacetabular impingementassociated morphology in a paediatric and adolescent population: a CT study of 225 patients. Bone Joint J. 2013;95-B(5):598-604.

84. Hack K, Di Primio G, Rakhra K, Beaulé PE. Prevalence of cam-type femoroacetabular impingement morphology in asymptomatic volunteers. J Bone Joint Surg Am. 2010;92(14):2436-44.

85. Dolan MM, Heyworth BE, Bedi A, Duke G, Kelly BT. CT reveals a high incidence of osseous abnormalities in hips with labral tears. Clin Orthop Relat Res. 2011;469(3):831-8.

86. Siebenrock KA, Schoeniger R, Ganz R. Anterior femoro-acetabular impingement due to acetabular retroversion. Treatment with periacetabular osteotomy. J Bone Joint Surg Am. 2003;85-A(2):278-86.

87. Kutty S, Schneider P, Faris P, Kiefer G, Frizzell B, Park R, et al. Reliability and predictability of the centre-edge angle in the assessment of pincer femoroacetabular impingement. Int Orthop. 2012;36(3):505-10.

88. Tannast M, Siebenrock KA, Anderson SE. Femoroacetabular impingement: radiographic diagnosis--what the radiologist should know. AJR Am J Roentgenol. 2007;188(6):1540-52.

89. Cabrita HABA, Trindade CAC, Gurgel HMC, Leal RD, Marques RFS. Artroscopia de quadril [Hip arthroscopy]. Rev Bras Ortop. 2015;50(3):245-53. 
90. Crestani MV, Telöken MA, Gusmão PDF. Impacto femoroacetabular: uma das condições precursoras da osteoartrose do quadril [Femoroacetabular impingement: a harbinger condition of hip joint osteoarthrosis]. Rev Bras Ortop. 2006;41(8):285-93.

91. Roos BD, Roos MV, Camisa Júnior A, Lima EMU, Gyboski DP, Martins LS. Abordagem extracapsular para tratamento artroscópico de impacto femoroacetabular: resultados clínicos, radiográficos e complicações [Extracapsular approach for arthroscopic treatment of femoroacetabular impingement: clinical and radiographic results and complications]. Rev Bras Ortop. 2015;50(4):430-7.

92. Labronici PJ, Alves SD, Silva AF, Giuberti GR, Hoffmann R, Azevedo Neto JN, et al. Estudo anatômico do terço proximal do fêmur: impacto femoroacetabular e o efeito cam [Anatomic study of the proximal third of the femur: femoroacetabular impact and the cam effect]. Rev Bras Ortop. 2009;44(2):120-4.

93. Frank JM, Harris JD, Erickson BJ, Slikker W 3rd, Bush-Joseph CA, Salata MJ, et al. Prevalence of Femoroacetabular Impingement Imaging Findings in Asymptomatic Volunteers: A Systematic Review. Arthroscopy. 2015;31(6):1199-204.

94. Nepple JJ, Prather H, Trousdale RT, Clohisy JC, Beaulé PE, GlynJones $\mathrm{S}$, et al. Clinical diagnosis of femoroacetabular impingement. J Am Acad Orthop Surg. 2013;21 Suppl 1:S16-9.

95. Sankar WN, Nevitt M, Parvizi J, Felson DT, Agricola R, Leunig M. Femoroacetabular impingement: defining the condition and its role in the pathophysiology of osteoarthritis. J Am Acad Orthop Surg. 2013;21 Suppl 1:S7-S15. 
96. Larson CM, Sikka RS, Sardelli MC, Byrd JW, Kelly BT, Jain RK, et al. Increasing alpha angle is predictive of athletic-related "hip" and "groin" pain in collegiate National Football League prospects. Arthroscopy. 2013;29(3):405-10.

97. Eijer H, Leunig M, Mahomed M, Ganz R. Cross-table lateral radiographs for screening of anterior femoral head-neck offset in patients with femoro-acetabular impingement. Hip International. 2001;11:37-41.

98. Harris WH. Etiology of osteoarthritis of the hip. Clin Orthop Relat Res. 1986;(213):20-33.

99. Pollard TC, Villar RN, Norton MR, Fern ED, Williams MR, Simpson DJ, et al. Femoroacetabular impingement and classification of the cam deformity: the reference interval in normal hips. Acta Orthop. 2010;81(1):134-41.

100. Laborie LB, Lehmann TG, Engesæter IØ, Sera F, Engesæter LB, Rosendahl K. The alpha angle in cam-type femoroacetabular impingement: new reference intervals based on 2038 healthy young adults. Bone Joint J. 2014;96-B(4):449-54.

101. Siebenrock KA, Wahab KH, Werlen S, Kalhor M, Leunig M, Ganz R. Abnormal extension of the femoral head epiphysis as a cause of cam impingement. Clin Orthop Relat Res. 2004;(418):54-60.

102. Pfirrmann CW, Mengiardi B, Dora C, Kalberer F, Zanetti M, Hodler J. Cam and pincer femoroacetabular impingement: characteristic MR arthrographic findings in 50 patients. Radiology. 2006;240(3):778-85. 
103. Rakhra KS, Sheikh AM, Allen D, Beaulé PE. Comparison of MRI alpha angle measurement planes in femoroacetabular impingement. Clin Orthop Relat Res. 2009;467(3):660-5.

104. Mast NH, Impellizzeri F, Keller S, Leunig M. Reliability and agreement of measures used in radiographic evaluation of the adult hip. Clin Orthop Relat Res. 2011;469(1):188-99.

105. Carlisle JC, Zebala LP, Shia DS, Hunt D, Morgan PM, Prather H, et al. Reliability of various observers in determining common radiographic parameters of adult hip structural anatomy. lowa Orthop J. 2011;31:52-8.

106. Clohisy JC, Carlisle JC, Trousdale R, Kim YJ, Beaule PE, Morgan P, et al. Radiographic evaluation of the hip has limited reliability. Clin Orthop Relat Res. 2009;467(3):666-75.

107. Ross JR, Bedi A, Stone RM, Sibilsky Enselman E, Leunig M, Kelly BT, et al. Intraoperative Fluoroscopic Imaging to Treat Cam Deformities: Correlation With 3-Dimensional Computed Tomography. Am J Sports Med. 2014;42(6):1370-6.

108. Tannenbaum EP, Ross JR, Bedi A. Pros, cons, and future possibilities for use of computer navigation in hip arthroscopy. Sports Med Arthrosc. 2014;22(4):e33-41.

109. Giunti A, Moroni A, Olmi R, Rimondi E, Soldati D, Vicenzi G. The importance of the angle of anteversion in the development of arthritis of the hip. Ital J Orthop Traumatol. 1985;11(1):23-7.

110. Reikerås $\mathrm{O}$, Høiseth $\mathrm{A}$. Femoral neck angles in osteoarthritis of the hip. Acta Orthop Scand. 1982;53(5):781-4. 
111. Fabricant PD, Fields KG, Taylor SA, Magennis E, Bedi A, Kelly BT. The effect of femoral and acetabular version on clinical outcomes after arthroscopic femoroacetabular impingement surgery. J Bone Joint Surg Am. 2015;97(7):537-43.

112. Ferro FP, Ho CP, Briggs KK, Philippon MJ. Patient-centered outcomes after hip arthroscopy for femoroacetabular impingement and labral tears are not different in patients with normal, high, or low femoral version. Arthroscopy. 2015;31(3):454-9.

113. Domb BG, Shindle MK, McArthur B, Voos JE, Magennis EM, Kelly BT. lliopsoas impingement: a newly identified cause of labral pathology in the hip. HSS J. 2011;7(2):145-50.

114. Kalberer F, Sierra RJ, Madan SS, Ganz R, Leunig M. Ischial spine projection into the pelvis: a new sign for acetabular retroversion. Clin Orthop Relat Res. 2008;466(3):677-83.

115. Siebenrock KA, Kalbermatten DF, Ganz R. Effect of pelvic tilt on acetabular retroversion: a study of pelves from cadavers. Clin Orthop Relat Res. 2003;(407):241-8.

116. Tannast M, Fritsch S, Zheng G, Siebenrock KA, Steppacher SD. Which radiographic hip parameters do not have to be corrected for pelvic rotation and tilt? Clin Orthop Relat Res. 2015;473(4):1255-66.

117. Murphy SB, Kijewski PK, Millis MB, Harless A. Acetabular dysplasia in the adolescent and young adult. Clin Orthop Relat Res. 1990;(261):214-23. 
118. Pullen WM, Henebry A, Gaskill T. Variability of acetabular coverage between supine and weightbearing pelvic radiographs. Am J Sports Med. 2014;42(11):2643-8.

119. Ross JR, Clohisy JC, Baca G, Sink E, ANCHOR Investigators. Patient and disease characteristics associated with hip arthroscopy failure in acetabular dysplasia. J Arthroplasty. 2014;29(9 Suppl):160-3 .

120. Matsuda DK, Khatod M. Rapidly progressive osteoarthritis after arthroscopic labral repair in patients with hip dysplasia. Arthroscopy. 2012;28(11):1738-43.

121. Hapa O, Bedi A, Gursan O, Akar MS, Güvencer M, Havitçioğlu H, et al. Anatomic footprint of the direct head of the rectus femoris origin: cadaveric study and clinical series of hips after arthroscopic anterior inferior iliac spine/subspine decompression. Arthroscopy. 2013;29(12):1932-40.

122. Philippon MJ. The role of arthroscopic thermal capsulorrhaphy in the hip. Clin Sports Med. 2001;20(4):817-29.

123. Elias-Jones CJ, Farrow L, Reilly JH, Kerr S, Meek RM, Kelly MP, et al. Inflammation and Neovascularization in Hip Impingement: Not Just Wear and Tear. Am J Sports Med. 2015;43(8):1875-81.

124. Hashimoto S, Rai MF, Gill CS, Zhang Z, Sandell LJ, Clohisy JC. Molecular characterization of articular cartilage from young adults with femoroacetabular impingement. J Bone Joint Surg Am. 2013;95(16):1457-64. 
125. Ayeni OR, Chan K, Al-Asiri J, Chien T, Sprague S, Liew S, et al. Sources and quality of literature addressing femoroacetabular impingement. Knee Surg Sports Traumatol Arthrosc. 2013;21(2):415-9. 